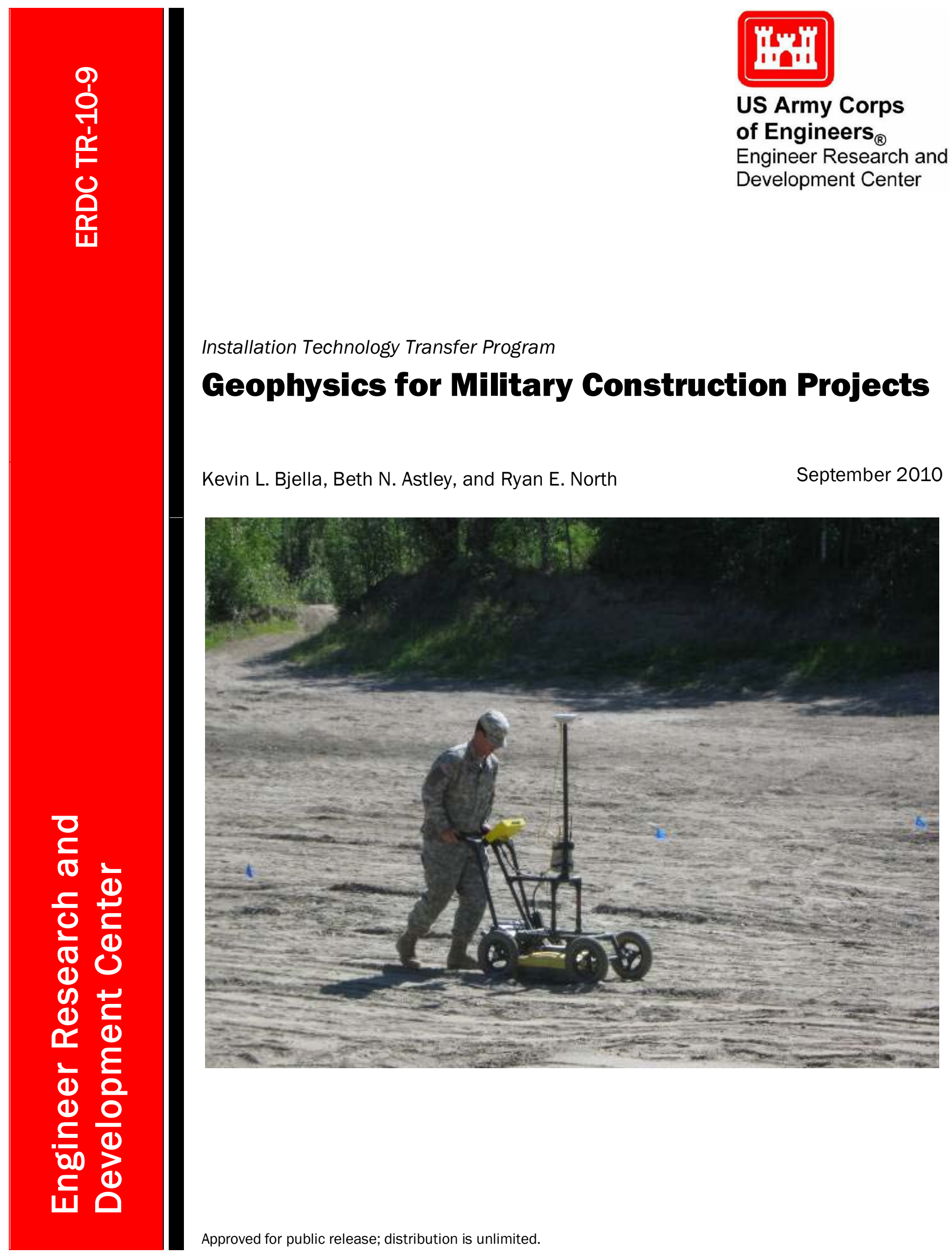





\title{
Geophysics for Military Construction Projects
}

\author{
Kevin L. Bjella and Beth N. Astley \\ Cold Regions Research and Engineering Laboratory (CRREL) \\ U.S. Army Engineer Research and Development Center \\ 72 Lyme Road \\ Hanover, NH 03755-1217 \\ Ryan E. North \\ Geotechnical and Structures Laboratory \\ U.S. Army Engineer Research and Development Center \\ 3909 Halls Ferry Road \\ Vicksburg, MS 39180-6199
}

Final Report

Approved for public release; distribution is unlimited.

\footnotetext{
Prepared for Headquarters, U.S. Army Corps of Engineers

Washington, DC 20314-1000
} 


\begin{abstract}
Buried infrastructure at Military Construction (MILCON) project sites can cause large project cost overruns if not located and removed prior to the start of the project. This study demonstrated how geophysical survey tools can be utilized to locate buried materials commonly found at MILCON sites. Utility pipelines and 55-gallon drums were buried in three soil types at depths representative of typical situations and standard off-the-shelf geophysical equipment was used to image the materials and quantify the benefits and pitfalls of each method. The techniques and examples from this demonstration can be used as a guide by personnel involved with MILCON project scoping when historic buried utilities or debris of unknown origin are present or suspected.
\end{abstract}

DISCLAIMER: The contents of this report are not to be used for advertising, publication, or promotional purposes. Citation of trade names does not constitute an official endorsement or approval of the use of such commercial products. All product names and trademarks cited are the property of their respective owners. The findings of this report are not to be construed as an official Department of the Army position unless so designated by other authorized documents. 


\section{Table of Contents}

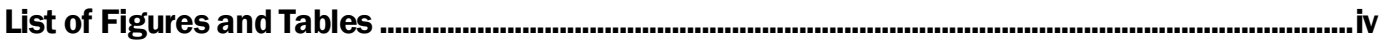

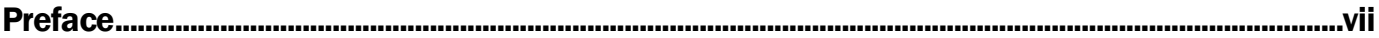

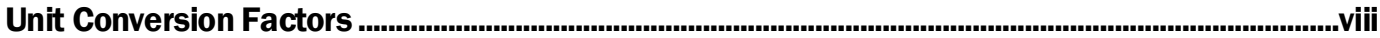

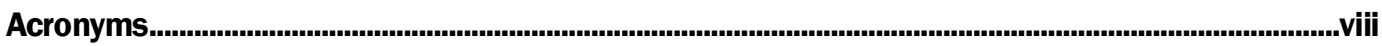

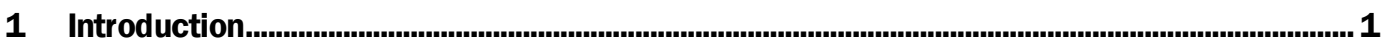

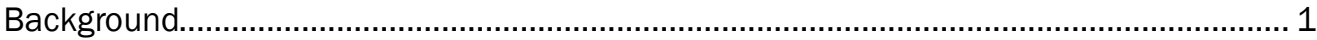

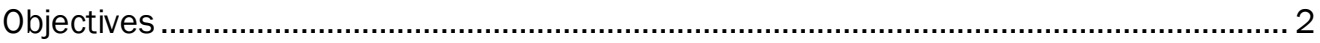

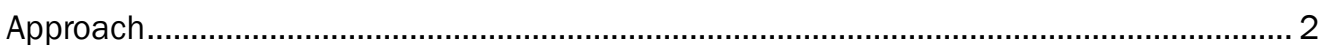

Scope

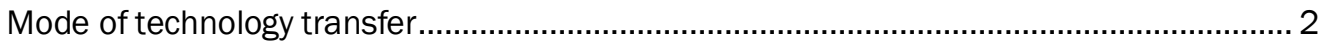

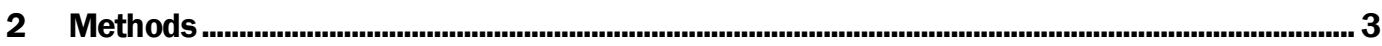

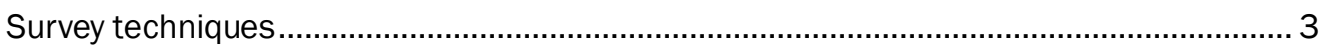

Ground penetrating radar ....................................................................................................... 4

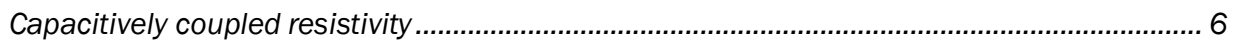

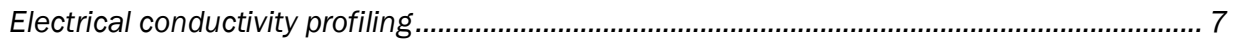

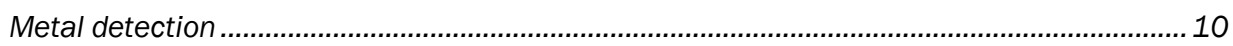

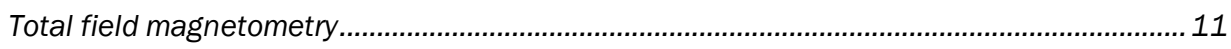

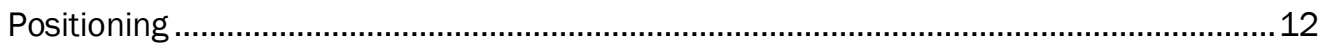

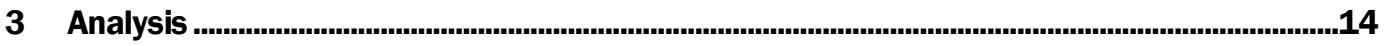

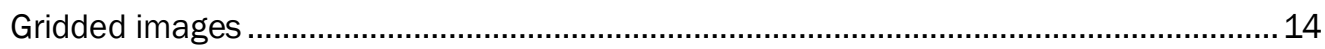

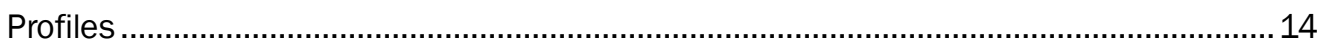

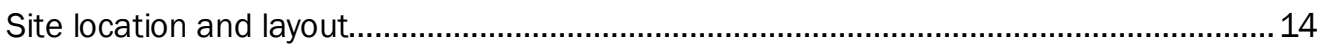

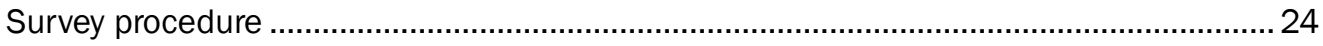

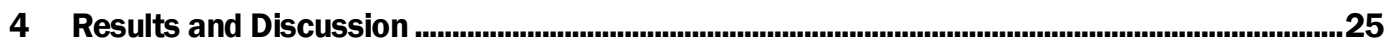

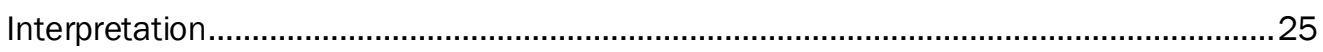

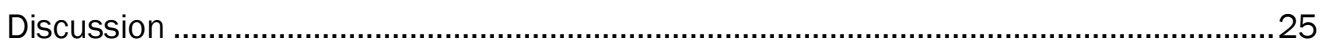

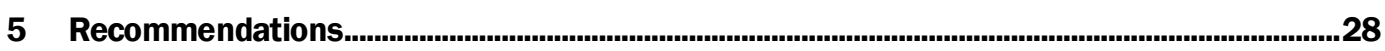

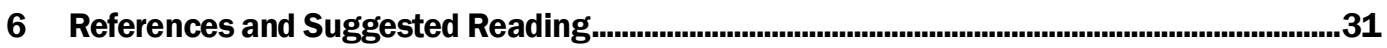

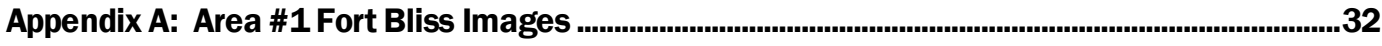

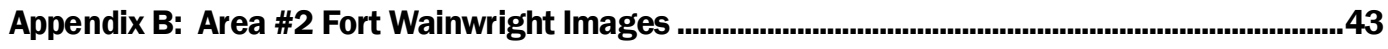

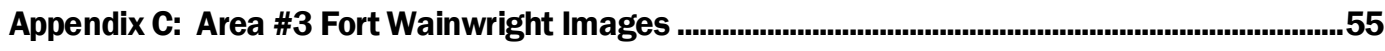

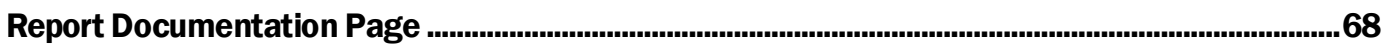




\section{List of Figures and Tables}

\section{Figures}

Figure 1. GSSI SIR-3000 GPR with $200 \mathrm{MHz}$ antenna .................................................................. 5

Figure 2. Sensors and Software Noggin Plus GPR with $250 \mathrm{MHz}$ antenna ......................................... 5

Figure 3. OhmMapper TR-5 capacitively-coupled pull along resistivity system ..................................... 7

Figure 4. GF Instruments CMD-4 electromagnetic conductivity system ............................................ 8

Figure 5. Geonics EM31 electromagnetic conductivity system............................................................

Figure 6. GSSI Profiler EMP-400 electromagnetic induction system ..................................................

Figure 7. Geonics EM61-MK2 time domain metal detector system ....................................................11

Figure 8. Geometrics G-858 total field magnetometer system .............................................................12

Figure 9. Copper pipe: 2-in. $(5-\mathrm{cm})$ diameter.................................................................................

Figure 10. PVC pipe: 6-in. (15-cm) diameter, water filled ........................................................................18

Figure 11. Ductile iron pipe: 12 -in. $(30.5-\mathrm{cm})$..................................................................................19

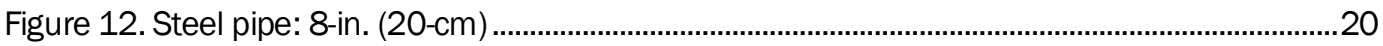

Figure 13. Plan view of study area \#2 Fort Wainwright, Alaska..........................................................21

Figure 14. Cross-section of the pipe layout for study area \#2 ...............................................................22

Figure 15. Intact, clean 55 gallon (208 liter) drum laid horizontally..................................................23

Figure 16. Intact 55 gallon (208 liter) drum laid vertically ..................................................................23

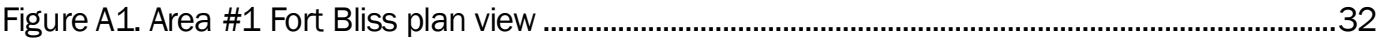

Figure A2. Area \#1 Fort Bliss cross section view of pipe placement ....................................................32

Figure A3. Area \#1 GSSI SIR-3000 GPR (400MHz antenna) data over deep end of pipes ...............33

Figure A4. Area \#1 GSSI SIR-3000 GPR ( 400 MHz antenna) data over shallow end of pipes...........33

Figure A5. Area \#1 S\&S Noggin Plus GPR (250 MHz antenna) data over deep end of pipes ...........34

Figure A6. Area \#1 S\&S Noggin Plus GPR (250 MHz antenna) data over shallow end of

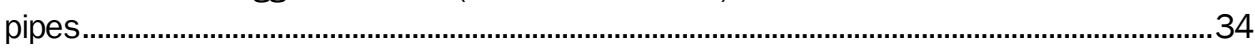

Figure A7. Area \#1 GSSI Profiler EMP-400 $(15000 \mathrm{~Hz})$ conductivity data before

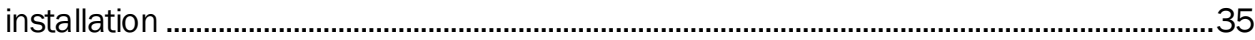

Figure A8. Area \#1 GSSI Profiler EMP-400 $(15000 \mathrm{~Hz})$ conductivity data after installation...............35

Figure A9. Area \#1 GSSI Profiler EMP-400 $(15000 \mathrm{~Hz})$ inphase data before installation...................36

Figure A10. Area \#1 GSSI Profiler EMP-400 (15000 Hz) inphase after installation ............................36

Figure A11. Area \#1 Geonics EM61-MK2 channel 1 data before installation ....................................37

Figure A12. Area \#1 Geonics EM61-MK2 channel 1 data after installation ........................................37

Figure A13. Area \#1 GF Instruments CMD-4 conductivity data before installation..............................38

Figure A14. Area \#1 GF Instruments CMD-4 conductivity data after installation.................................38

Figure A15. Area \#1 GF Instruments CMD-4 inphase data before installation ....................................39

Figure A16. Area \#1 GF Instruments CMD-4 inphase data after installation ......................................39

Figure A17. Area \#1 Geonics EM31 conductivity data before installation............................................40 
Figure A18. Area \#1 Geonics EM31 conductivity data after installation ............................................40

Figure A19. Area \#1 Geonics EM31 inphase data before installation ..................................................41

Figure A20. Area \#1 Geonics EM31 inphase data after installation ....................................................41

Figure A21. Area \#1 Geometrics OhmMapper TR-5 resistivity data after installation .........................42

Figure A22. Area \#1 Geometrics G-858 gradient data after installation.............................................42

Figure B1. Area \#2 Fort Wainwright plan view .................................................................................43

Figure B2. Area \#2 Fort Wainwright cross-section view of pipe placement ........................................43

Figure B3. Area \#2 GSSI SIR-3000 GPR (200 MHz antenna) over deep end of pipes .......................44

Figure B4. Area \#2 GSSI SIR-3000 GPR (200 MHz antenna) data over shallow end of pipes .........44

Figure B5. Area \#2 S\&S Noggin Plus (250 MHz antenna) data over deep end of pipes....................45

Figure B6. Area \#2 S\&S Noggin Plus (250 MHz antenna) data over shallow end of pipes ...............45

Figure B7. Area \#2 Geonics EM61-MK2 channel 1 data before installation .......................................46

Figure B8. Area \#2 Geonics EM61-MK2 channel 1 data after installation...........................................46

Figure B9. Area \#2 GSSI Profiler EMP-400 (15000 Hz) inphase data before installation ..................47

Figure B10. Area \#2 GSSI Profiler EMP-400 $(15000 \mathrm{~Hz})$ inphase data after installation ................... 47

Figure B11. Area \#2 GSSI Profiler EMP-400 $(15000 \mathrm{~Hz})$ conductivity data before

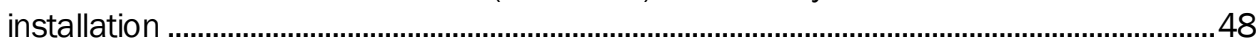

Figure B12. Area \#2 GSSI Profiler EMP-400 (15000 Hz) conductivity data after

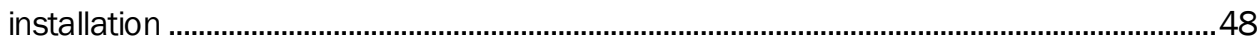

Figure B13. Area \#2 GF Instruments CMD-4 inphase data after installation.......................................49

Figure B14. Area \#2 GF Instruments CMD-4 conductivity data after installation ...............................49

Figure B15. Area \#2 Geonics EM31 inphase data before installation .................................................50

Figure B16. Area \#2 Geonics EM31 inphase data after installation ...................................................50

Figure B17. Area \#2 Geonics EM31 conductivity data before installation .........................................51

Figure B18. Area \#2 Geonics EM31 conductivity data after installation...........................................51

Figure B19. Area \#2 Geonics EM38B inphase data before installation .............................................52

Figure B20. Area \#2 Geonics EM38B inphase data after installation ...............................................52

Figure B21. Area \#2 Geonics EM38B conductivity data before installation.......................................53

Figure B22. Area \#2 Geonics EM38B conductivity data after installation .........................................53

Figure B23. Area \#2 Geometrics G-858 vertical gradient data before installation.............................54

Figure B24. Area \#2 Geometrics G-858 vertical gradient data after installation ...............................54

Figure C1. Area \#3 Fort Wainwright plan view ..............................................................................5

Figure C2. Area \#3 cross section view of pipe placement ………………………………………......55

Figure C3. Area \#3 GSSI SIR-3000 GPR (200 MHz antenna) data over deep end of pipes ..............56

Figure C4. Area \#3 GSSI SIR-3000 GPR (200 MHz antenna) data over shallow end of pipes .........56

Figure C5. Area \#3 S\&S Noggin Plus GPR ( $250 \mathrm{MHz}$ antenna) data over deep end of pipes...........57

Figure C6. Area \#3 S\&S Noggin Plus GPR (250 MHz antenna) data over shallow end of

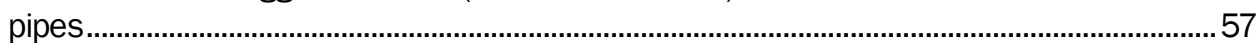

Figure C7. Area \#3 Geonics EM61-MK2 channel 1 data before installation .....................................58

Figure C8. Area \#3 Geonics EM61-MK2 channel 1 data after installation.........................................58

Figure C9. Area \#3 GSSI Profiler (15000 Hz) inphase data before installation ...................................59 
Figure C10. Area \#3 GSSI Profiler (15000 Hz) inphase data after installation...................................59

Figure C11. Area \#3 GSSI Profiler $(15000 \mathrm{~Hz}$ ) conductivity data before installation .........................60

Figure C12. Area \#3 GSSI Profiler (15000 Hz) conductivity data after installation ............................60

Figure C13. Area \#3 GF Instruments CMD-4 inphase data before installation.....................................61

Figure C14. Area \#3 GF Instruments CMD-4 inphase data after installation ......................................61

Figure C15. Area \#3 GF Instruments CMD-4 conductivity data before installation .............................62

Figure C16. Area \#3 GF Instruments CMD-4 conductivity data after installation..................................62

Figure C17. Area \#3 Geonics EM31 inphase data before installation..................................................63

Figure C18. Area \#3 Geonics EM31 inphase data after installation .....................................................63

Figure C19. Area \#3 Geonics EM31 conductivity data before installation..........................................64

Figure C20. Area \#3 Geonics EM31 conductivity data after installation ..............................................64

Figure C21. Area \#3 Geonics EM38B inphase data before installation .............................................65

Figure C22. Area \#3 Geonics EM38B inphase data after installation ..................................................65

Figure C23. Area \#3 Geonics EM38B conductivity data before installation........................................66

Figure C24. Area \#3 Geonics EM38B conductivity data after installation ...........................................66

Figure C25. Area \#3 Geometrics G-858 vertical gradient data before installation..............................67

Figure C26. Area \#3 Geometrics G-858 vertical gradient data after installation ................................67

\section{Tables}

Table 1. Test area locations 16

Table 2. Imaging ability to depth of $2 \mathrm{~m}$..............................................................................................2

Table 3. Overall technique comparison...............................................................................................2 


\section{Preface}

This study was conducted for the Installation Management Command (IMCOM) for the Installation Technology Transfer Program. The technical monitors were Mr. Barry Bartley, Public Works Division, IMCOM, Arlington, VA; Mr. Al Lucht, Chief, Directorate of Public Works (DPW), U.S. Army Garrison Alaska; and Dr. Robert Lenhart, Petroleum Storage Tank Program Manager, DPW, Environmental Division, Fort Bliss, Texas.

The work was managed and executed by the Force Protection and Sustainment Branch (RR-H) of the Research and Engineering Division (RR), Cold Regions Research and Engineering Laboratory (CRREL). The CRREL principal investigator was Kevin Bjella. The Geotechnical and Structures Laboratory (GSL) principal investigator was Ryan North, from the Geotechnical Engineering and Geosciences Branch (GS-G) of the Geotechnical and Structures Division (GS). Appreciation is owed to Art Gelvin and Stephanie Saari, Physical Science Technicians with CRREL, Tim Tracy (U.S. Military Academy Cadet), and Seth Campbell, also from CRREL, for their expertise and assistance.

J im Buska was Acting Chief, RR-H, and Dr. J ustin Berman was Chief, RR. The Acting Technical Director for Earth Sciences and Engineering was J ohn Zufelt, RV-T. The Director of CRREL was Dr. Robert E. Davis. Dr. Monte Pearson was Chief, GS-G, and Bartley Durst was Chief, GS. The Technical Director for Military Engineering was Dr. David Horner, GS-T. The Director of GSL was Dr. David Pittman.

CRREL and GSL are elements of the U.S. Army Engineer Research and Development Center (ERDC), U.S. Army Corps of Engineers. The Commander and Executive Director of ERDC was COL Gary E. J ohnston, and the Director of ERDC was Dr. J effery P. Holland. 


\section{Unit Conversion Factors}

\begin{tabular}{|l|l|l|}
\hline Multiply & By & To Obtain \\
\hline feet & 0.3048 & meters \\
\hline gallons (U.S. liquid) & $3.785412 \mathrm{E}-03$ & cubic meters \\
\hline in. & 0.0254 & meters \\
\hline
\end{tabular}

\section{Acronyms}

$\begin{array}{ll}\text { 2D } & \text { two dimensional } \\ \text { 3D } & \text { three dimensional } \\ \text { ASCII } & \text { American Standard Code for Information Interchange } \\ \text { DOS } & \text { disc operating system } \\ \text { FDEM } & \text { frequency domain electromagnetic } \\ \text { GHz } & \text { gigahertz } \\ \text { GIS } & \text { geographic information system } \\ \text { GPS } & \text { Global Positioning System } \\ \text { GPR } & \text { ground penetrating radar } \\ \text { GSSI } & \text { Geophysical Survey Systems International } \\ \text { MHz } & \text { megahertz } \\ \text { MILCON } & \text { Military Construction } \\ \text { OTS } & \text { off-the-shelf } \\ \text { PVC } & \text { polyvinyl chloride } \\ \text { RTK } & \text { Real Time Kinematic } \\ \text { TDEM } & \text { time domain electromagnetic } \\ \text { TFM } & \text { unexploded ordnance } \\ \text { UXO } & \end{array}$




\section{Introduction}

\section{Background}

Natural and man-made materials found in the Earth's subsurface such as soil, water, organics, plastics and metal have measurable physical properties including electrical resistivity, dielectric permittivity, magnetic susceptibility, and density. These properties may be measured in-situ to gain an understanding of what lies beneath the subsurface, both in lateral extent and depth. Engineers and project planners are most interested in the location and description of existing and past utilities and buried debris (e.g., demolition materials, storage containers, and landfill materials). If these materials are not located prior to the design or the start of a Military Construction (MILCON) project, the resulting mitigation can cost hundreds of thousands of dollars in additional expenses and lost project time.

Geophysical techniques have been used for decades to survey these properties and identify and quantify the subsurface. Recent improvements in instrument design and the incorporation of Global Positioning System (GPS) technology have resulted in more accurate and efficient geophysical surveys. At the same time, the costs of geophysical instruments have decreased as more engineers and scientists realize the advantages of these techniques for a wide range of applications including preconstruction surveys.

This study focused on examining buried materials common to MILCON sites such as utility pipelines and 55-gallon (208 liter) drums. Various offthe-shelf geophysical techniques were used to image these buried materials in three differing soil types. This report discusses these geophysical techniques and provides applicable examples and images. Based on these findings, we recommend that all MILCON projects require at a minimum an initial reconnaissance survey of the entire site which may be either an electrical conductivity profiling survey or a metal detector survey, and preferably also a Ground Penetrating Radar survey of any areas of potential high risk. 


\section{Objectives}

This study was designed to illustrate specific examples of several geophysical techniques, including instruments from several commonly available manufacturers, and their ability to image and locate commonly found buried objects pertaining to MLCON projects.

\section{Approach}

The study was designed to illustrate the typical results that project engineers and managers would most likely encounter utilizing geophysics during a MILCON project. This required the use of varying types of infrastructure materials, placed at varying depths, and buried in three common types of soil.

\section{Scope}

Besides material type, depth, and soil type, many variables affect the detection of buried objects (e.g., soil moisture, soil mineral content, frozen soil, vegetation cover and terrain). It was not possible to alter all the variables for the scope of this project, and more detailed surveys would need to be conducted to include the wide range of possible scenarios.

\section{Mode of technology transfer}

This report will be made accessible through the World Wide Web (WWW) at URL: 


\section{Methods}

\section{Survey techniques}

The optimal geophysical method for detecting a subsurface target depends on the soil properties, target shape and composition, and burial depth of the target. Subsurface targets of interest in most MILCON projects are typically shallow (less than 3 meters [m]) and compact (pipes and 55gallon drums). The goal of this study was to evaluate the following off-theshelf (OTS) geophysical methods for potential use by MILCON personnel to detect and discriminate these targets of interest:

- ground penetrating radar

- capacitively coupled resistivity

- electrical conductivity profiling

- metal detection

- total field magnetometry

A reconnaissance survey is typically conducted over the entire study area with wide line spacings to determine if further investigation is required and to focus the regions requiring more detailed surveys. Three of the methodologies demonstrated in this study could be used for reconnaissance surveys depending on the expected targets and geology: total field magnetometry, electrical conductivity profiling, or metal detection.

Total field magnetometry is commonly the first method used for reconnaissance surveys, specifically because of speed and a high probability of detection. Metal detection, typically using a cart-mounted system with a nominal coil diameter of between $0.5 \mathrm{~m}$ and $1 \mathrm{~m}$, would find most shallow metallic objects. For slightly deeper targets, an electrical conductivity profiling system may be used to find targets up to $5 \mathrm{~m}$ below the surface. Ground Penetrating Radar (GPR) can also be used to detect metal targets, however GPR has the additional capability to detect non-metallic targets. Capacitively coupled resistivity can be used where targets may be large and deep, and where it is possible to pull the instrument along the ground for long distances. A brief introduction to each methodology and instrument follows. For more detailed discussion of the geophysical methods discussed here, please refer to Engineer Manual (EM)-1110-1-1802, Telford et al. 1990, Milsom 2003, or Reynolds 1997. 
The geophysical equipment, discussed in this report is generally sold as components of a pre-arranged system depending on the intended use; some are mass produced, which allows for OTS acquisition. Data processing software has also evolved rapidly over the past decade to provide features such as GPS position integration, target picking, and three dimensional (3D) viewing. Computer output of the data processing varies by technique. Electrical resistivity and GPR imaging software can yield a two dimensional (2D) or 3D view of the subsurface, while the other methods primarily yield a plan view (downward looking) output with contour lines highlighting the intensity of subsurface conditions. The types of geophysical techniques and instruments utilized are described below.

\section{Ground penetrating radar}

GPR is a geophysical method that transmits high frequency radio waves (10 megahertz [MHz] to 4 gigahertz [GHz]) into the subsurface and records the reflections of these waves from subsurface discontinuities. A GPR system is typically composed of two antennas (a transmitter and receiver) a signal generator, and a recording unit. A subsurface discontinuity is a contrast in electrical properties, specifically dielectric permittivity, electrical conductivity, and magnetic susceptibility. A contrast can exist due to buried objects or variations in soil properties. Soil property contrasts are usually due to differential water retention by the different soil types. GPR results are the most sensitive to soil properties among the discussed methods. The performance of GPR will degrade with increasing soil moisture content, clay content and saline content.

GPR systems from two manufacturers, as well as several different frequencies of operation, were compared for this study: a Sensors \& Software Noggin Plus and a Geophysical Survey Systems International (GSSI) SIR3000 system (Figures 1 and 2). While both systems are GPR, they take slightly different approaches to the instrument design and operation. Both systems use a pulsed waveform to generate a wide band of energy that is centered on one frequency. GPR antennas are specified by their frequency of operation (approximately $50 \mathrm{MHz}$ to $2 \mathrm{GHz}$ ), each manufacturer will have a small number (on the order of 5 antenna options) of antenna frequencies available for each of their GPR systems. The Noggin Plus uses bistatic antennas, which means that there are separate transmitter and receiver antennas, and the antenna operated (for this effort) at a frequency of $250 \mathrm{MHz}$. The SIR-3000 system used for this study utilized monostatic antennas, which means that a single antenna is used for both transmitting 
and receiving the GPR signals. The antennas used for this effort operated at frequencies of 200 and $400 \mathrm{MHz}$. GSSI offers bistatic arrangements as well.

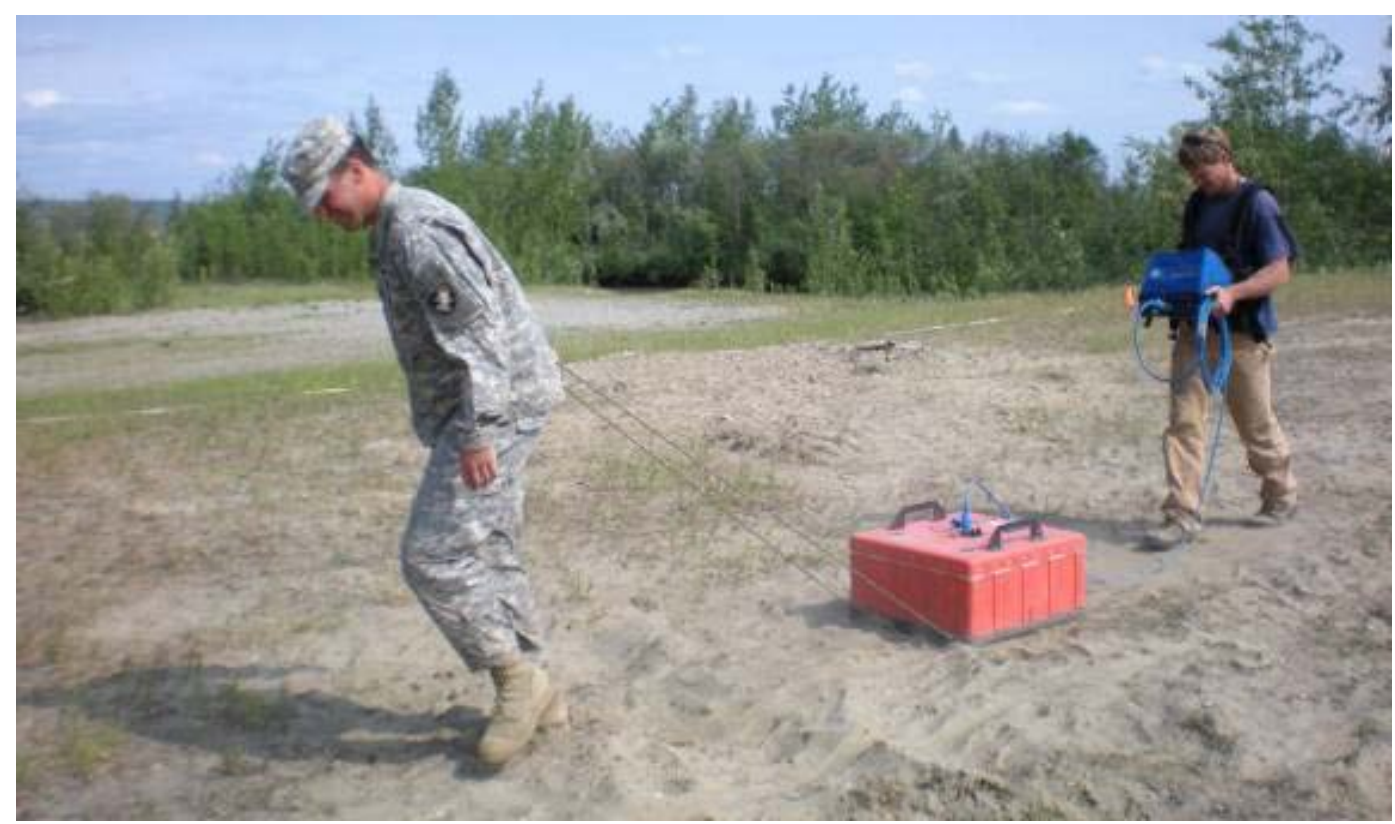

Figure 1. GSSI SIR-3000 GPR with $200 \mathrm{MHz}$ antenna.

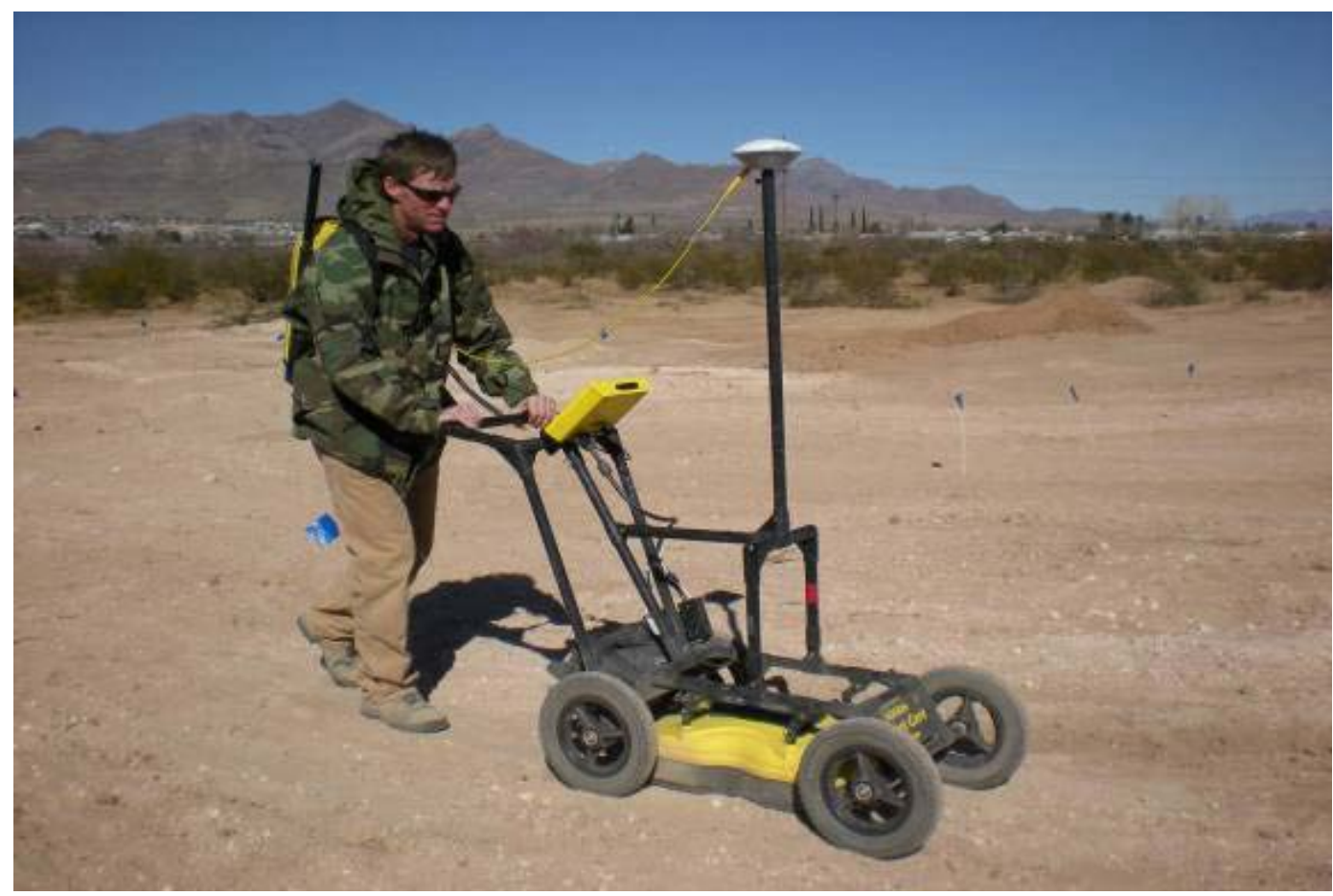

Figure 2. Sensors and Software Noggin Plus GPR with $250 \mathrm{MHz}$ antenna. 
The Noggin Plus system uses a Disc Operating System (DOS) on its controller. The primary advantage of this approach is that the system can sample fast enough to record all GPS data internally and can tag every trace with a position if so desired. The SIR-3000 system uses Windows CE as an operating system, which allows for color displays that DOS does not, but the GPS data acquisition is more complex. It requires an additional step in the field to merge the GPR and GPS data.

\section{Capacitively coupled resistivity}

Electrical resistivity surveying is a geophysical method that involves injecting current into the ground through a pair of electrodes and measuring the electrical potential (voltage) between another pair of electrodes. By measuring the current and voltage, and also the geometry of the electrodes, the resistivity of the subsurface can be calculated. Electrical resistivity is the resistance of a material to current passing through it, and is the inverse of electrical conductivity. Since electrical resistivity surveys require the electrodes to be galvanically coupled to the material, it is very time and manpower intensive to perform. Capacitively coupled resistivity surveying uses the earth as one conductor of a parallel plate capacitor. The transmitter is composed of two coaxial cables connected to the electronics, and the receiver setup is identical. The transmitter sends a continuous current sine wave through the transmitter cables, which polarizes the surrounding material. The receiver measures the polarization from which the resistivity is calculated.

The Geometrics OhmMapper TR-5 used in this study (Figure 3) is a constant-current capacitively-coupled, dipole-dipole resistivity system. It has one transmitter and up to five receivers, for which the geometry can be modified by changing the dipole lengths or the distance between the transmitter and the first receiver. These options give the operator the ability to survey to the depths of interest. 


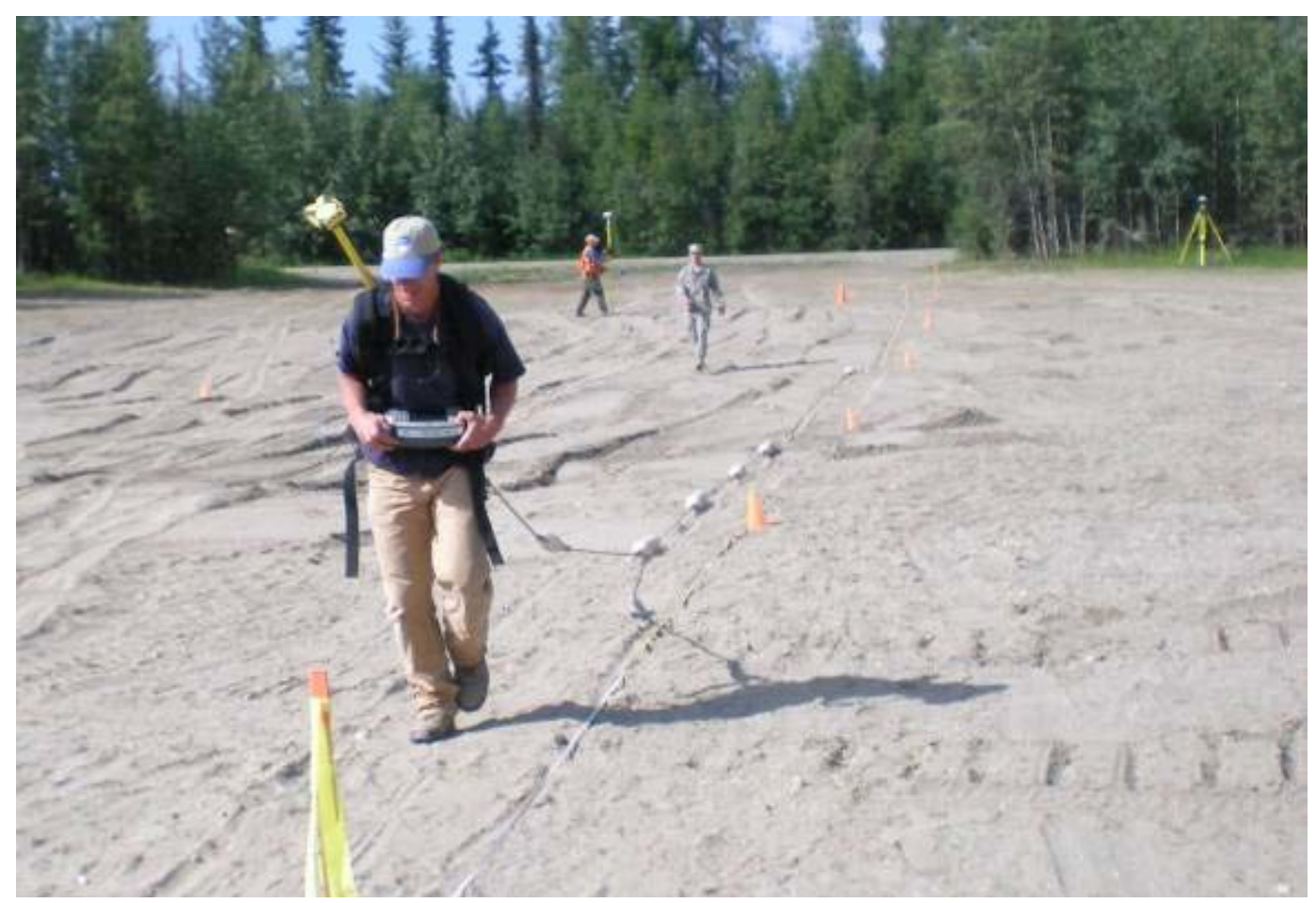

Figure 3. OhmMapper TR-5 capacitively-coupled pull along resistivity system.

\section{Electrical conductivity profiling}

Electrical conductivity profiling is a geophysical method used to detect variations of electrical conductivity and magnetic susceptibility as a function of depth and lateral distance. The systems that are most commonly used operate as frequency domain electromagnetic (FDEM) induction instruments in a Slingram configuration. This configuration is composed of two loops of wire, one transmitter and one receiver, separated by a distance. The wire loops can be oriented in a number of ways relative to each other and the ground. A very common orientation is horizontal co-planer coils. The depth of investigation of these types of instruments is a function of frequency of operation and coil separation, lower frequencies and larger separtions allow for deeper investigations. The recorded data for each instrument is the quandrature phase which is calibrated to the electrical conductivity of the soil and the inphase (IP) response, which is related to the magnetic susceptibility of the soil and functions as a metal detector. The instrument is carried by the operator along a number of parallel survey lines, and the resulting data can be displayed as lines or a surface grid. The instruments used for this project are the GF Instruments CMD-4, the Geonics EM31 (Figures 4 and 5), the Geonics EM38B, the Geonics EM38-MK2, and the GSSI Profiler EMP400. 


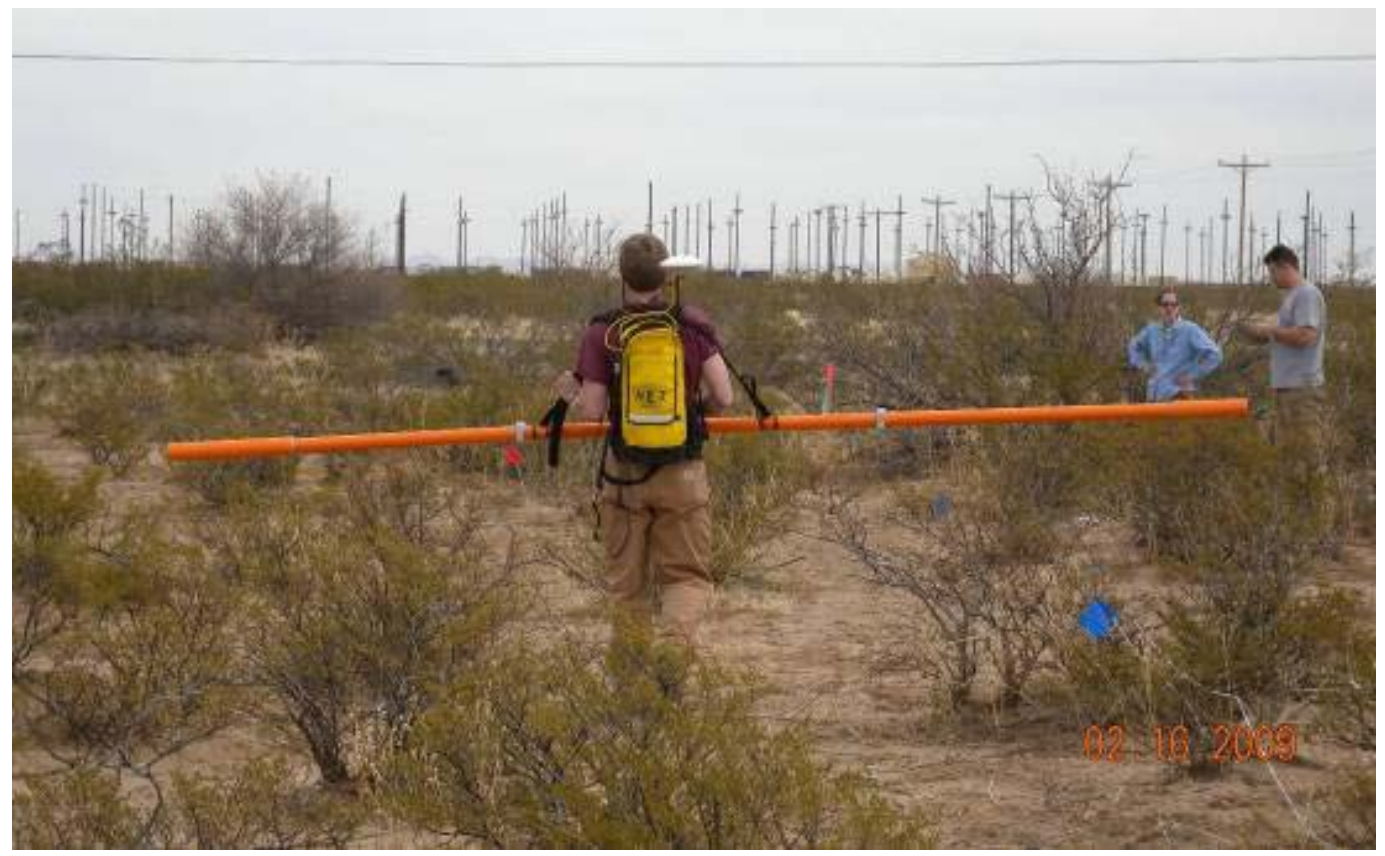

Figure 4. GF Instruments CMD-4 electromagnetic conductivity system.

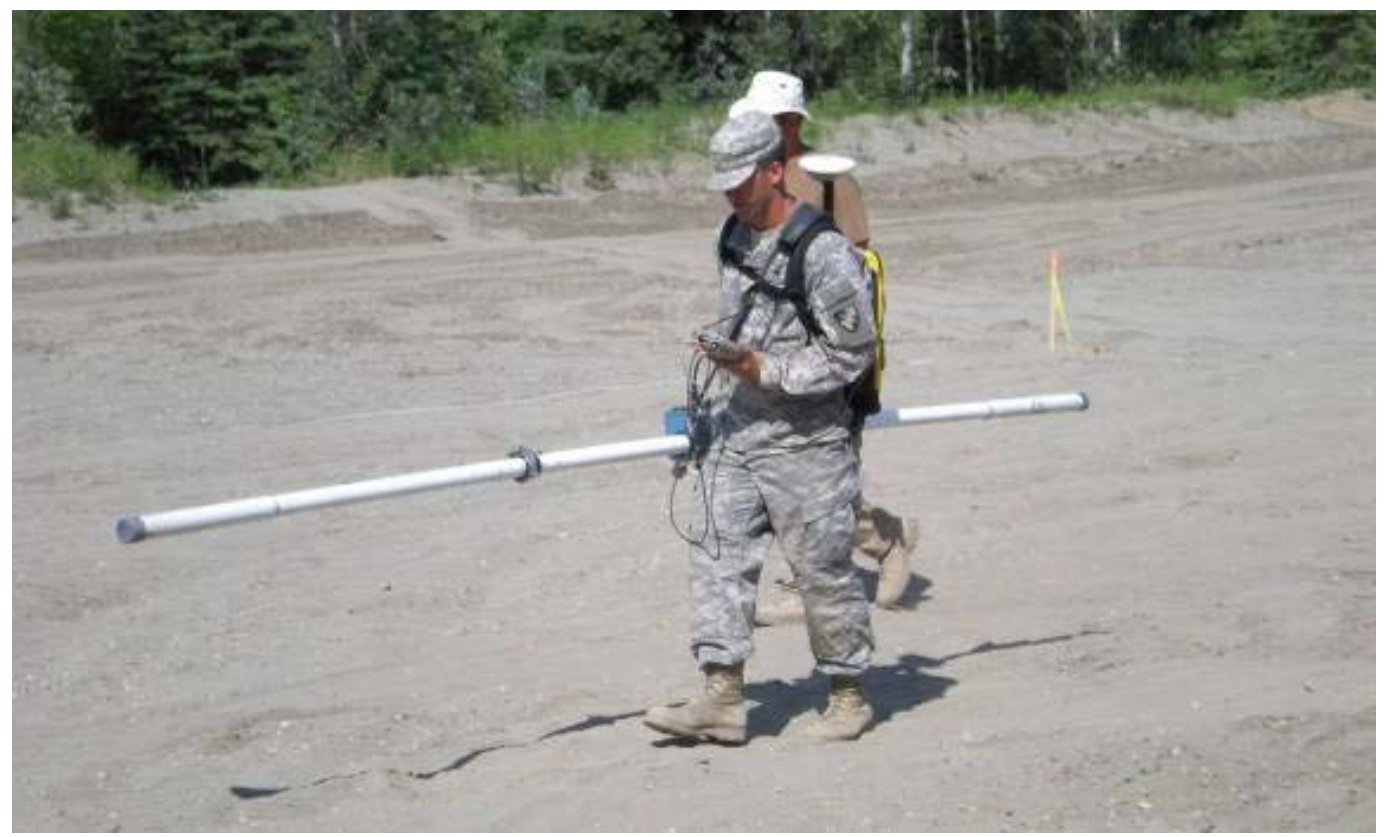

Figure 5. Geonics EM31 electromagnetic conductivity system.

The Geonics instruments are all continous-wave single frequency electromagnetic induction sensors. The major differences in the instruments are the coil spacing and frequency of operation. Larger coil spacings and lower frequencies allow for deeper investigations. The EM31 operates at 9.8 kilohertz $(\mathrm{kHz})$ with a coil spacing of $3.66 \mathrm{~m}$ and a maximum depth of investigation of $6 \mathrm{~m}$. The EM38B operates at $14.6 \mathrm{kHz}$ with a coil spacing 
of $1 \mathrm{~m}$ and maximum depth of investigation of $1.5 \mathrm{~m}$. The EM38-MK2 is a newer version of the EM38B that adds an additional receiver coil at a spacing of $0.5 \mathrm{~m}$ to allow simultaneous surveying at depths of 0.75 and 1.5 $\mathrm{m}$. All of the Geonics instruments record the electrical conductivity, IP response, and GPS position at each measurement location.

The GF Instruments CMD-4 is also a continous-wave single frequency electromagnetic induction sensor. The coils are horizontal co-planer separated by approximately $4 \mathrm{~m}$ with an operating frequency of $10 \mathrm{kHz}$. The CMD- 4 was operated in continuous GPS mode with a sampling rate of 10 samples per second.

The GSSI Profiler EMP-400 (Figure 6) is also a continous-wave electromagnetic induction sensor, with the capability for multifrequency measurements. The Profiler can operate at up to three frequencies between 1 and $16 \mathrm{kHz}$ that are transmitted sequentially. The transmitter and receiver coils are separated by a distance of approximately $1.3 \mathrm{~m}$. The choice of frequencies will potentially allow for optimizing the depth of investigation. The disadvantage of the sequential multiple frequencies is that the sampling rate decreases for each additional frequency used, which may result in small targets not appearing in the data unless the acquisition speed is much slower than with most of the other instruments. For this study three frequencies were used on the Profiler (3, 10, and $15 \mathrm{kHz})$.

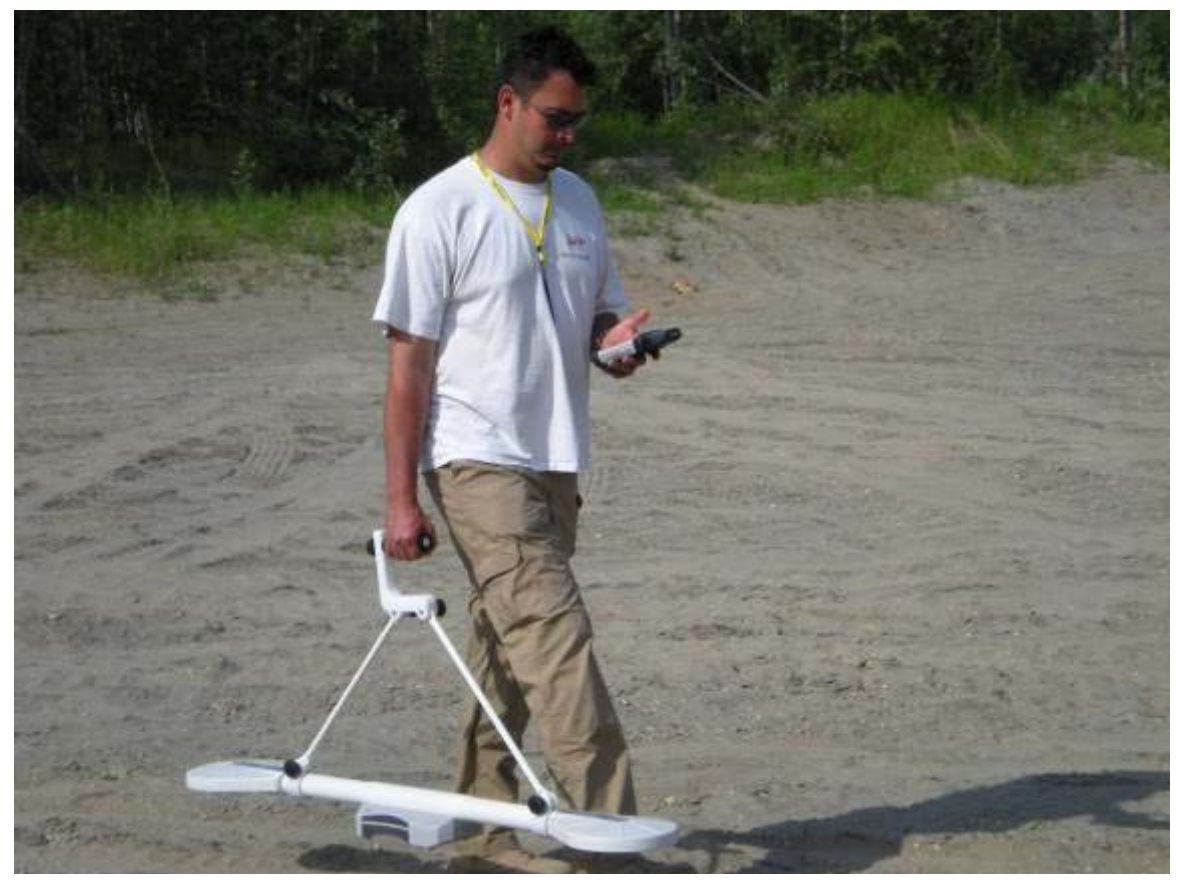

Figure 6. GSSI Profiler EMP-400 electromagnetic induction system. 


\section{Metal detection}

Metal detection is a geophysical method that uses electromagnetic induction to locate both ferrous and non-ferrous objects in the subsurface. Time domain and frequency domain are the two primary types of metal detectors. A time domain electromagnetic (TDEM) induction metal detector typically has two loops of wire: the transmitter loop and the receiver loop. The loops are usually co-axial and co-planer to allow for the maximum accuracy in positioning the data. A current is applied to the transmitter loop and then the transmitter is turned off generating a magnetic field. The magnetic field propagates away from the transmitter loop and interacts with all of the materials in the subsurface. The interaction generates secondary magnetic fields that propagate back towards the receiver. The secondary magnetic fields are measured as changes in voltage in the receiver coil while the transmitter is off. This process repeats hundreds of times per second. Data from the receiver coil is recorded several times after the transmitter is turned off.

A frequency domain electromagnetic induction (FDEM) metal detector generates a continuous wave signal in the transmitter coil. The magnetic field propagates away from the transmitter loop into the subsurface. As it passes through the subsurface, the field interacts with the soil or buried items that generate secondary magnetic fields. The secondary magnetic fields propagate back towards the receiver coil. The difference between FDEM and TDEM metal detectors here is that the FDEM instrument is always transmitting, so the secondary field is overwhelmed by the much larger primary field. To compensate for this, a third wire loop (the compensation coil) is situated between the transmitter and receiver loops. The compensation coil generates the same signal as the transmitter loop but out of phase so that the net effect at the receiver coil is zero when the sensor is far above the ground. An FDEM metal detector can transmit a single frequency or multiple frequencies, either sequentially or simultaneously.

For this study a Geonics EM61-MK2 (Geonics 2005c) metal detector was employed. The EM61-MK2 (Figure 7) is a TDEM metal detector commonly used for metal detection surveys when the targets are unexploded ordnance (UXO), buried drums, pipes, or metal scrap. The EM61-MK2 can locate an intact 55-gallon drum up to $3 \mathrm{~m}$ deep and can be easily interfaced for GPS positioning. 


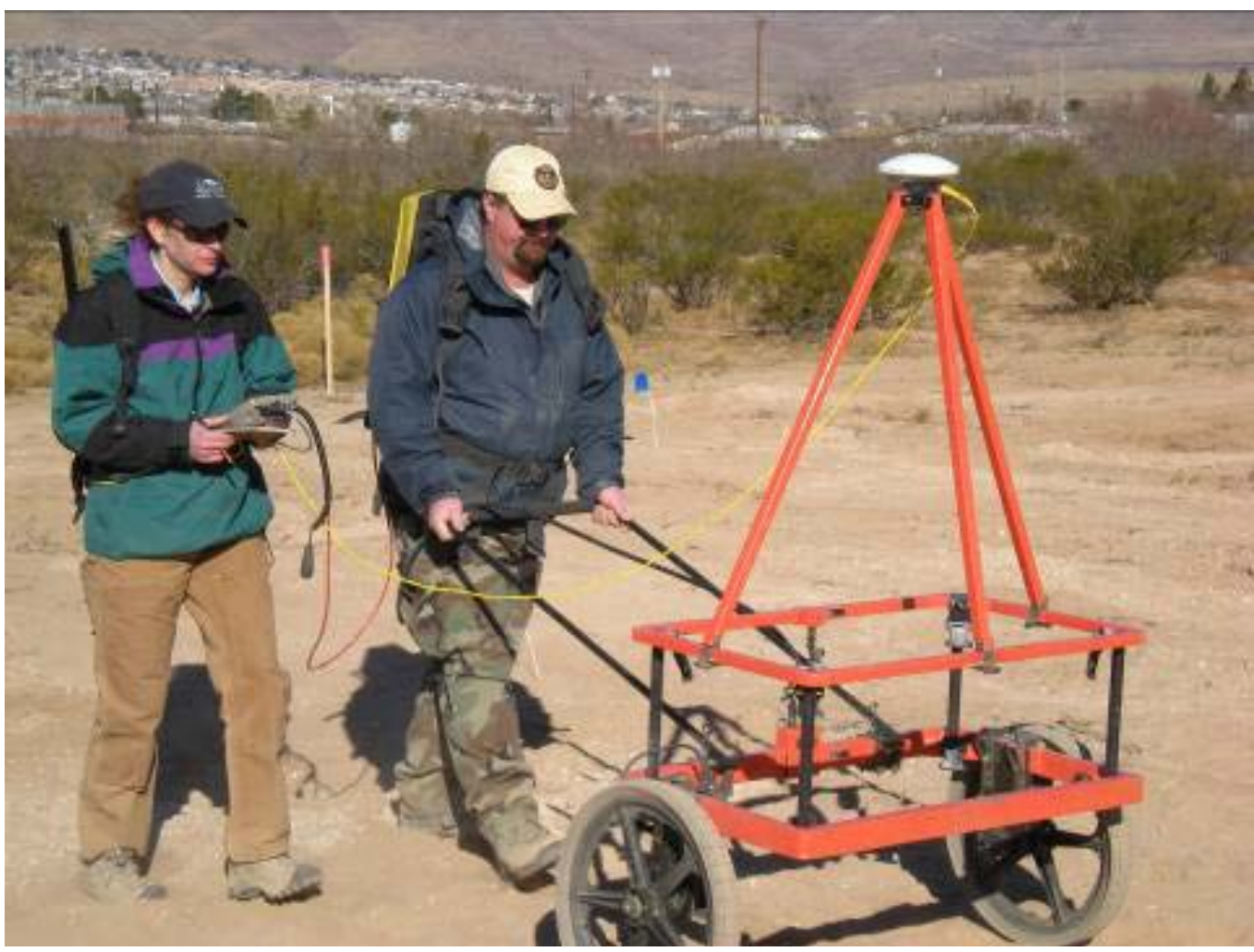

Figure 7. Geonics EM61-MK2 time domain metal detector system.

\section{Total field magnetometry}

Total field magnetometry (TFM) is a passive geophysical method that measures the magnitude of the secondary magnetic field generated by ferrous subsurface materials, including soils and other buried items. The primary field used in TFM is the Earth's magnetic field. The measured magnetic anomalies are the result of the vector addition of the Earth's primary magnetic field and the secondary magnetic fields generated by all of the subsurface materials. Earth's magnetic field varies over the course of a day due to the rotation of the Earth and the interaction of solar winds with the ionosphere, known as diurnal variation.

Diurnal variation can be on the order of 50 nanoTeslas (nT) (for reference the Earth's magnetic field is approximately 50,000 nT depending on latitude), and there are two methods to compensate for it. The first method is to set up a second magnetometer known as a base station at a location near the survey site. Both magnetometers will be equally affected by the diurnal variations, so the mobile sensor can have the diurnal variations removed based on the data from the base station. The second method for diurnal correction is to perform a gradiometer survey, which uses at least 
two mobile sensors, typically oriented vertically and separated by a distance of 0.5 to $1 \mathrm{~m}$. The gradiometer method has two advantages over the base station method: (1) no additional sensor needs to be set up, and (2) improved detection. Many magnetic anomalies are small and by subtracting a larger number from another large number, the small variations may be more pronounced in the data. The system used for this study is the Geometrics G-858 MagMapper (Figure 8) in a $1 \mathrm{~m}$ vertical gradiometer arrangement.

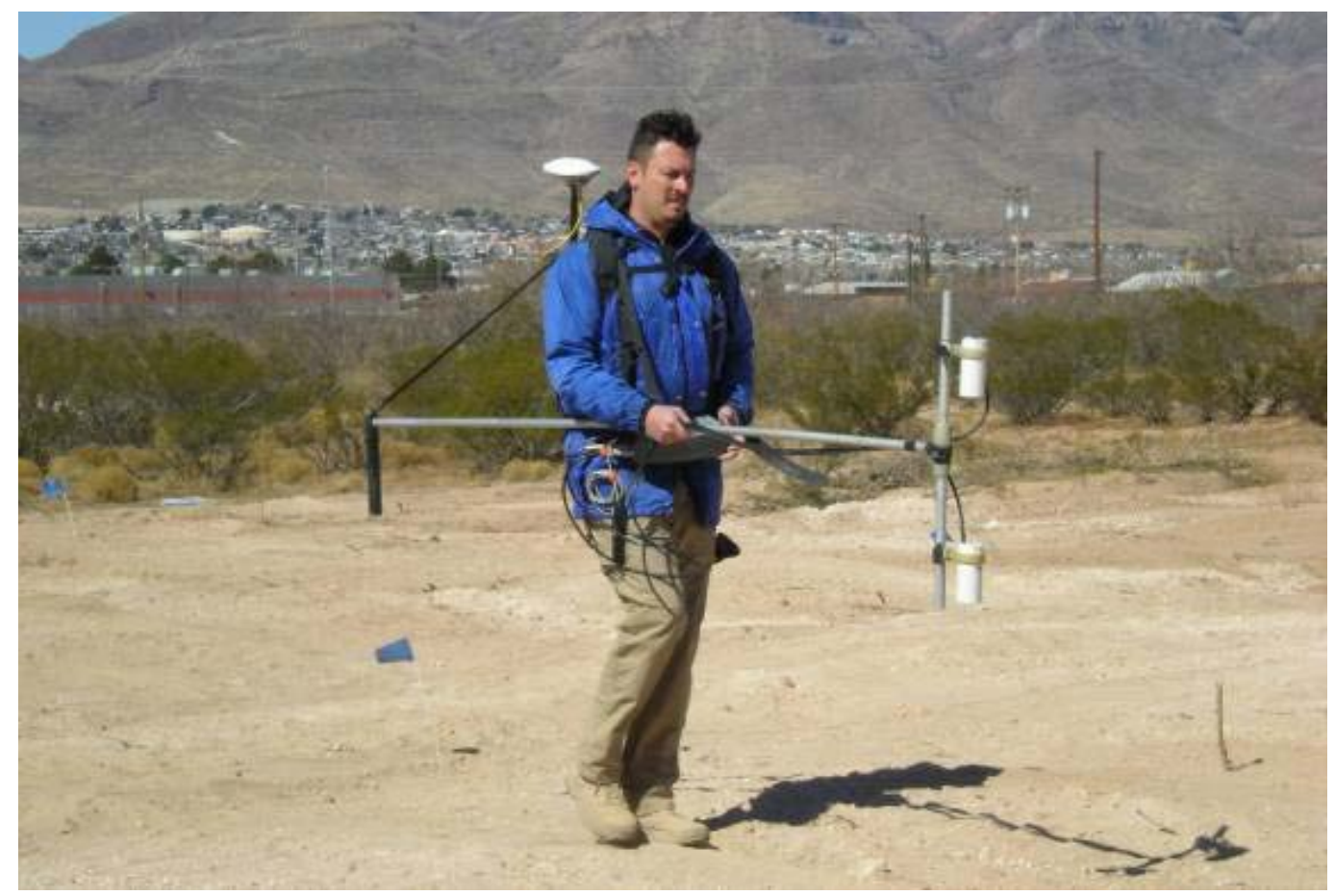

Figure 8. Geometrics G-858 total field magnetometer system.

\section{Positioning}

Positioning a geophysical measurement at the correct location can be done in many ways. The simplest method is to lay out a $2 \mathrm{D}$ grid with marks at each measurement location, then take a measurement at each marked location and record the location with the value. For continuous measurements, the previous method becomes cumbersome so the method used then is "dead reckoning." Dead reckoning involves laying tape measures around all sides of a survey grid, then putting flags at set distances along the path and a moveable marker at both ends of the current survey line. The operator walks at a constant speed from one end of the line to the other end of the line. As the operator passes each marker on the line, he places a fiducial marker in the data to indicate the location, typically by press- 
ing a hardware button on the instrument or a software based button on the data logger. At the end of the survey, the data can be shifted so that the beginning and ending points, as well as the fiducial markers, are in the correct locations. With an experienced operator, the dead reckoning method can be quite accurate, possibly better than $25 \mathrm{~cm}$ accuracy. With an inexperienced operator, however, the positioning can be quite poor. Dead reckoning surveys are currently used only when the survey area is small, the expected targets are few, and the targets are large.

Most modern geophysical surveys use GPS for positioning the data. All modern geophysical instruments have the capability to record the GPS data along with the instrument data. Raw, uncorrected GPS units that are used for driving directions or locating a geocache may only be accurate to $5 \mathrm{~m}$, but the corrected systems used for geographic information system (GIS) or geophysical work generally are accurate to better than $1 \mathrm{~m}$. For this project, several types of GPS were utilized, including a Real Time Kinematic (RTK) GPS for obtaining the ground truth positions. RTK GPS units usually have position accuracies of better than 1 centimeter $(\mathrm{cm})$ while stationary. The two RTK GPS units used were a Magellan system and a Trimble 5700 system. The Site 1 Fort Bliss surveys were performed with a Trimble DSM-232 system with OmniStar HP correction, which has positional accuracies of approximately $25 \mathrm{~cm}$. For the Site 3 EM61-MK2 surveys at Fort Wainwright, a Trimble ProXH GIS grade GPS was used that has real-time accuracies of less than $1 \mathrm{~m}$ and can be post-processed to accuracies of approximately $25 \mathrm{~cm}$. 


\section{Analysis}

All of the data collected, except for the GPR and OhmMapper, were processed in Geosoft's Oasis Montaj software. During data processing, geophysical data were integrated with the GPS positions and then were converted from the manufacturers' proprietary binary file formats into a standard ASCII format. In Oasis Montaj, each dataset was separated into individual lines so that the data could be inspected for obvious errors. These errors primarily include incorrect positions and spikes or noise in the data. Geophysical sensors are very reliable but still produce occasional erroneous data spikes. After the data were processed in Oasis Montaj, they were gridded for visualization on a map of the site. GPR data was processed with the software provided by the equipment manufacturer, GSSI data was processed using RADAN while Sensors \& Software data was processed with EKKO View Deluxe.

\section{Gridded images}

All of the magnetic and electromagnetic data were gridded with a linear color scale and are presented as figures in the appendices. The linear color scale allows the interpreter to attempt to match the before and after data color scales so that the reader can better understand the impact of the buried targets. This is mostly successful, with the primary exception being the inphase data presented for the electrical conductivity profiling data. Inphase data is relative so that data from one survey cannot necessarily be directly compared to another survey since it is not an intrinsic property of the material, it is dependent on the calibration of the instrument.

\section{Profiles}

GPR data are presented as 2D profiles with both a distance scale and depth scale. A future task may be to present selected profiles of each grid over known targets, which might give the end users a better idea of the relative amplitudes of various types of targets at known depths versus the background instrument response.

\section{Site location and layout}

The study locations were Fort Bliss, TX (FBT) in February of 2009 and Fort Wainwright, AK (FWA) in J une 2009. The testing was conducted in 
three soil types; silty sand (Area \#1) at FBT, silty gravel (Area \#2), and sandy gravel (Area \#3) both at FWA. The testing encompassed two tasks:

- Task \#1 - Test the detection capability and accuracy of various geophysical methods for buried utilities. The desired information is depth, lateral extent, and possible material type. This was accomplished by burying fluid conveyance utilities at a known depth in each of the three soil types. The excavations were large enough to allow for the simultaneous burial of all test utility materials with a minimum $6 \mathrm{~m}$ of length for each, and a minimum $3 \mathrm{~m}$ of lateral separation to the adjoining material type. Variable depth testing was accomplished by burying the pipe to the total desired depth at one end and shallower at the other end. The test pipe materials were 6-in. (15-cm) diameter water-filled polyvinyl chloride (PVC), 8-in. (20-cm) diameter steel, 12-in. (30-cm) diameter cast iron, and 2-in. (5-cm) diameter copper.

- Task \#2 - Test the detection capability and accuracy for buried items such as 55-gallon (208-liter) drums, both intact and crushed. The desired outcome was to differentiate depth, lateral extent, and container shape. This was accomplished by buying four drums, two in the original full volume shape and two in a crushed shape. These were buried at known depths and orientations and the drums were clean, containing no hazardous chemicals.

For each installation, candidate test areas were evaluated for soil type, access, terrain, and previous construction, as any remaining infrastructure or debris could adversely affect the study. Environmental personnel from the Department of Public Works were contacted, and maps, historical photographs, and anecdotal evidence were used to determine suitability. Prior to excavation, each site was surveyed with each technique and system to obtain the background signal as well as to ensure that no unexpected buried items were on the site. Because of the ability of metal detectors and electrical conductivity profiling systems to detect both ferrous and nonferrous metal objects, these background surveys also afforded the opportunity to locate and remove infrastructure remains. The layouts for all three areas were similar but not identical, as size constraints and lessons learned required redesign for each site (Table 1). 
Table 1. Test area locations.

\begin{tabular}{|l|l|l|l|l|l|}
\hline Area & Installation & $\begin{array}{l}\text { Predominant Soil } \\
\text { Type }\end{array}$ & $\begin{array}{l}\text { Soil } \\
\text { Moisture } \\
\text { (g/g) }\end{array}$ & $\begin{array}{l}\text { Type of Cultural } \\
\text { Remains }\end{array}$ & Cleaning Required \\
\hline $\begin{array}{l}\text { Area } \\
\# 1\end{array}$ & FBT & Silty Sand - SM & $<15 \%$ & $\begin{array}{l}\text { Minor Surface } \\
\text { Dumping }\end{array}$ & $\begin{array}{l}\text { Relocation of small } \\
\text { brick pile }\end{array}$ \\
\hline $\begin{array}{l}\text { Area } \\
\# 2\end{array}$ & FWA & Silty Gravel - GM & $<15 \%$ & $\begin{array}{l}\text { Previous Asphalt } \\
\text { Roadway }\end{array}$ & $\begin{array}{l}\text { Raking of the surface } \\
\text { and subsurface with } \\
\text { equipment to remove } \\
\text { asphalt chunks }\end{array}$ \\
\hline $\begin{array}{l}\text { Area } \\
\# 3\end{array}$ & FWA & Sandy Gravel - GP & $<10 \%$ & $\begin{array}{l}\text { Area used for } \\
\text { Engineer Training }\end{array}$ & $\begin{array}{l}\text { Some minor metal } \\
\text { debris }\end{array}$ \\
\hline
\end{tabular}

After completion of the background surveys and removal of any debris, the test materials were buried. At all three sites, the pipe materials were laid out parallel to each other (Figures 9- 12). The plan view and cross-section views of Area \#2 are shown in Figures 13 and 14, and Areas \#1 and \#3 are shown in Appendix A and C. At Area \#1, the ductile iron pipe was located adjacent to the steel pipe. Due to the size of the ductile iron pipe, the resulting signal overwhelmed discrete detection of the smaller steel pipe. This issue was corrected at Areas \#2 and \#3 by separating the pipes by a greater distance and isolating the ductile iron from the steel pipe with the PVC pipe. The locations and geometry of the buried drums differed at all three sites; however, at each site one 55-gallon (208-liter) drum in the intact shape was buried in the horizontal position, one drum was buried in the intact shape in the vertical position, and two crushed drums were buried in various positions (Figures 15 and 16). The sites were excavated with a standard construction backhoe tractor, and burial was performed by replacing successive lifts of approximately $20 \mathrm{~cm}$ to $30 \mathrm{~cm}$ of excavated native fill material. Each lift was compacted with the backhoe bucket and also by personnel foot traffic. Samples were collected and screened for bulk gradation at each area, and no compacted density measurements were conducted. The top surface of the ends of the pipes and the top surface of the drums were surveyed prior to burial. 


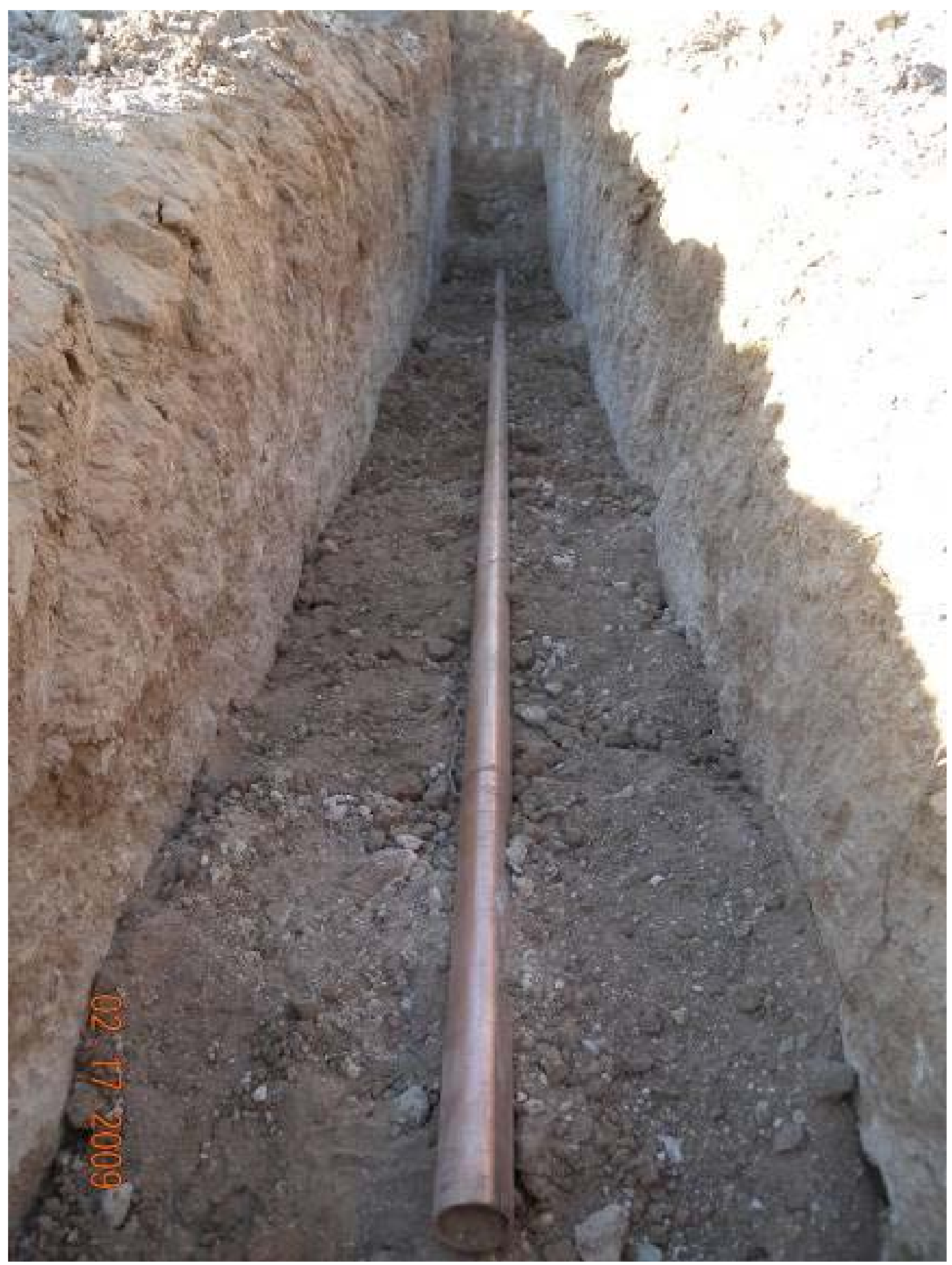

Figure 9. Copper pipe: 2-in. (5 -cm) diameter. 


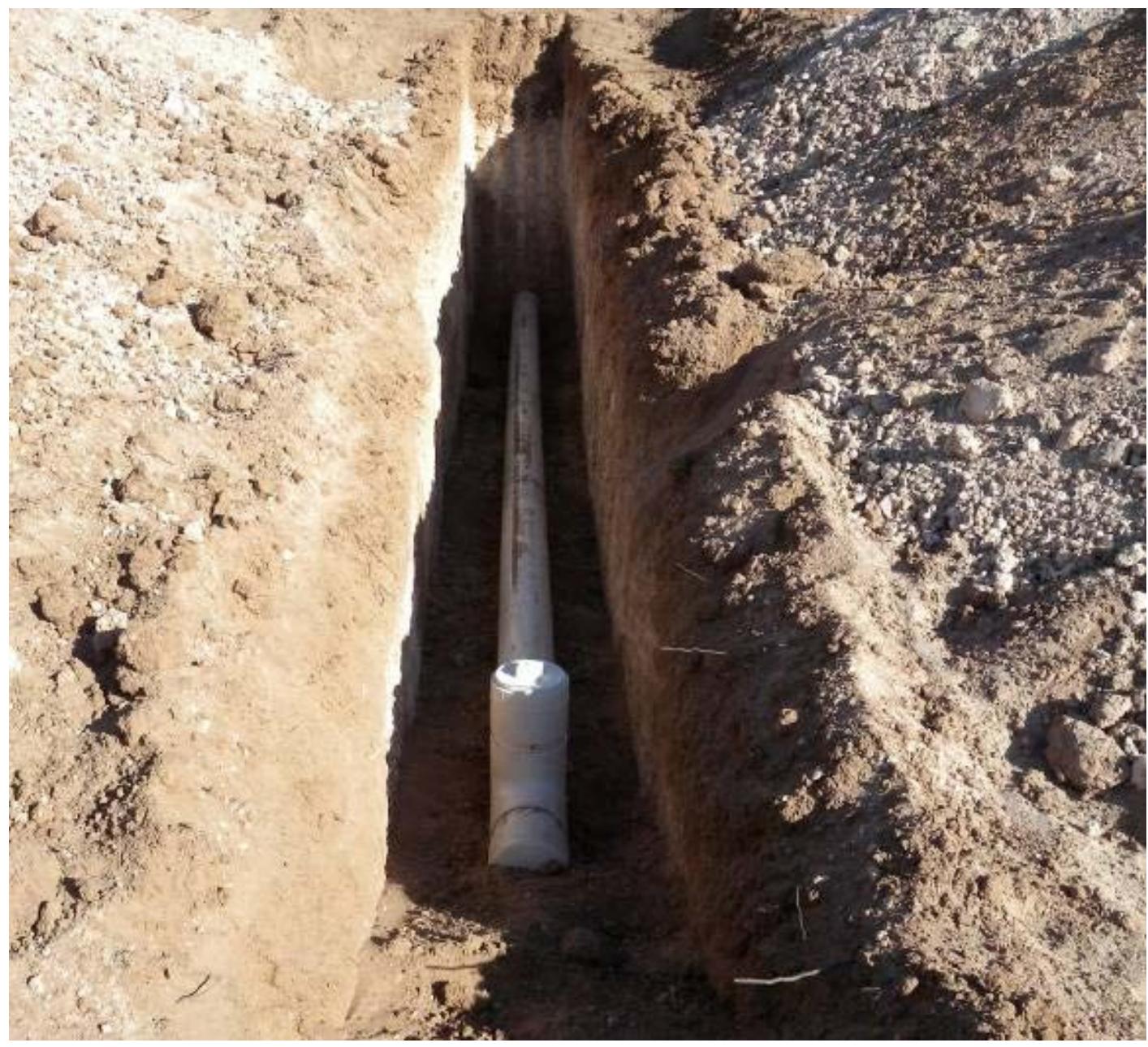

Figure 10. PVC pipe: 6-in. (15-cm) diameter, water filled. 


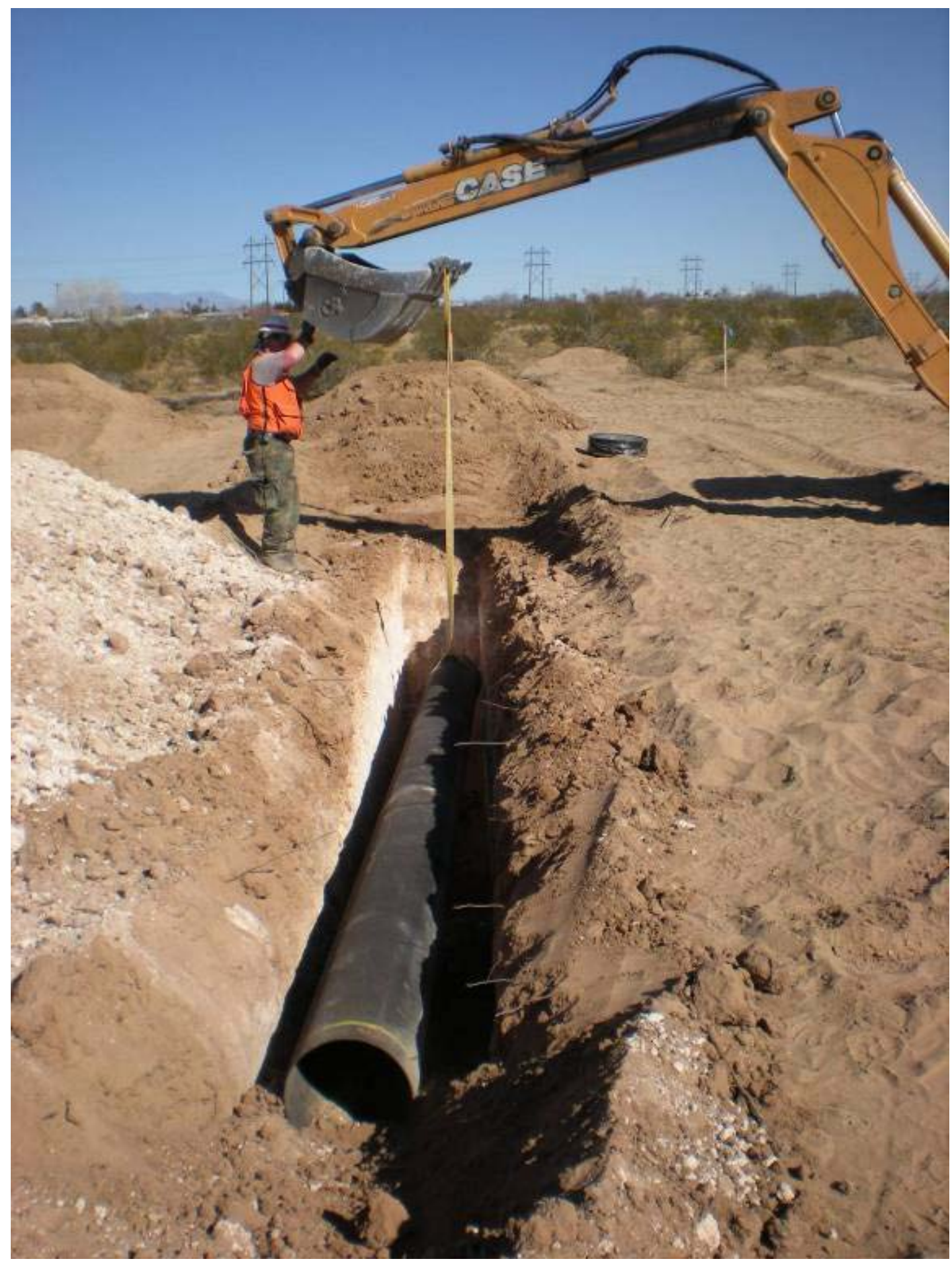

Figure 11. Ductile iron pipe: 12-in. (30.5-cm). 


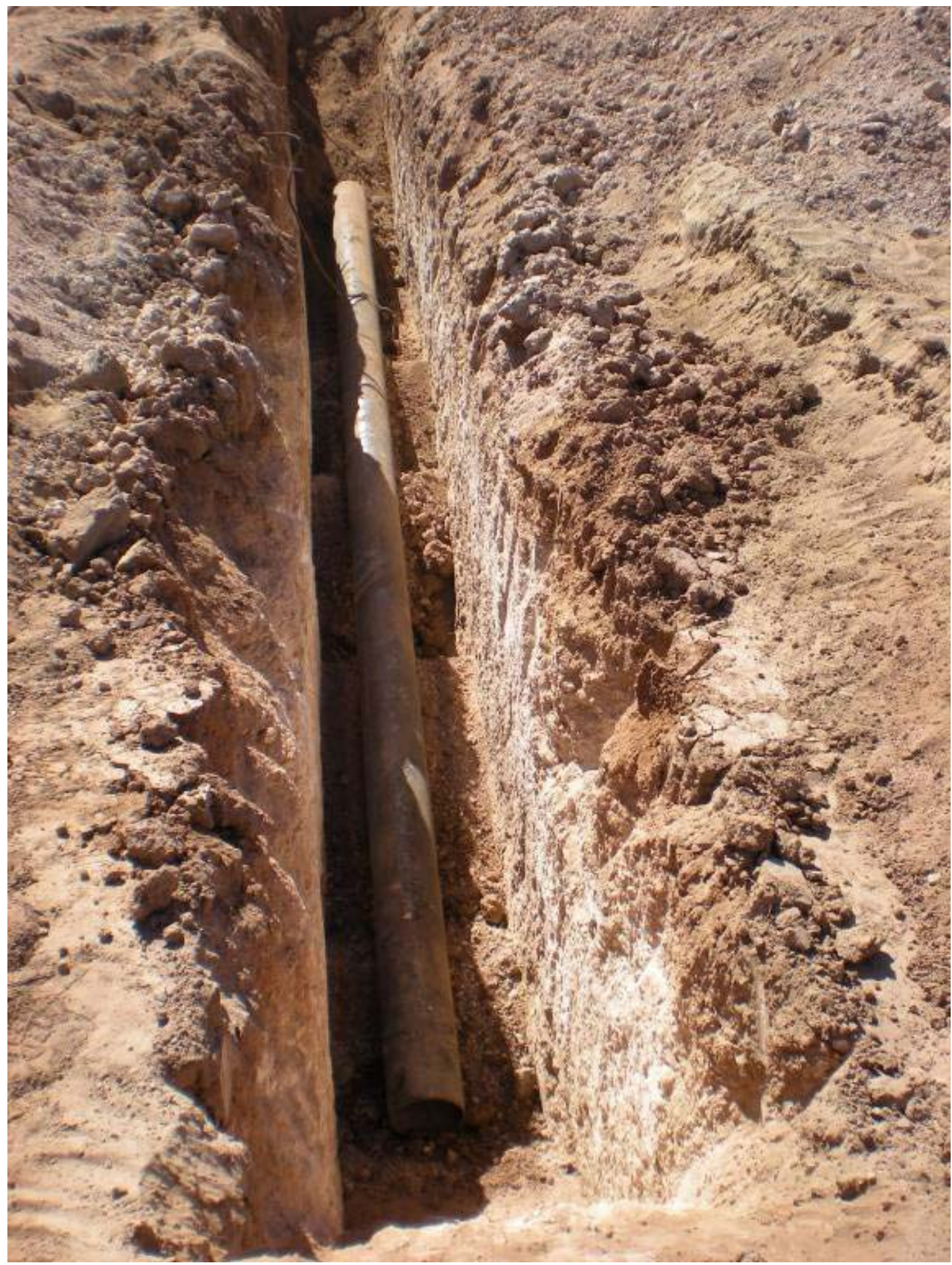

Figure 12. Steel pipe: 8-in. (20-cm). 


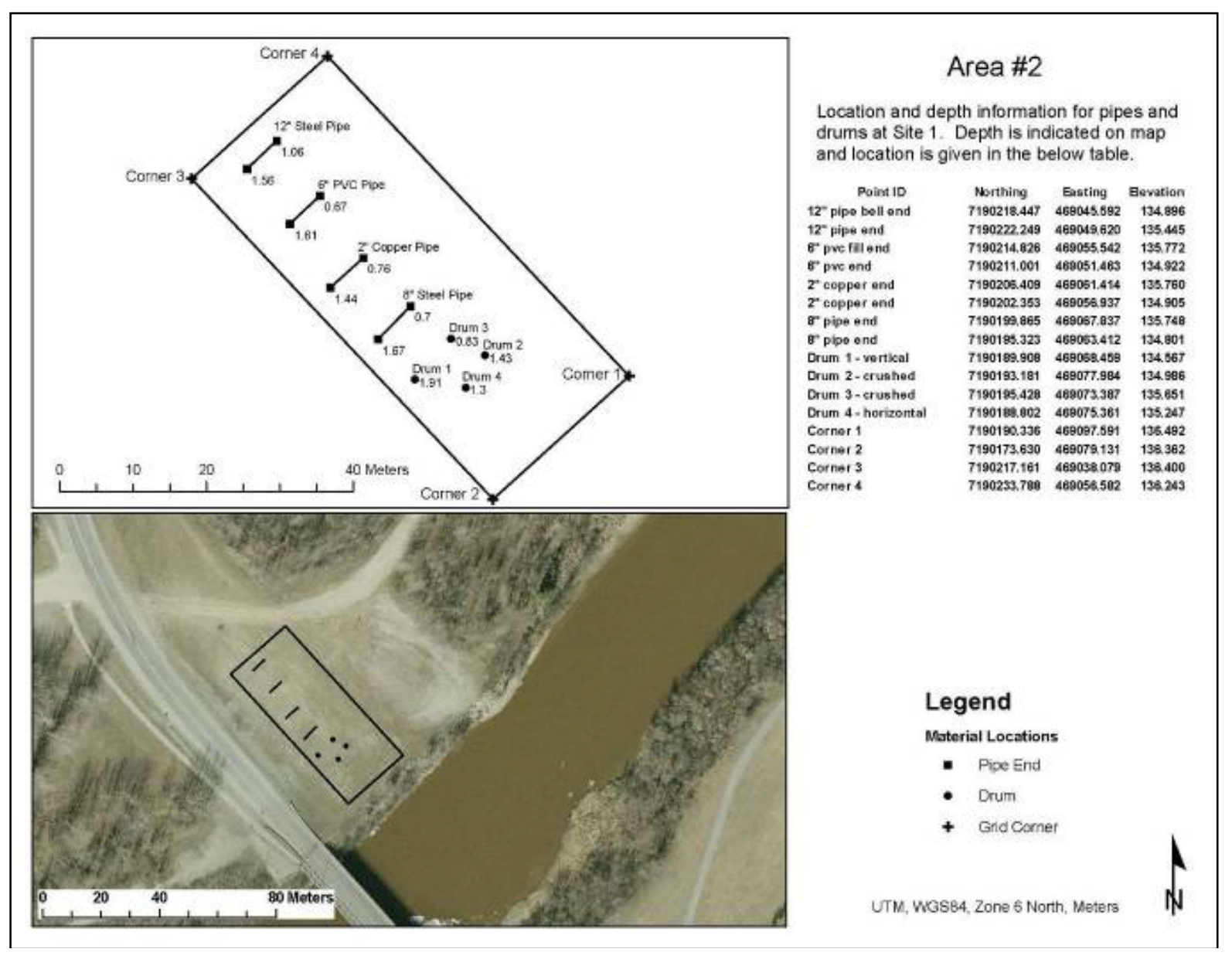

Figure 13. Plan view of study area \#2 Fort Wainwright, Alaska. 


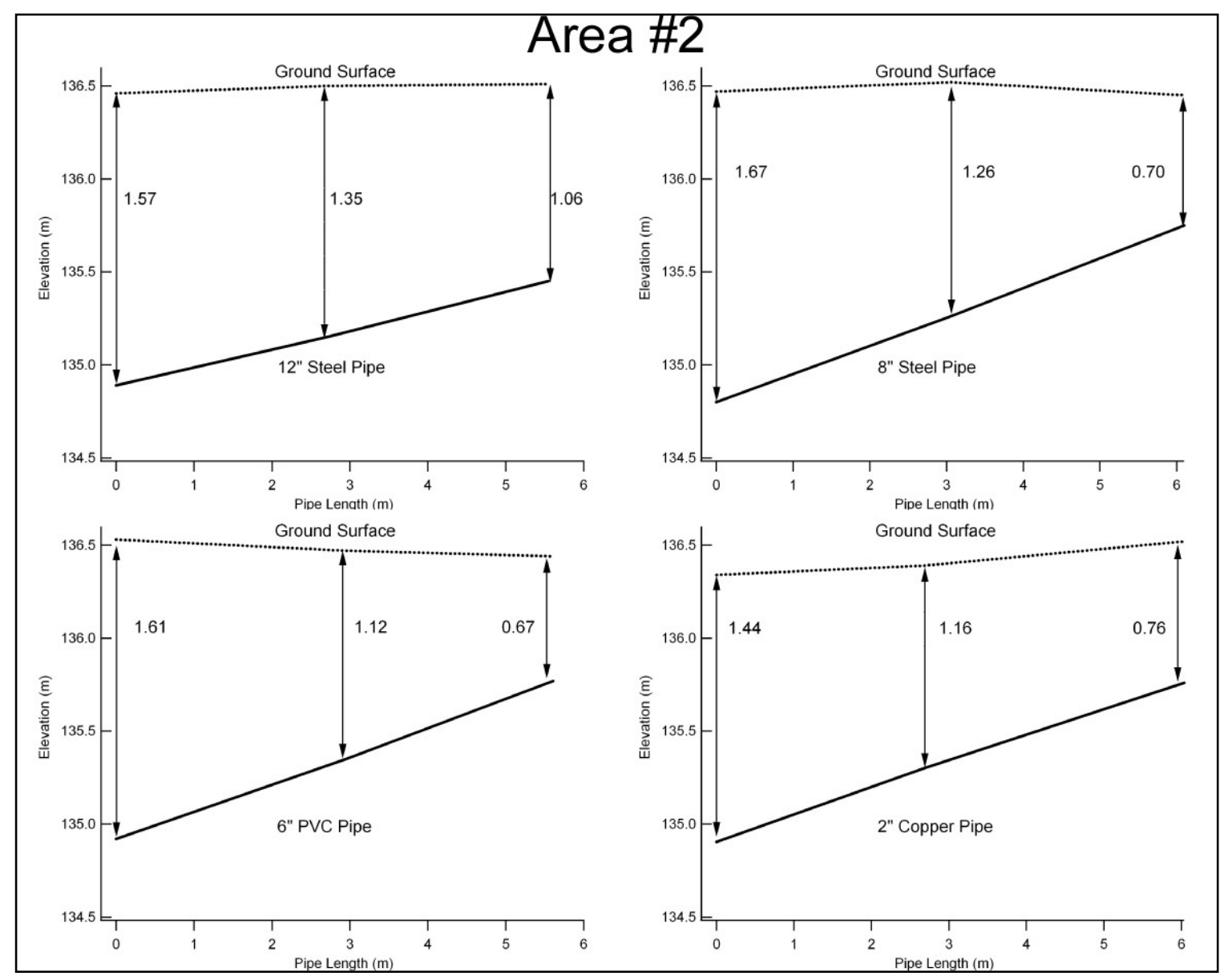

Figure 14. Cross-section of the pipe layout for study area \#2. 


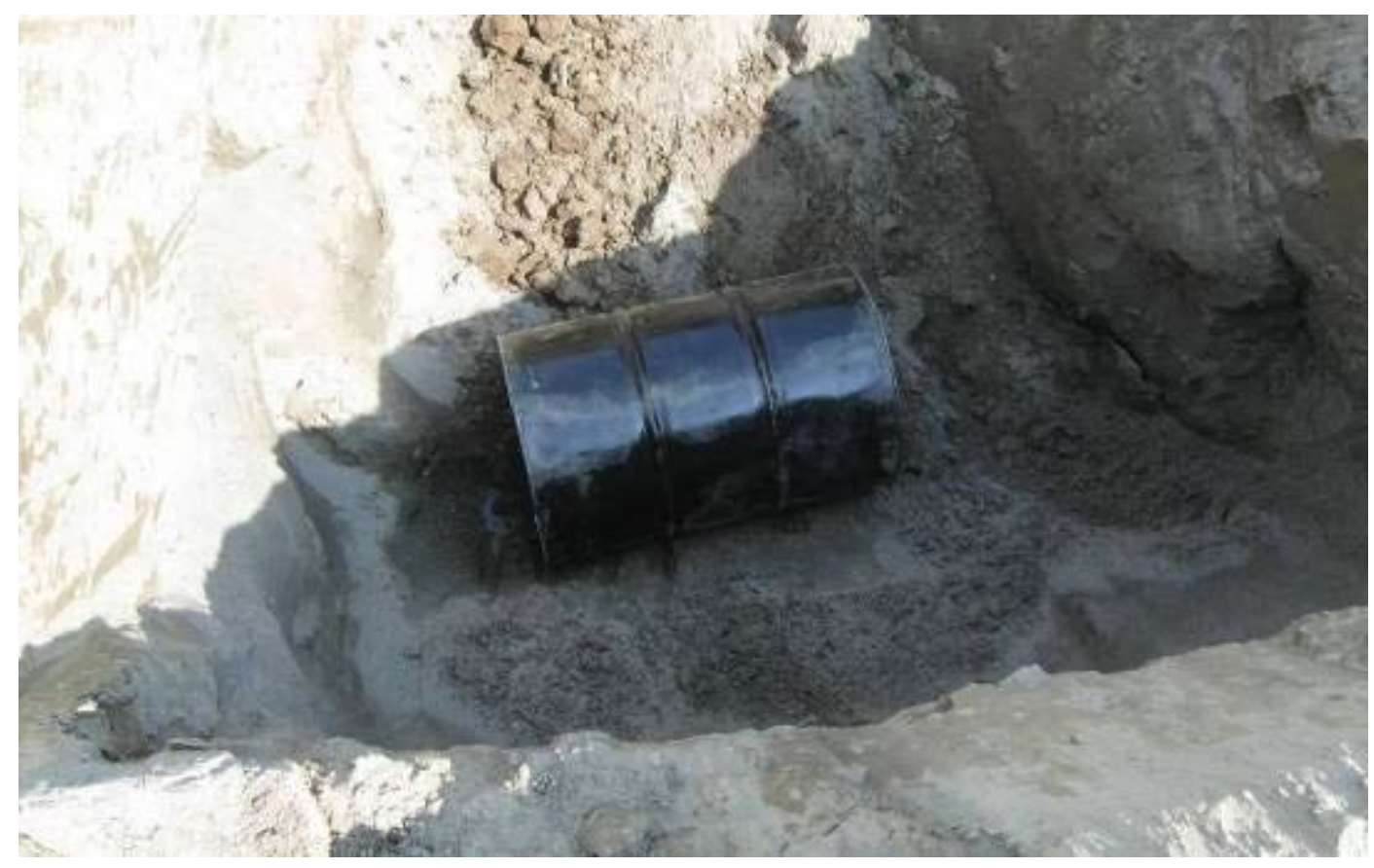

Figure 15. Intact, clean 55 gallon (208 liter) drum laid horizontally.

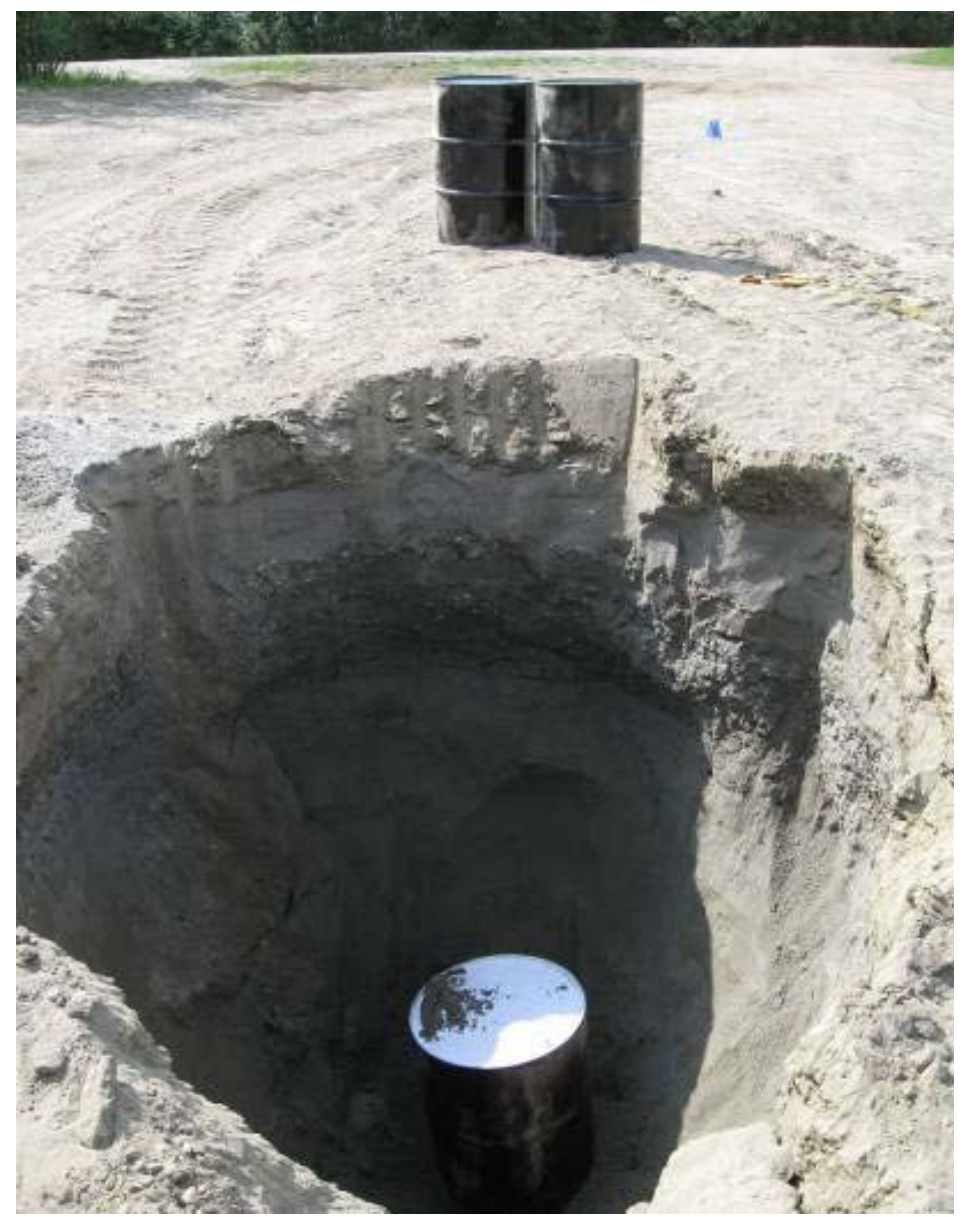

Figure 16. Intact 55 gallon (208 liter) drum laid vertically. 


\section{Survey procedure}

Most geophysical technique systems have the capability of integration with the GPS, including all the systems used for this study. This capability is especially useful when relocating anomalous points from an image. The survey systems also have the capability of placing fiducial marks into the data files, that are useful if the operator wishes to mark a particular point of interest, or if GPS is not available. If GPS is not available, a grid is established by laying out long measuring tapes and placing markers at even intervals, such as every $10 \mathrm{~m}$. The operator marks these points on the file as they are passed. This allows for quick relocation of an anomalous point from the image. For this study, both GPS and fiducial marks were used for comparison.

For all surveys, the origin of the grid $(0,0)$ was used as the beginning location of the surveys. Because the target orientation was known, the travel direction was perpendicular to the long axis orientation of the buried pipes and drums. During production work, it is possible or even likely that target orientation will not be known; therefore, it is advised that an orthogonal survey also be conducted to clarify anomalous results. All of the surveys were collected using parallel profiles that were spaced 1 or $2 \mathrm{~m}$ apart. The initial surveys of the buried materials were processed and adjustments were made. Surveys were repeated if needed. The OhmMapper resistivity system data extend beyond the limits of the survey grid end points due to the long distance between the transmitter and receivers, which led to data quality issues on several lines due to trenches off the end of the grids. The OhmMapper requires ground contact by both the transmitter and receiver for accurate data.

The surveys were manually processed in the field or at the hotel to validate the data so that repeat surveys could be conducted if necessary. The results were then evaluated from the various methods and three different soil types. Rankings were given to each method depending on target recognition success rate (Table 2 in the next chapter). 


\section{Results and Discussion}

\section{Interpretation}

The gridded images of all of collected data are presented in Appendices A, $B$, and C. Typical field surveys will not have before and after results, but when they are available for this study the before and after gridded images for each methodology are presented on the same page. All of the electromagnetic instruments (metal detectors and electrical conductivity profiling) are displayed in map view with the target locations clearly marked on each figure. The colors used for the gridding were selected to best emphasize the anomalies and allow for comparison between the before and after images.

The two large metal pipes were detected by all of the methods and instruments used in this study, but dominated the magnetic data as expected since they are essentially huge dipoles that are oriented either North/South or closer to North/South than east west, which maximizes their coupling to the Earth's magnetic field. This effect is most visible in the data from Area \#1, which led to a change in site design for the following sites. The copper pipe was only detected by the EM61-MK2 and the GPR. The PVC pipe did not show up in any of the data except for the GPR.

All of the metal targets showed up in the data with varying levels of contrast versus the background. The crushed drums did not show up as well as the intact drums, but this is also expected since the volume has decreased but not the mass. Since electromagnetic induction is a volume effect, the smaller volume means that the drums have less surface area.

\section{Discussion}

All of the electrical conductivity profiling systems produced similar results as expected. Any of these instruments should be acceptable for a MILCON site survey. The metal detector was the only instrument that reliably detected all of the metal targets, which makes it an excellent choice for MLCON site surveys. The capacitively-coupled resistivity method was not considered applicable for MILCON site surveys for several reasons. First the length of the towed instrumentation made it quite difficult to use at several sites due to vegetation. The second reason is that the length of the 
towed instrumentation was over half the length of all the survey grids, which made it unwieldy. The third reason is that the size of the targets is relatively small versus the spatial resolution of the method. The final reason is that the processing is more complex than the other methods.

Table 2 can be used a guide on the applicability of each method to detection of the targets used in this study to a depth of $2 \mathrm{~m}$. The copper pipe and water-filled PVC were difficult to image with any technique other than GPR, which was most applicable for all material types. GPR is not suggested for initial large scale surveys, but as a secondary method over smaller regions of interest. Table 3 lists the overall applicability of each system to MILCON projects.

Table 2. Imaging ability to depth of $2 \mathrm{~m}$.

\begin{tabular}{|c|c|c|c|c|c|c|c|}
\hline Technique & Soil Type & Ductile Iron & Steel & Copper & $\begin{array}{l}\text { Water-Filled } \\
\text { PVC }\end{array}$ & \begin{tabular}{|l|}
55 -gal Drums \\
Vertical
\end{tabular} & $\begin{array}{l}\text { 55-gal Drums } \\
\text { Horizontal }\end{array}$ \\
\hline \multirow{3}{*}{$\begin{array}{l}\text { GSSI GPR } \\
400 \mathrm{MHz}\end{array}$} & SM & VG & VG & VG & VG & VG & VG \\
\hline & GM & G & G & $\mathrm{P}$ & $\mathrm{P}$ & G & VG \\
\hline & GP & $G$ & $G$ & $\mathrm{P}$ & $P$ & $G$ & VG \\
\hline \multirow{3}{*}{$\begin{array}{l}\text { GSSI GPR } \\
200 \mathrm{MHz}\end{array}$} & SM & VG & VG & VG & VG & VG & VG \\
\hline & GM & VG & VG & VG & VG & VG & VG \\
\hline & GP & VG & VG & VG & VG & VG & VG \\
\hline \multirow{3}{*}{$\begin{array}{l}\text { S\&S GPR } \\
250 \mathrm{MHz}\end{array}$} & SM & VG & VG & VG & VG & VG & VG \\
\hline & GM & VG & VG & VG & VG & VG & VG \\
\hline & GP & VG & VG & VG & VG & VG & VG \\
\hline \multirow{3}{*}{ Profiler } & SM & VG & G & NA & NA & $\mathrm{P}$ & VG \\
\hline & GM & VG & G & NA & NA & G & G \\
\hline & GP & VG & $G$ & NA & NA & VG & VG \\
\hline \multirow{3}{*}{ EM-61 } & SM & VG & $G$ & NA & NA & NA & VG \\
\hline & GM & VG & $G$ & NA & NA & VG & VG \\
\hline & GP & VG & $G$ & NA & NA & VG & VG \\
\hline \multirow{3}{*}{ CMD-4 } & SM & VG & NA & NA & NA & NA & NA \\
\hline & GM & G & VP & NA & NA & VG & VG \\
\hline & GP & VG & $\mathrm{G}$ & NA & NA & VG & VG \\
\hline \multirow{3}{*}{ EM-31 } & SM & VG & NA & NA & NA & NA & NA \\
\hline & GM & VG & VG & NA & NA & VG & VG \\
\hline & GP & VG & VG & NA & NA & VG & VG \\
\hline \multirow{3}{*}{ OhmMapper } & SM & VP & VP & NA & NA & VP & $\mathrm{VP}$ \\
\hline & GM & $\mathrm{VP}$ & VP & NA & NA & VP & $\mathrm{VP}$ \\
\hline & GP & VP & VP & NA & NA & VP & VP \\
\hline \multirow{3}{*}{ G-858 } & SM & VG & VG & NA & NA & NA & NA \\
\hline & GM & VP & VG & NA & NA & VP & VP \\
\hline & GP & VG & VG & NA & NA & VP & $\mathrm{P}$ \\
\hline
\end{tabular}

(VG=Very Good, G=Good, P=Poor, VP=Very Poor, NA=Not Applicable) 
Table 3. Overall technique comparison.

\begin{tabular}{|l|l|l|l|l|l|}
\hline Technique & Imaging Ability & $\begin{array}{l}\text { Survey } \\
\text { Simplicity }\end{array}$ & $\begin{array}{l}\text { Post-Processing } \\
\text { Simplicity }\end{array}$ & $\begin{array}{l}\text { Target } \\
\text { Accuracy }\end{array}$ & $\begin{array}{l}\text { Applicability for } \\
\text { MILCON }\end{array}$ \\
\hline $\begin{array}{l}\text { GSSI GPR } \\
\text { 400 MHz }\end{array}$ & Good to Poor & Moderate & Complex & Moderate & Moderate \\
\hline $\begin{array}{l}\text { GSSI GPR } \\
200 \mathrm{MHz}\end{array}$ & Very Good & Moderate & Complex & Moderate & Very Good \\
\hline $\begin{array}{l}\text { S\&S GPR } \\
250 \mathrm{MHz}\end{array}$ & Very Good & Moderate & Complex & Moderate & Very Good \\
\hline Profiler & Very Good & Simple & Simple & Very Good & Very Good \\
\hline EM-61 & Very Good & Very Simple & Very Simple & Very Good & Very Good \\
\hline CMD-4 & Moderate & Very Simple & Very Simple & Poor & Poor \\
\hline EM-31 & Moderate & Very Simple & Very Simple & Poor & Poor \\
\hline OhmMapper & Very Poor & Poor & Complex & Very Poor & Very Poor \\
\hline G-858 & Moderate & Moderate & Simple & Good & Moderate \\
\hline
\end{tabular}




\section{Recommendations}

The results of this study indicate that geophysical techniques can be used to assess if infrastructure is present at a MILCON site. GPR can image all the tested materials regardless of material composition. The 2-in. copper pipe was clearly defined, and it has been observed from previous surveys that 1-in. diameter electrical conductors can be imaged in the near surface as well. Metal objects are frequently associated with buried infrastructure and are the most easily imaged by most electromagnetic techniques. The exception appears to be small diameter ( 2 in. or $5 \mathrm{~cm}$ ) copper pipe, and PVC pipe. PVC is very difficult to image due to its plastic composition, which has no conductive properties, even if water filled.

The 55-gallon drums were very detectable with nearly all the techniques, in either the horizontal or vertical orientation. For the crushed 55-gallon drums, the detectability dropped off dramatically for all techniques. The decreased volume of the crushed drums accounts for this decrease.

For all the techniques, the buried material surveys contrasted very well when compared to the background surveys. However, the user should exercise caution in determining what color intensity range has been used for each survey to ensure that misinterpretation of the background conditions does not occur.

It is difficult with nearly all electromagnetic techniques to determine the depth and size of the objects without knowing exactly what the objects are. However, once the imaged infrastructure has been visually examined after excavation, the pertinent technique is now calibrated to that site and much greater inferences can be made from future imaging. During this study, it was difficult to determine the ultimate depth of the surveys as no deeper objects were known to exist at these sites. 
Items that should be taken into account when considering the use of geophysics are:

1. What is the purpose of the survey?

a. Site reconnaissance to determine if additional surveys are required.

b. Complete survey with continuous coverage across the area to assess if and where buried infrastructure or debris exists.

c. Detailed survey of a small subset of the area to identify individual targets.

2. What type of buried material is expected?

a. Shallow or deep?

b. Metallic or non-metallic

c. Size of targets

3. What are the soil type(s) and moisture conditions?

4. Resolution required from the survey?

5. Size of the area

6. Speed of the survey and results

7. Is resolving the depth to buried targets necessary?

8. What are potential sources of interference with the geophysical survey?

a. overhead powerlines

b. fences or buildings

c. known buried utilities, aurora, or other nearby electromagnetic sources

d. site geology and mineralogy

e. topography

f. vegetation

If an area to be surveyed is completely unknown as to the type, amount, and depth of buried infrastructure, either a TDEM metal detector or an electrical conductivity system will serve as a good initial evaluation tool. Although plastic-type materials will not be detected, metallic appurtenances associated with the plastic, such as isolation valves and check valves, will generally show up in images to lead to discovery of the plastic.

For the initial evaluation, GPR can also be used; however, many natural objects in the soil, such as stones or bedrock, will produce diffractions that may confuse the interpretation. For this reason, GPR is generally used as a secondary survey tool to evaluate the depth and orientation of the object. The results of this study also show that GPR frequencies in the $200 \mathrm{MHz}$ range seem to be the most appropriate for MILCON work. 
All the techniques tested for this study are easily operated in the field by properly trained technicians. The same personnel can easily produce the image output with appropriate training. There are numerous consulting companies that can perform these surveys and provide the construction manager with both paper and digital maps and reports that will show areas requiring additional investigation. There are also numerous groups within the US Army Corps of Engineers that can provide these same survey capabilities. One exception to this conclusion is GPR, for which parameter adjustments can be difficult if one is not thoroughly aware of the implications of the parameters and the changes that occur to the survey due to adjustments. GPR processing and interpretation can also be technical, requiring additional training or considerable hands-on experience. However, it is possible to operate and process directly OTS with these units as well under ideal conditions. 


\section{References and Suggested Reading}

Daniels, D. 2004. Ground Penetrating Radar, 2nd ed. London: Institution of Electrical Engineers.

Engineer Manual (EM)-1110-1-1802. 1995. Geophysical Exploration for Engineering and Environmental Investigations. Washington, DC: U.S. Army.

Geometrics. 2001 OhmMapper TR1 Operation Manual. San J ose, CA: Geometrics.

Geometrics. 2001 G-858 MagMapper Operation Manual. San J ose, CA: Geometrics.

Geonics. 2005a. EM31 Operating Manual 1st ed. Mississauga, Ontario, Canada: Geonics Limited.

Geonics. 2005b. EM38B Ground Conductivity Meter Dual Output Version Operating Manual. Mississauga, Ontario, Canada: Geonics Limited.

Geonics. 2005c. EM61-MK2 and EM61-MK2HP 4 Channel High Sensitivity Metal Detectors Operating Manual. Mississauga, Ontario, Canada: Geonics Limited.

Geonics. 2008. EM38-MK2 Ground Conductivity Meter Operating Manual. Mississauga, Ontario, Canada: Geonics Limited.

Geophysical Survey Systems. 2007. Profiler EMP-400 User's Manual. Salem, NH: Geophysical Survey Systems, Inc.

Geophysical Survey Systems. 2009. SIR System-3000 Manual. Salem, NH: Geophysical Survey Systems, Inc. www.geophysical.com.

GF Instruments. CMD Electromagnetic Conductivity Meter User Manual, 1st ed. Czech Republic: GF Instruments.

Magellan. 2007. ProMark3 / ProMark3 RTK Reference Manual, Revision D. Magellan, Inc. www.promagellangps.com.

Milsom, J. 2003. Field Geophysics, 3rd ed. (Wiley).

Reynolds, J . M., 1997. An Introduction to Applied and Environmental Geophysics. Wiley.

Sensors and Software. 1998. Noggin User's Manual. Mississauga, Ontario, Canada: Sensors and Software.

Telford, W. M., L. P. Geldart, and R. E. Sheriff. 1990. Applied Geophysics, 2nd ed. Cambridge University Press.

Trimble. 2003. Trimble R7/R8 GPS Receiver User Guide 1st ed. Sunnyvale, CA: Trimble. www.trimble.com.

Trimble. 2005. DSM 232 GPS Receiver User Guide, 1st ed. Sunnyvale, CA: Trimble. www.trimble.com. 


\section{Appendix A: Area \#1 Fort Bliss Images}

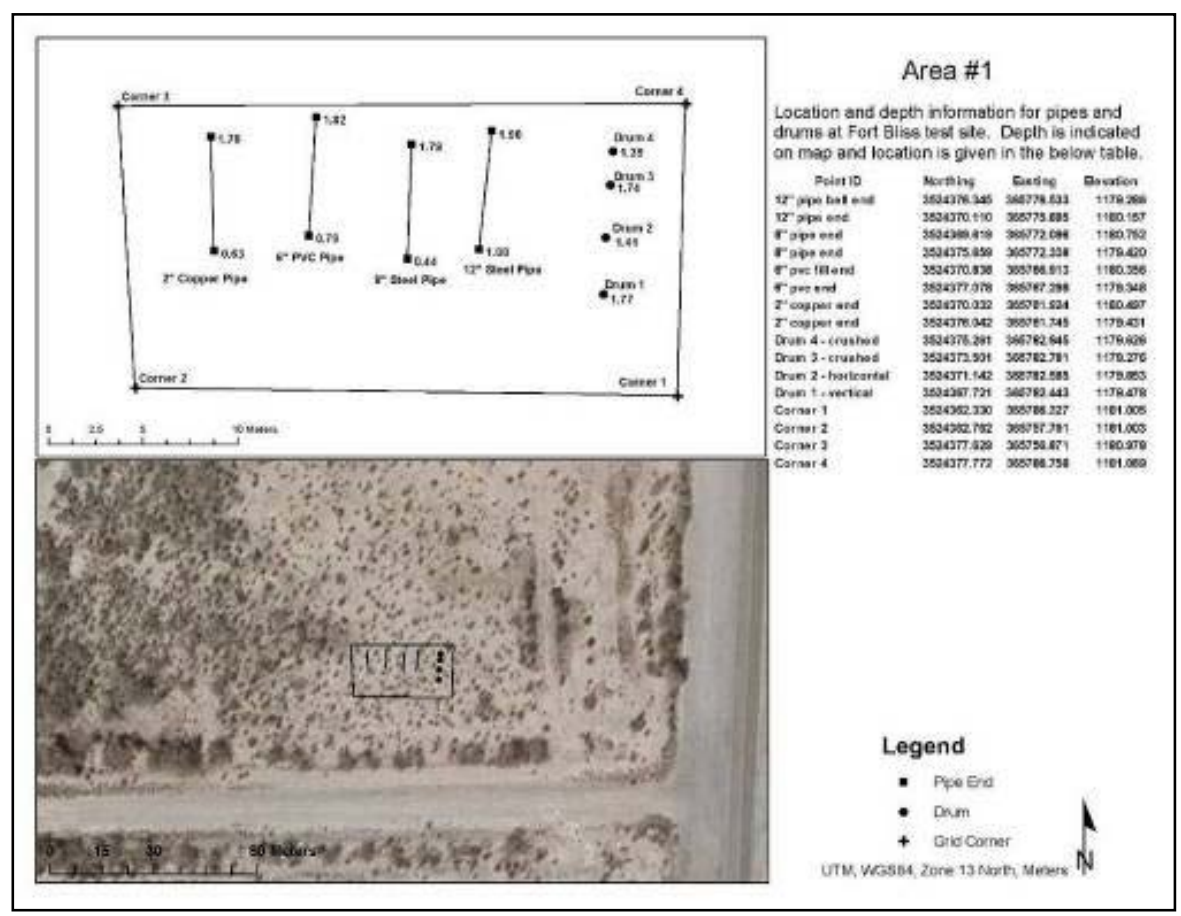

Figure A1. Area \#1 Fort Bliss plan view.

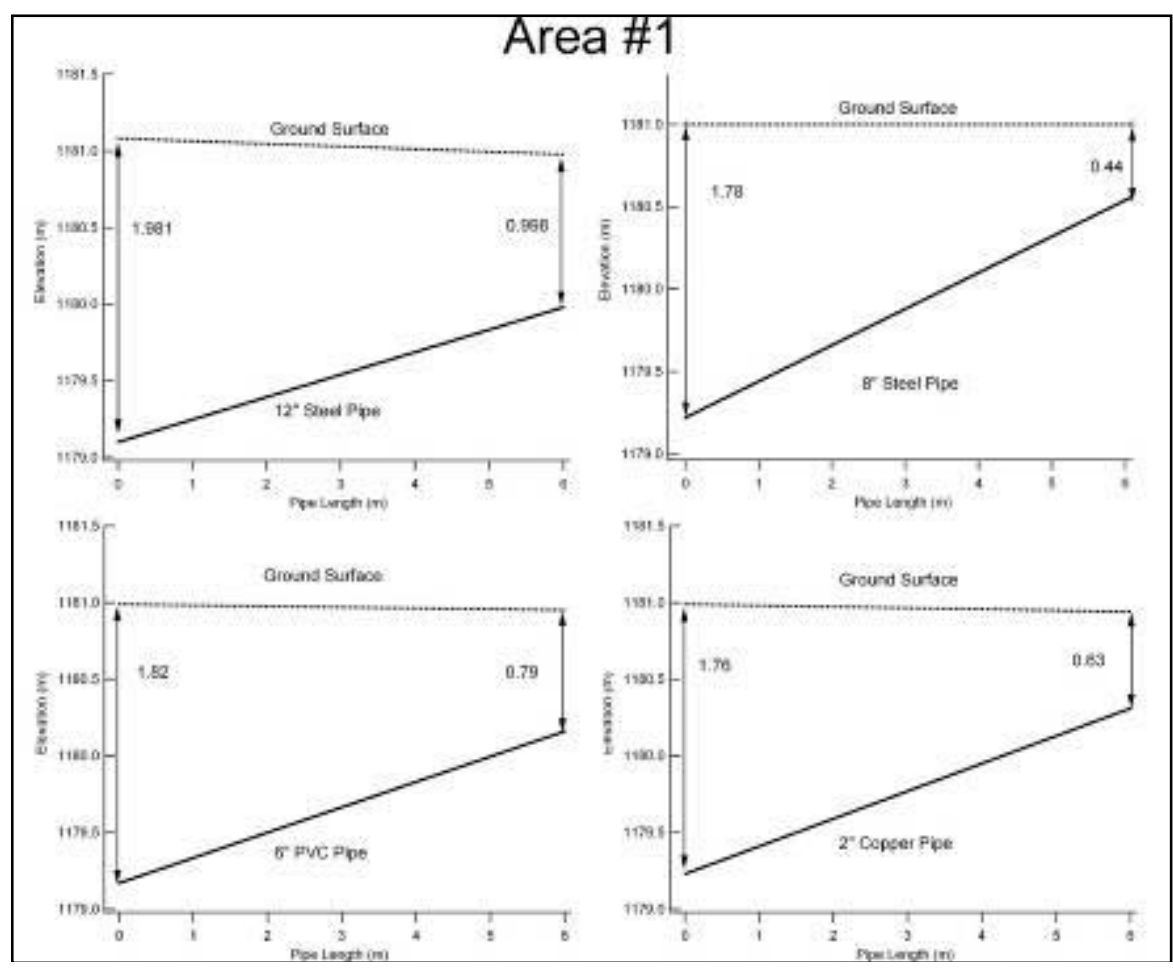

Figure A2. Area \#1 Fort Bliss cross section view of pipe placement. 


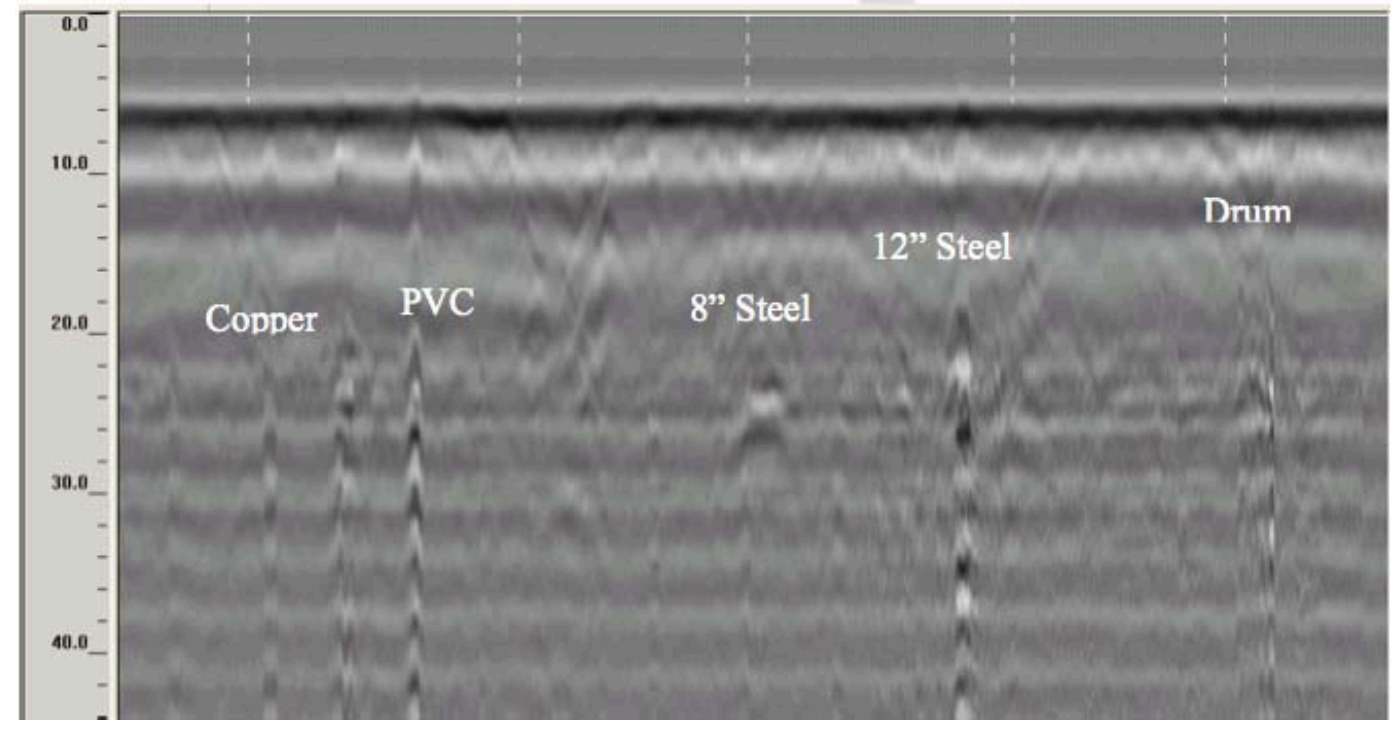

Figure A3. Area \#1 GSSI SIR-3000 GPR (400MHz antenna) data over deep end of pipes.

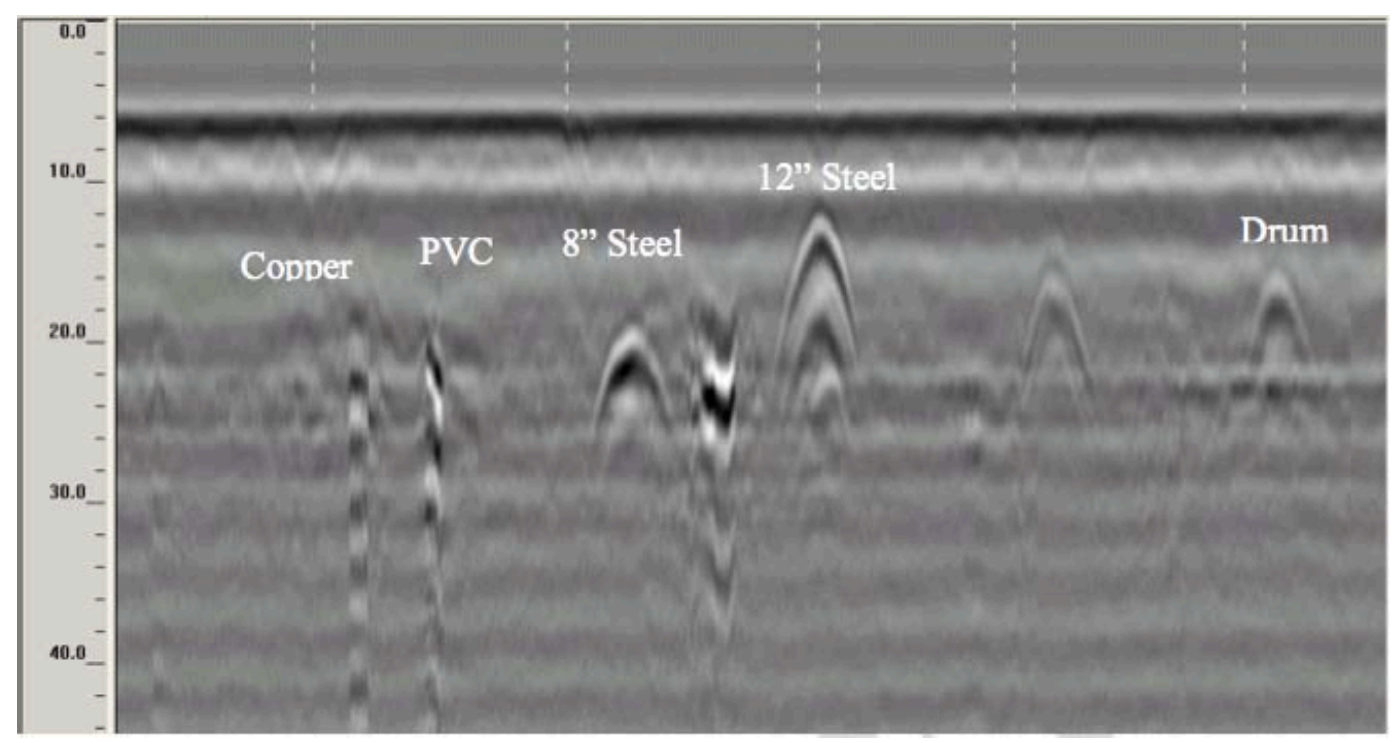

Figure A4. Area \#1 GSSI SIR-3000 GPR (400 MHz antenna) data over shallow end of pipes. ${ }^{1}$

\footnotetext{
1 Note: For all GSSI radargrams, fiducial marks (dotted white vertical lines) indicate 5-m spacing; depth scale is nanoseconds. Also note: For all plan view intensity maps, the color scale remains constant for the changing relative signal values.
} 


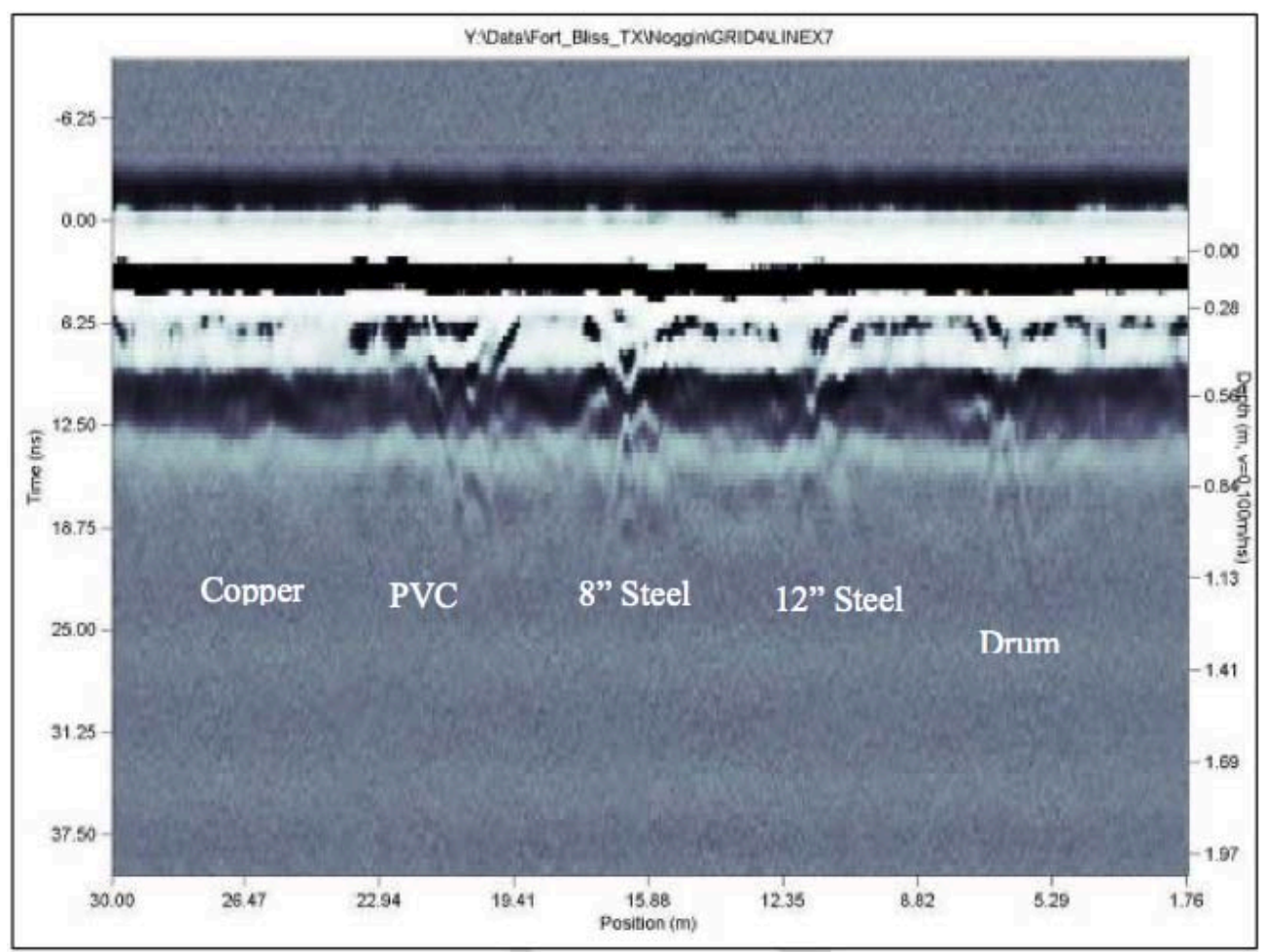

Figure A5. Area \#1 S\&S Noggin Plus GPR (250 MHz antenna) data over deep end of pipes.

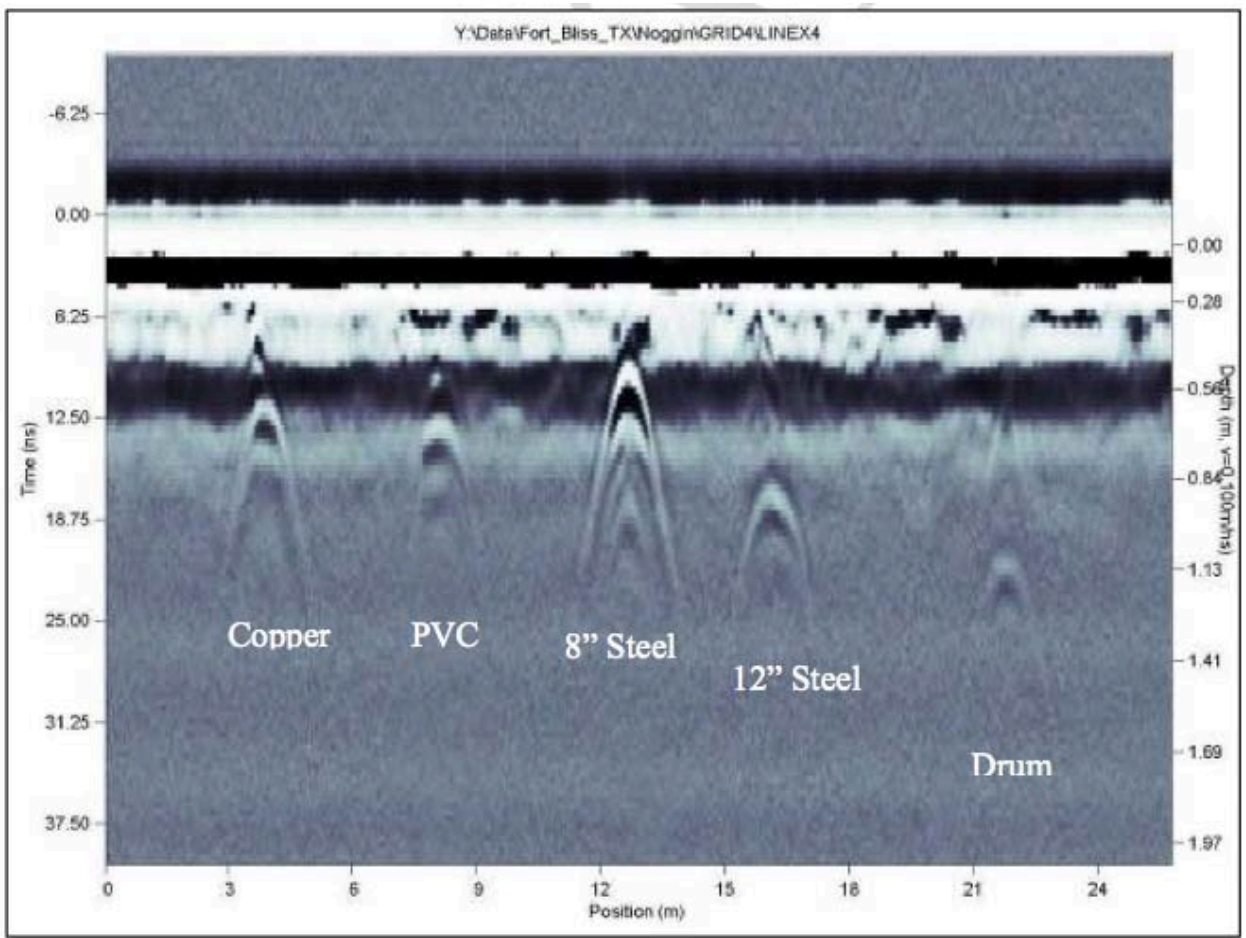

Figure A6. Area \#1 S\&S Noggin Plus GPR (250 MHz antenna) data over shallow end of pipes. 


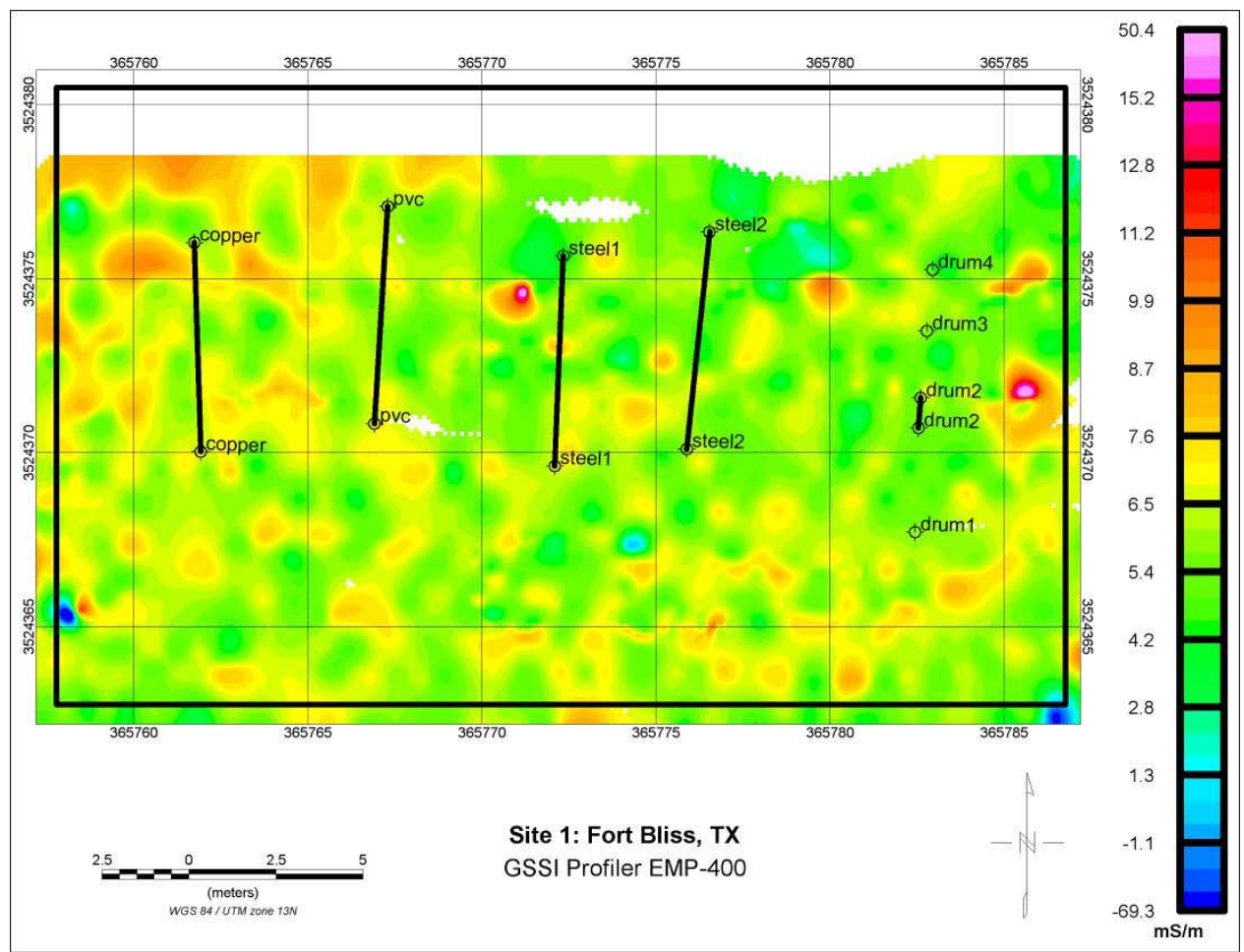

Figure A7. Area \#1 GSSI Profiler EMP-400 $(15000 \mathrm{~Hz})$ conductivity data before installation.

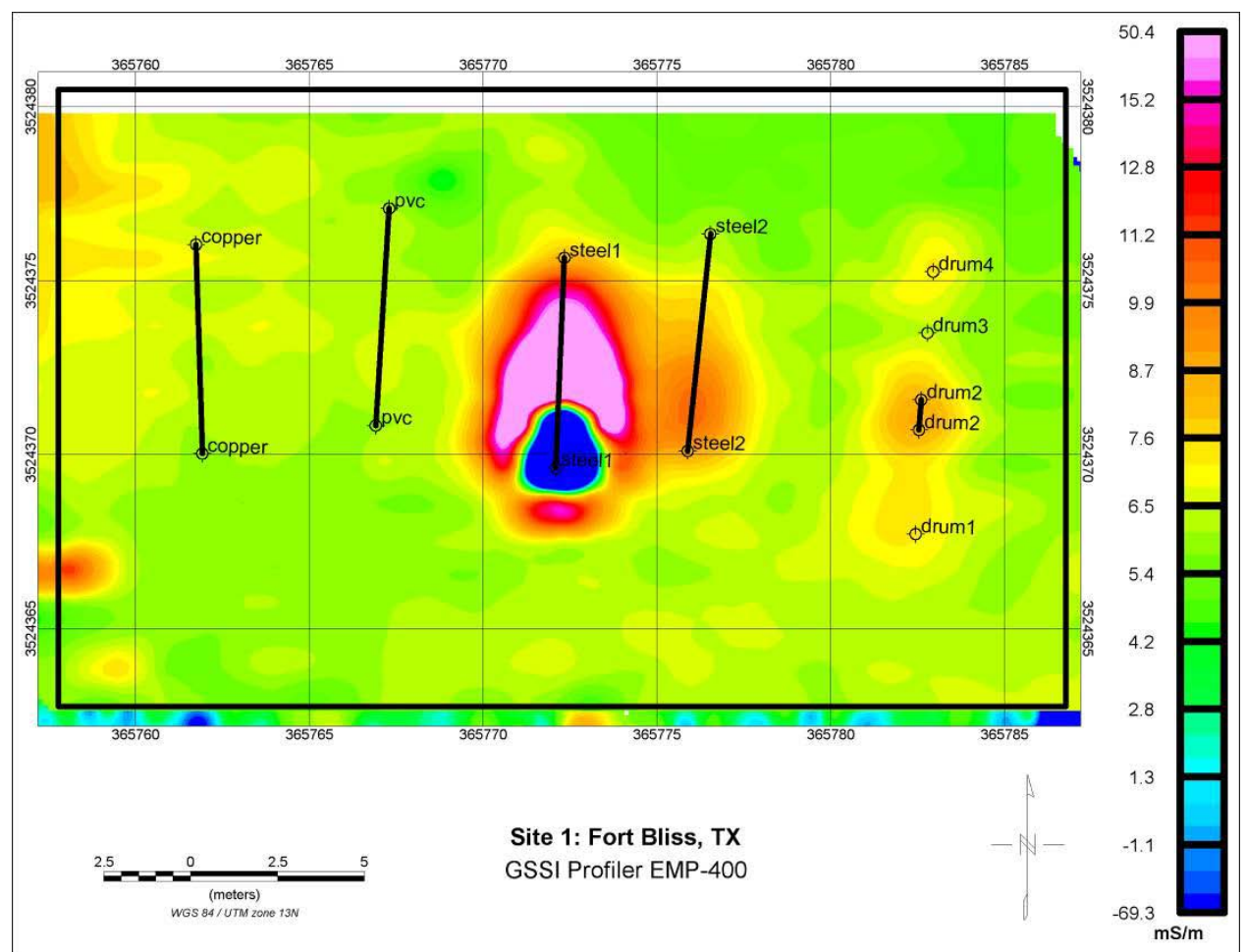

Figure A8. Area \#1 GSSI Profiler EMP-400 $(15000 \mathrm{~Hz})$ conductivity data after installation. 


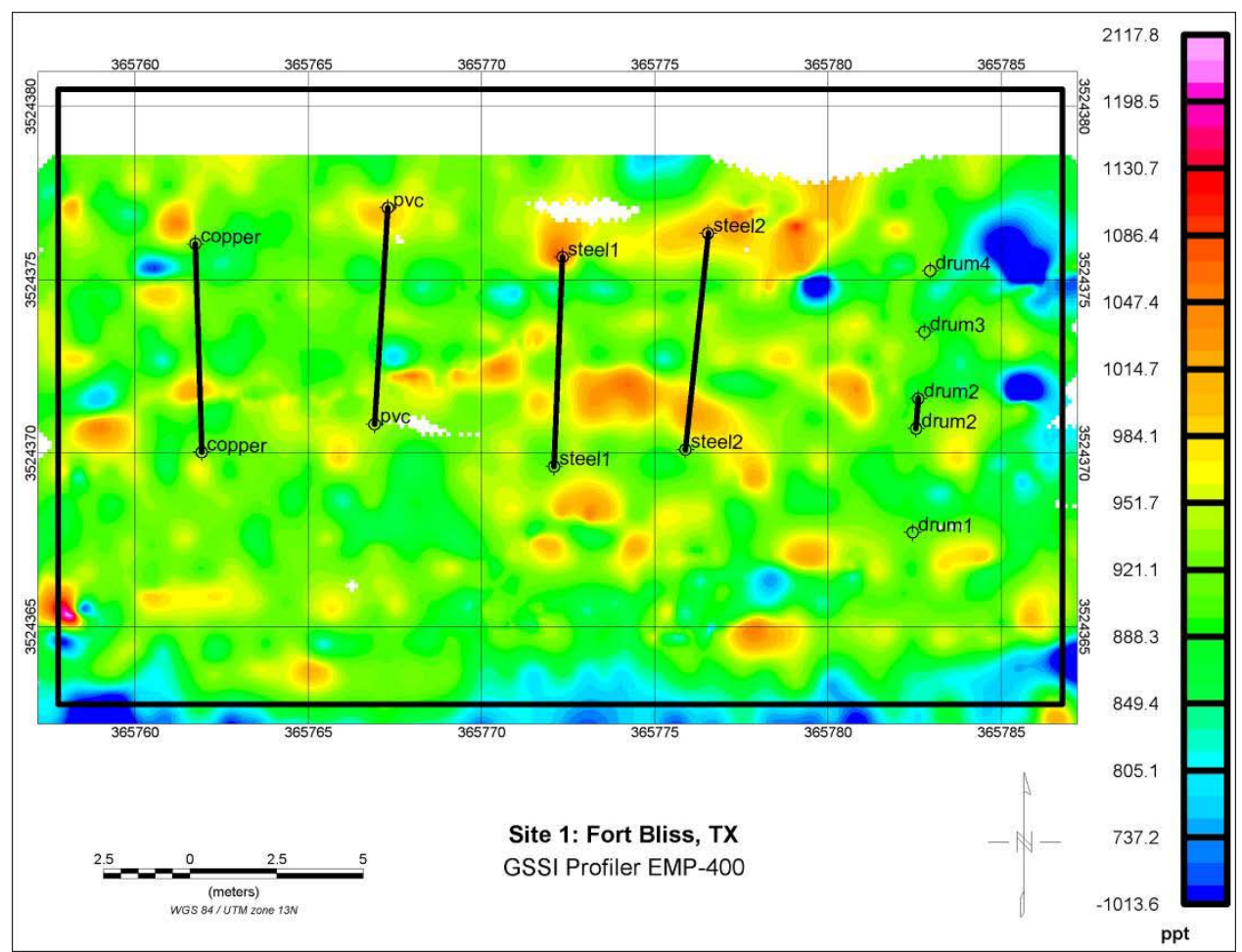

Figure A9. Area \#1 GSSI Profiler EMP-400 $(15000 \mathrm{~Hz})$ inphase data before installation.

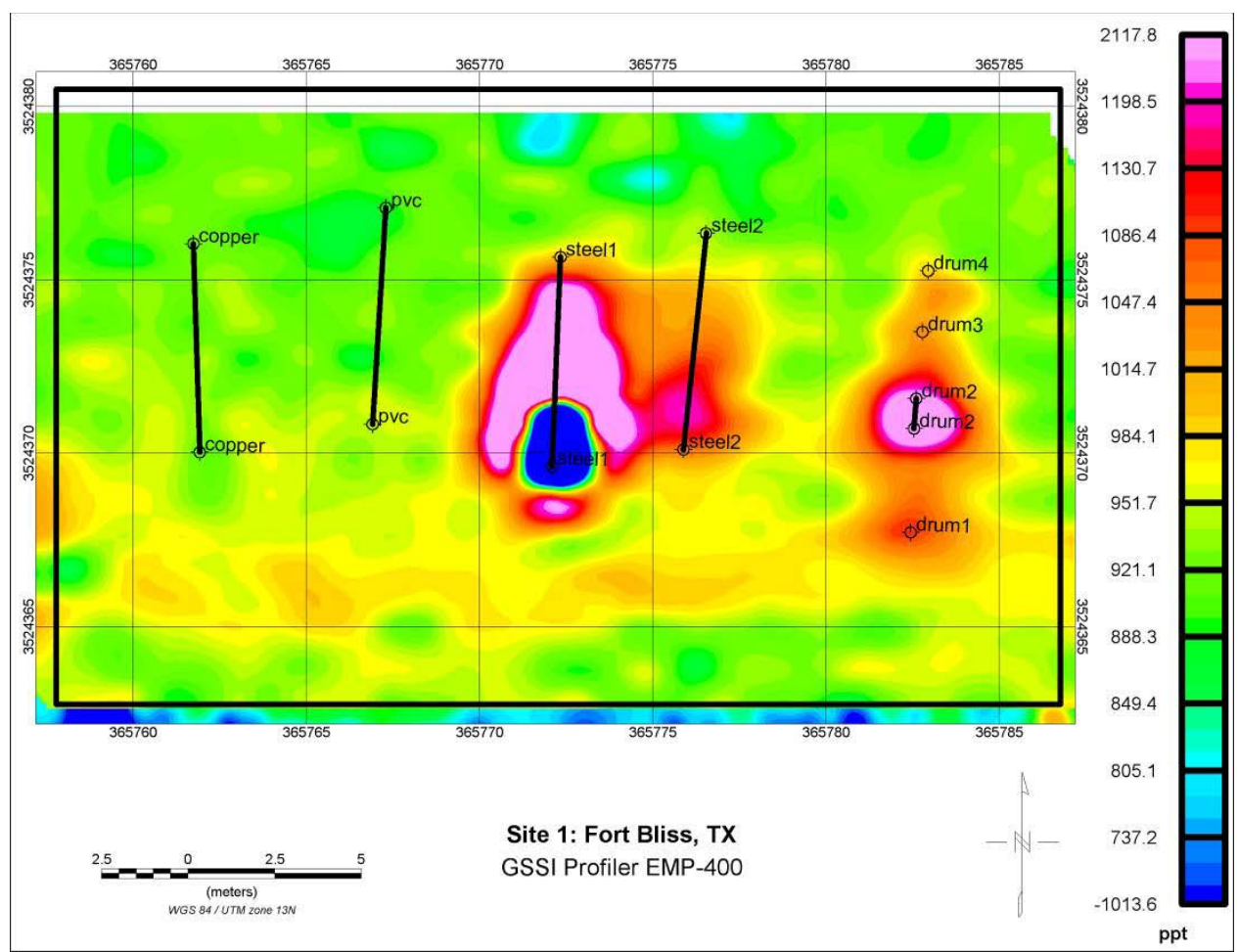

Figure A10. Area \#1 GSSI Profiler EMP-400 (15000 Hz) inphase after installation. 


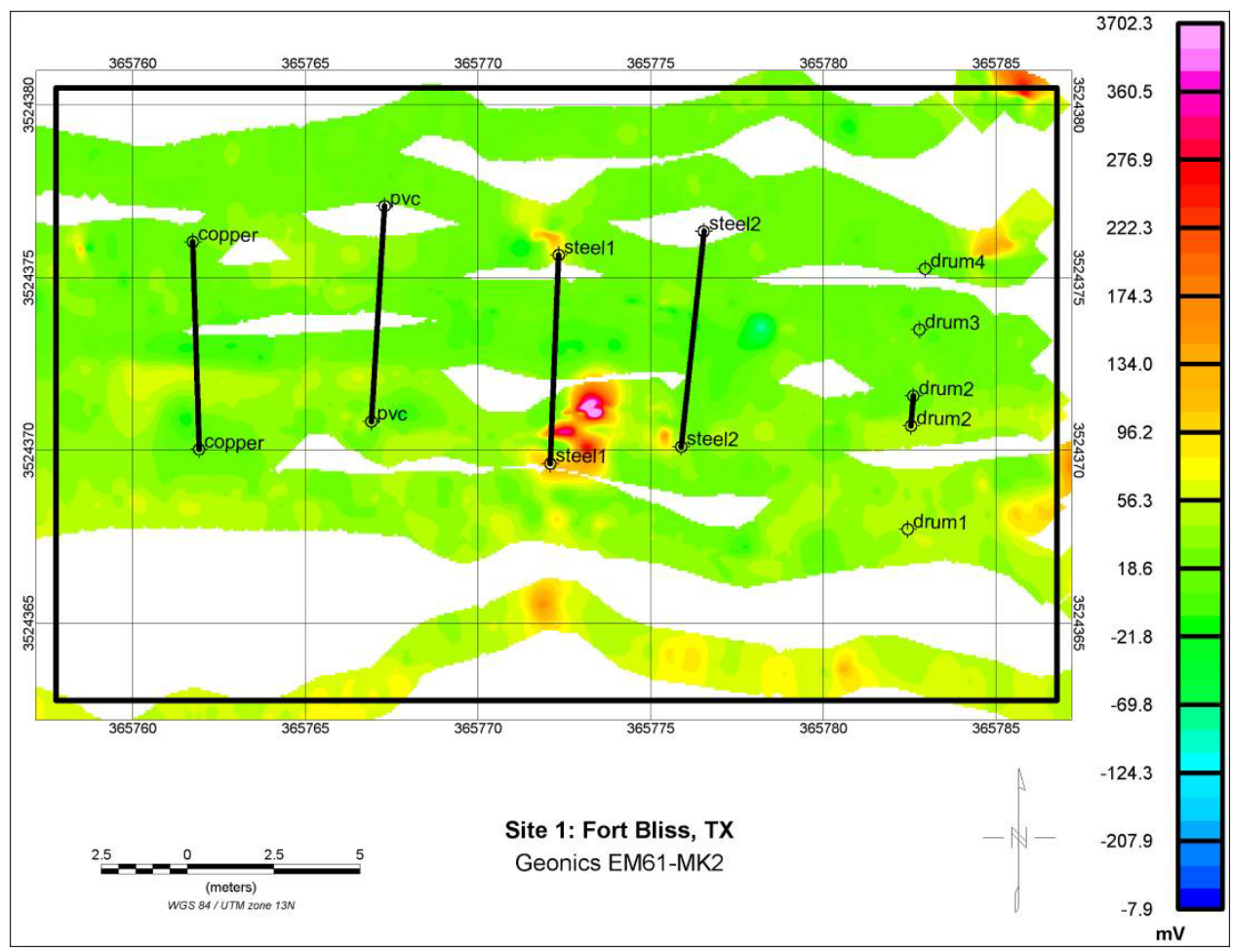

Figure A11. Area \#1 Geonics EM61-MK2 channel 1 data before installation.

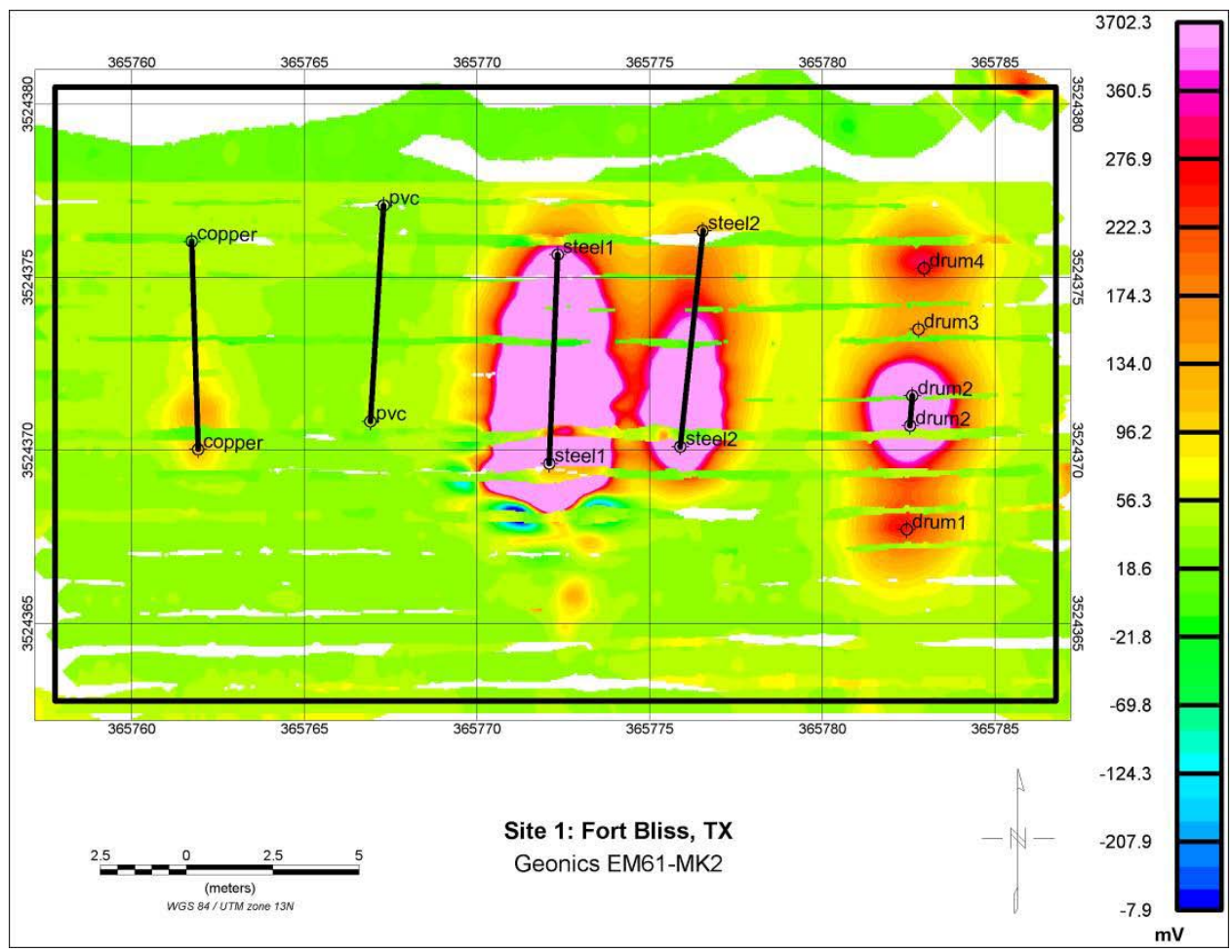

Figure A12. Area \#1 Geonics EM61-MK2 channel 1 data after installation. 


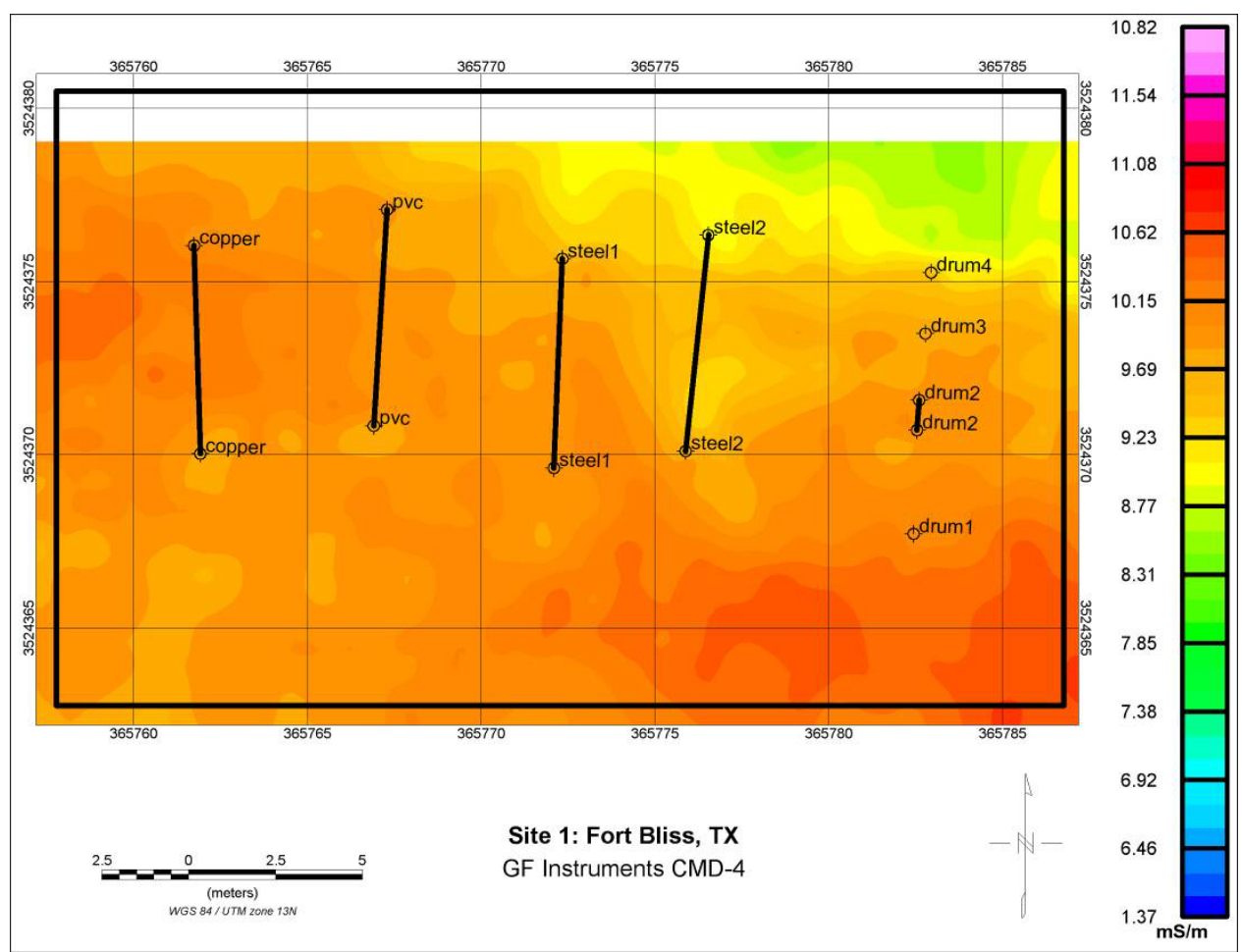

Figure A13. Area \#1 GF Instruments CMD-4 conductivity data before installation.

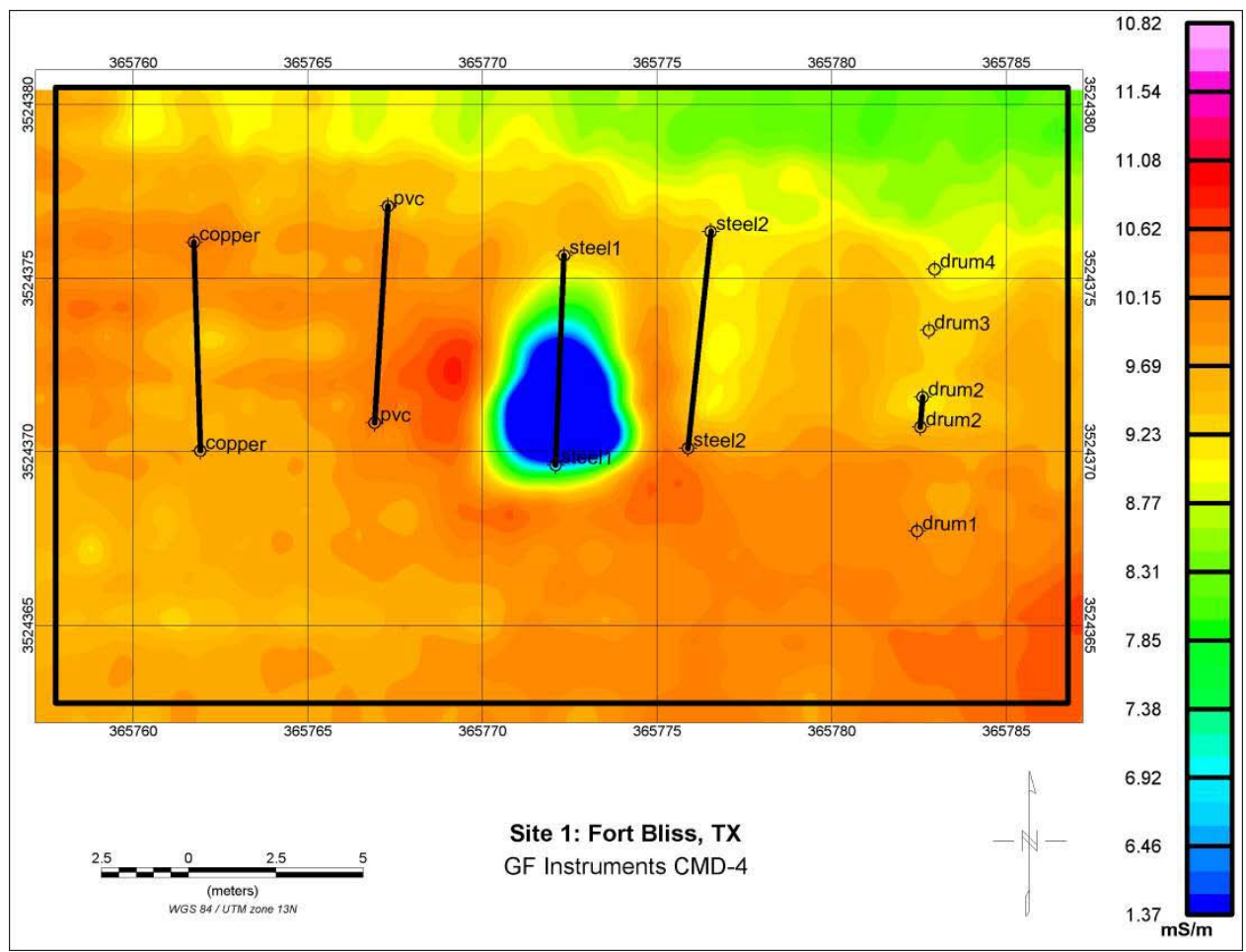

Figure A14. Area \#1 GF Instruments CMD-4 conductivity data after installation. 


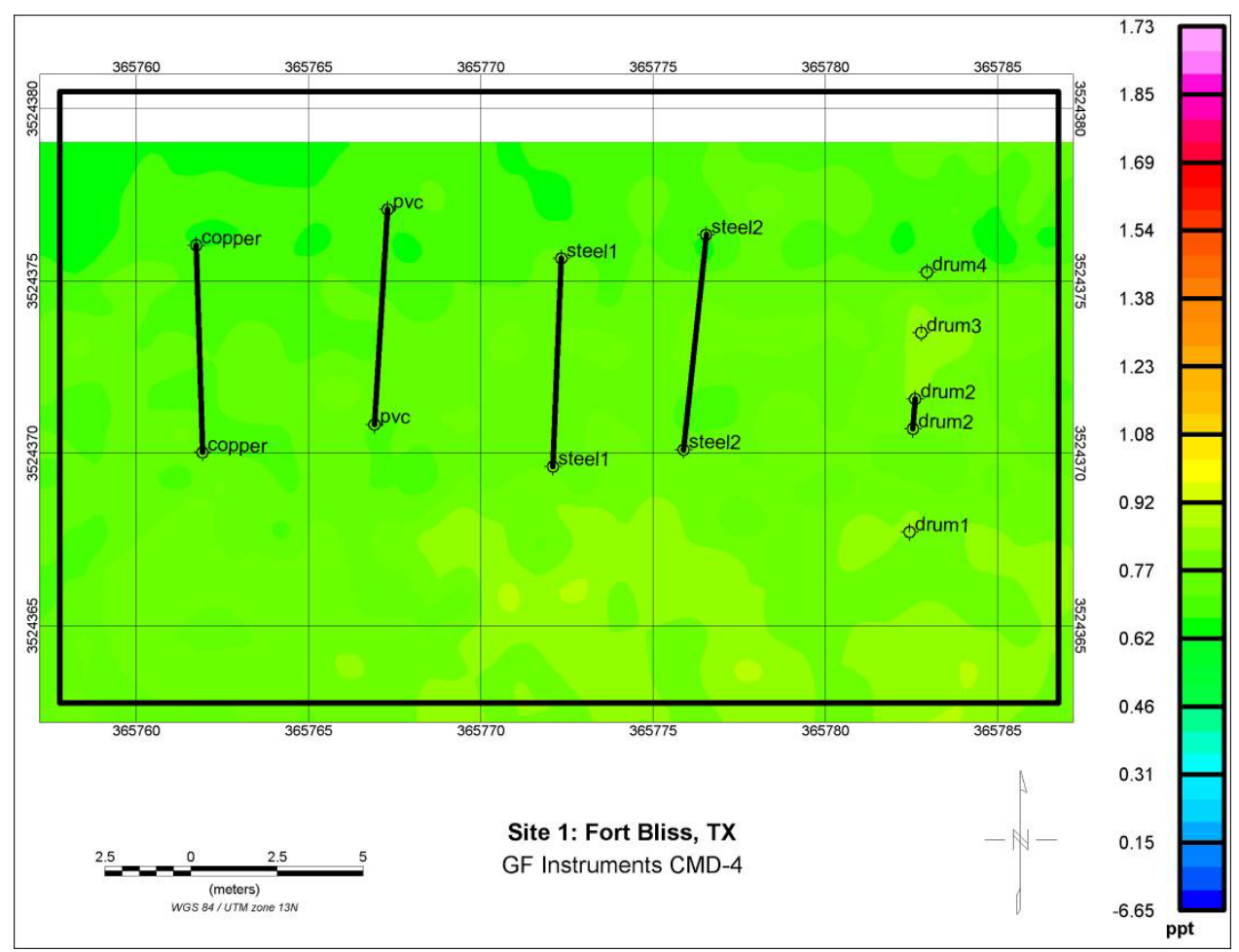

Figure A15. Area \#1 GF Instruments CMD-4 inphase data before installation.

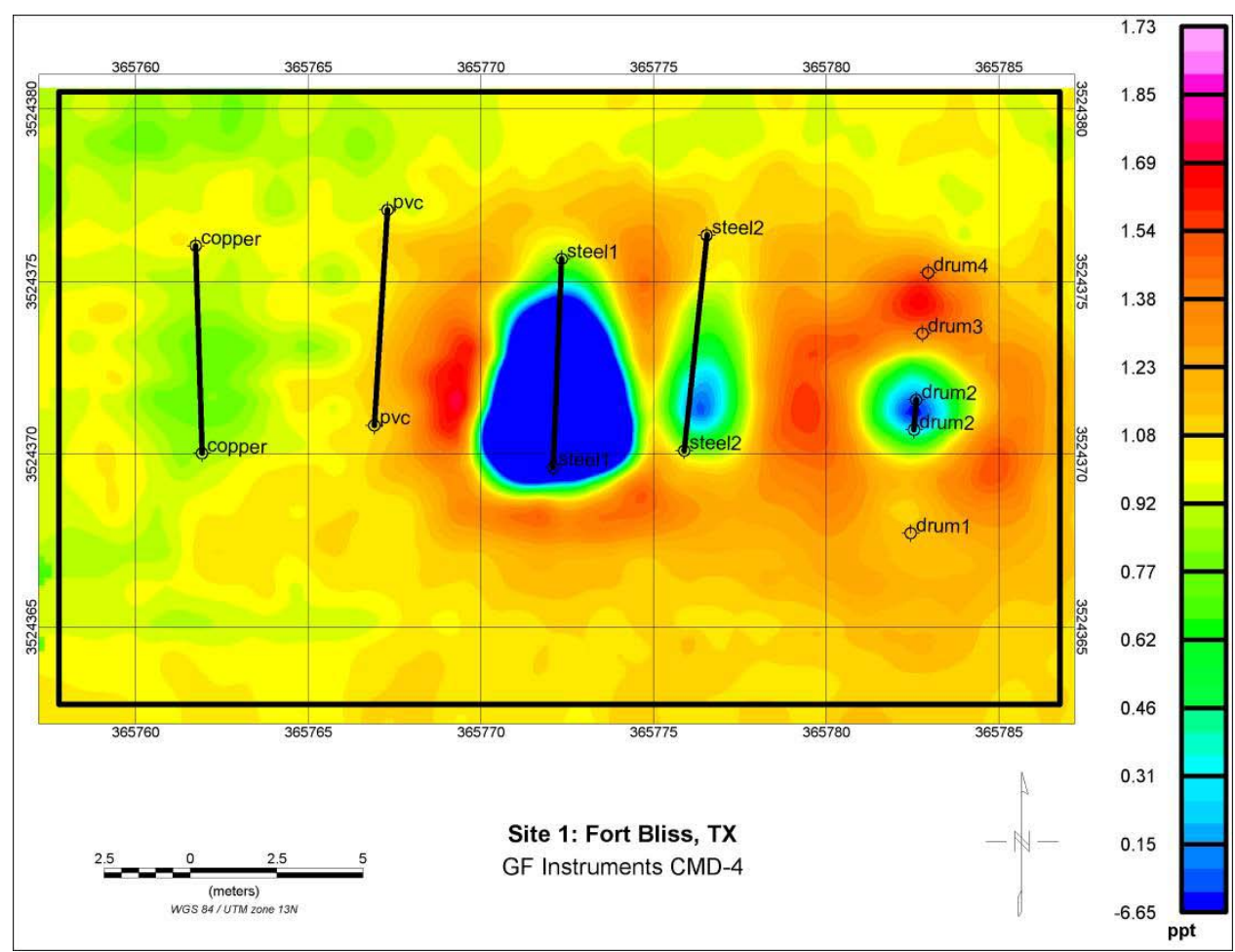

Figure A16. Area \#1 GF Instruments CMD-4 inphase data after installation. 


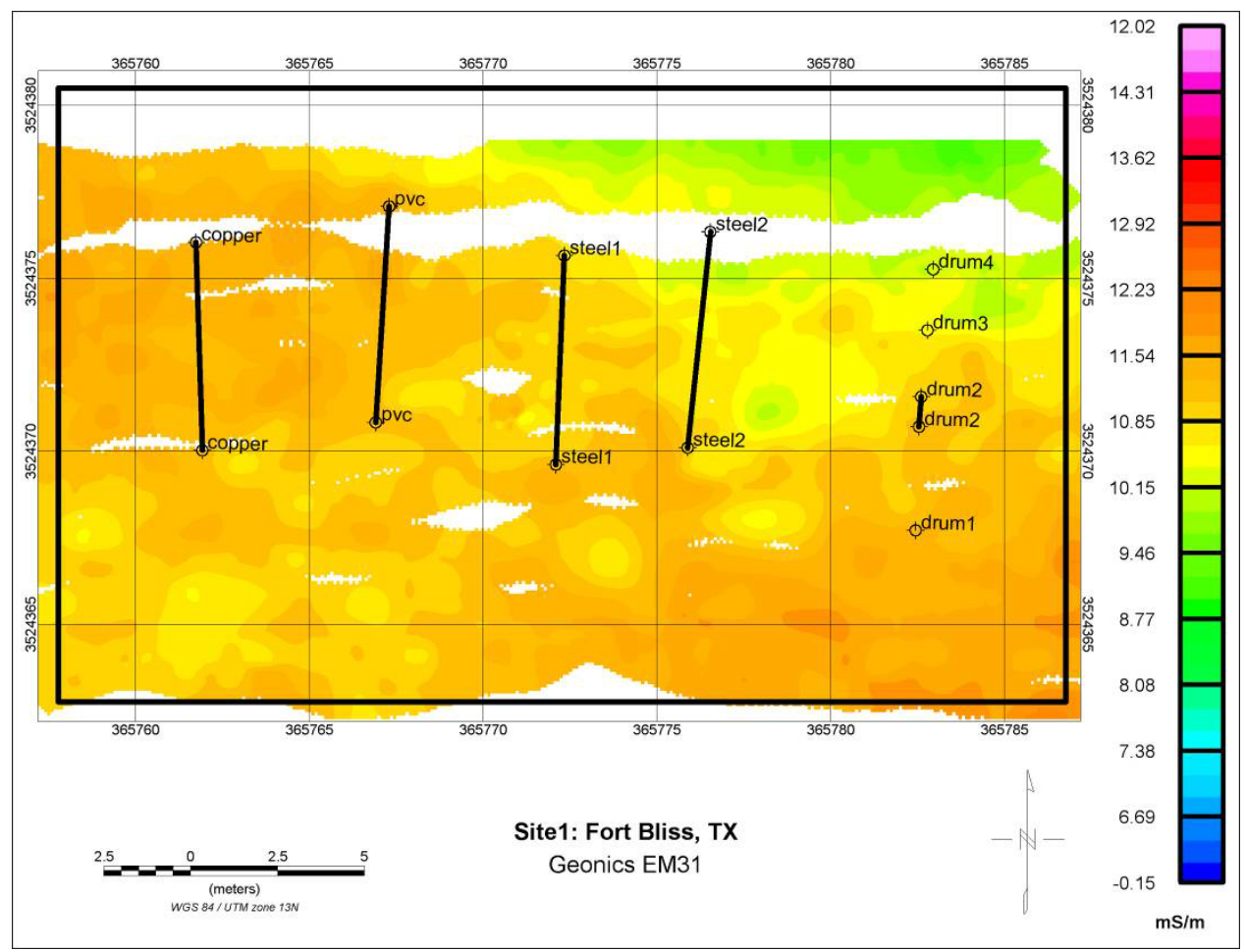

Figure A17. Area \#1 Geonics EM31 conductivity data before installation.

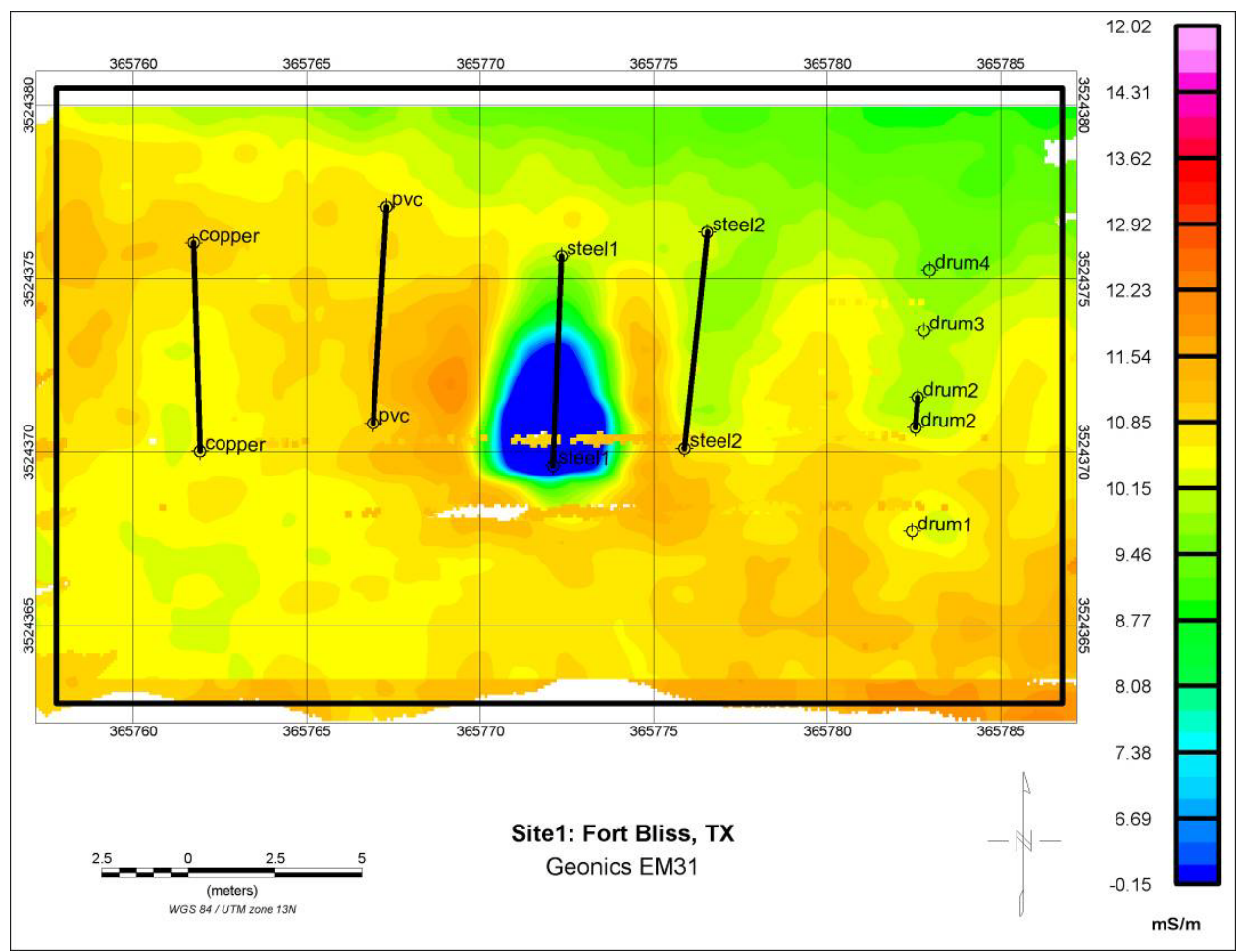

Figure A18. Area \#1 Geonics EM31 conductivity data after installation. 


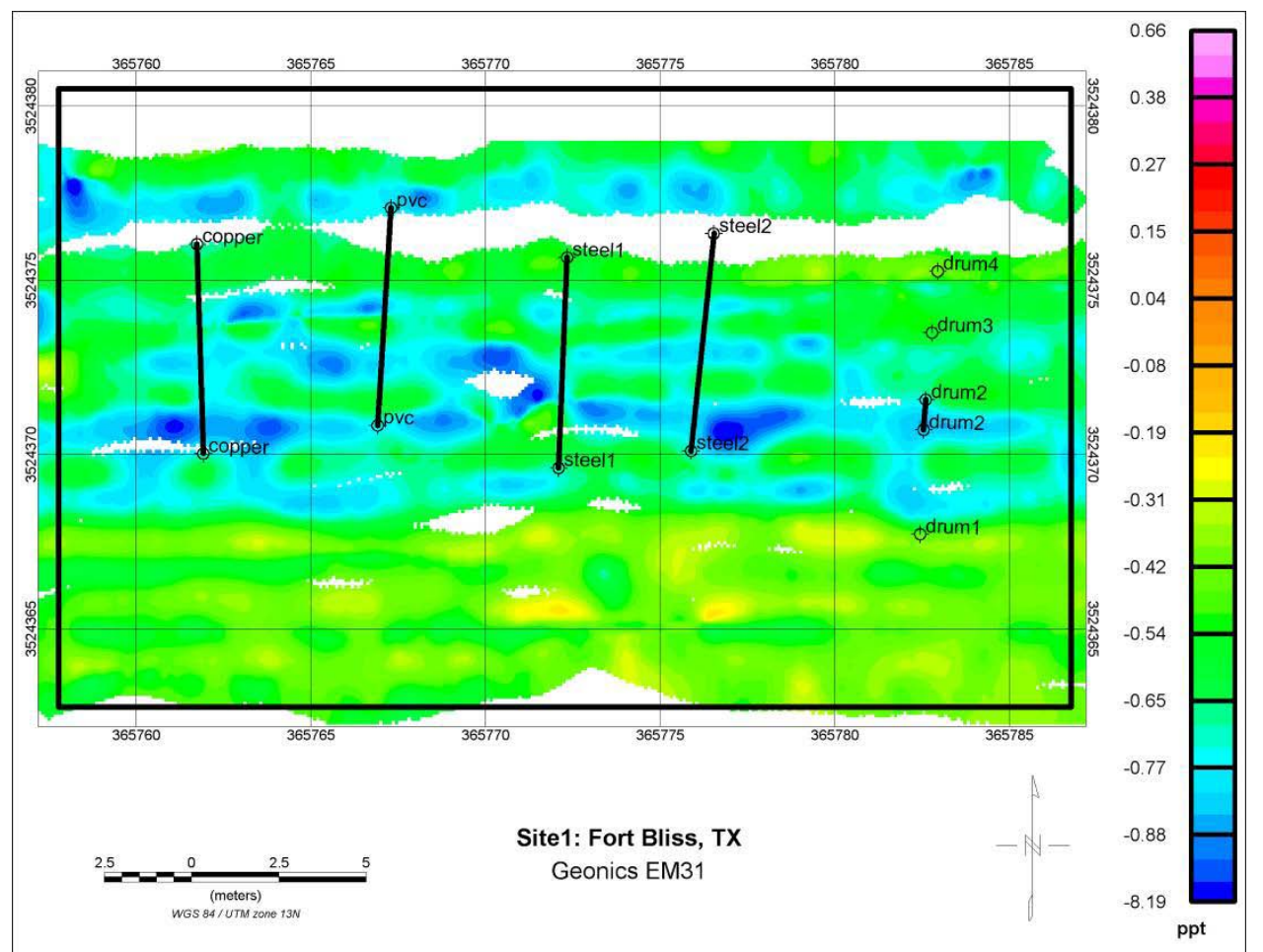

Figure A19. Area \#1 Geonics EM31 inphase data before installation.

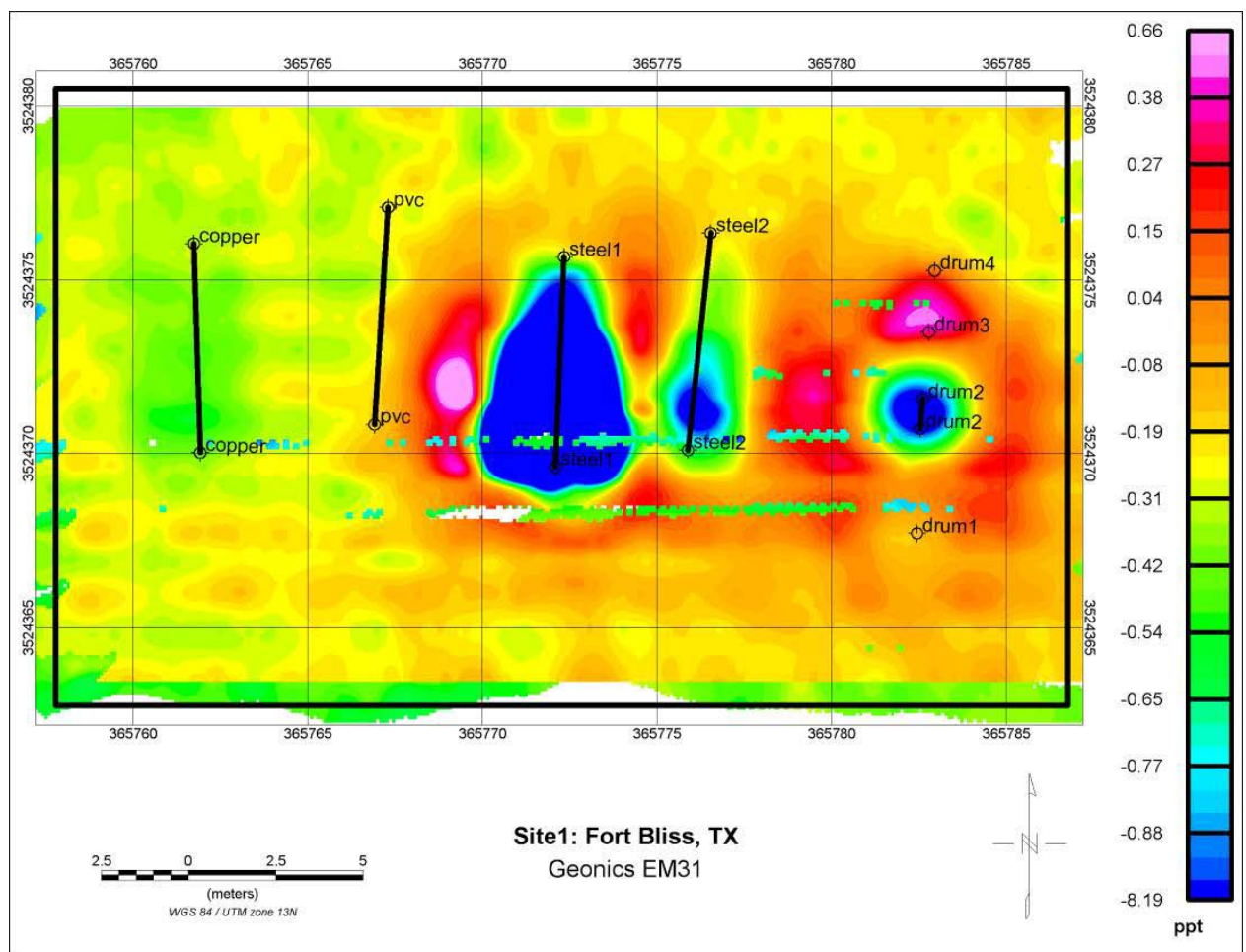

Figure A20. Area \#1 Geonics EM31 inphase data after installation. 


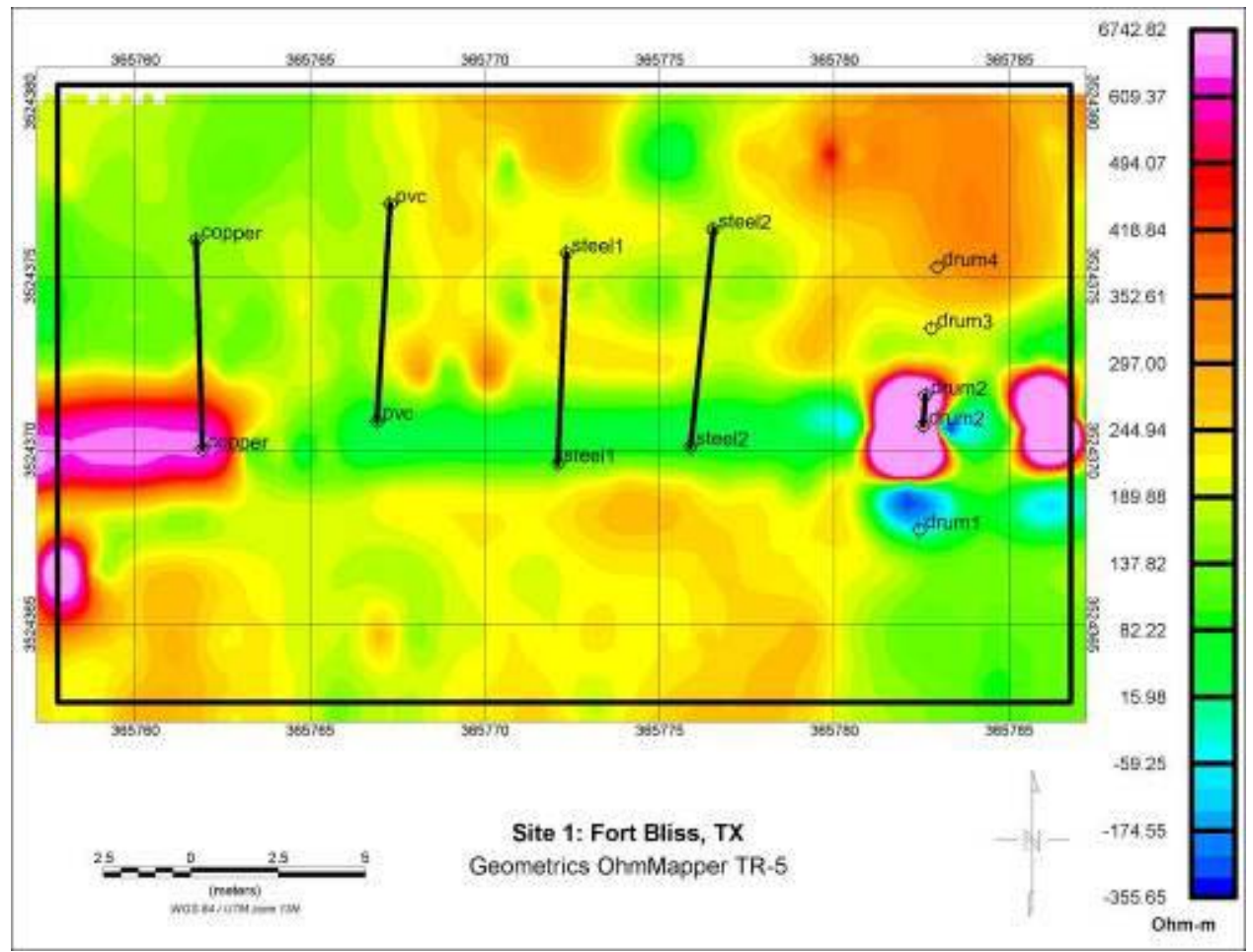

Figure A21. Area \#1 Geometrics OhmMapper TR-5 resistivity data after installation.

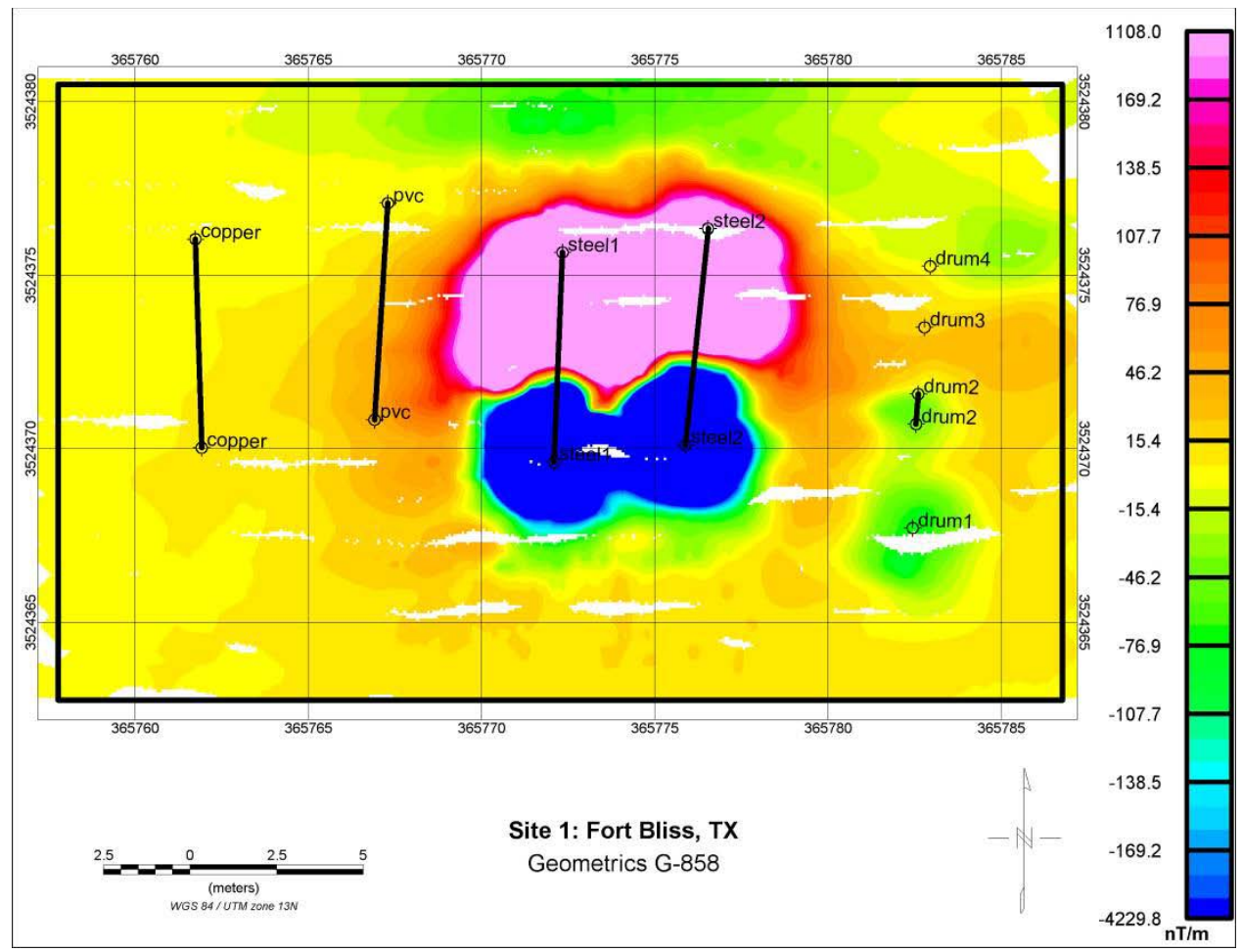

Figure A22. Area \#1 Geometrics G-858 gradient data after installation. 


\section{Appendix B: Area \#2 Fort Wainwright Images}

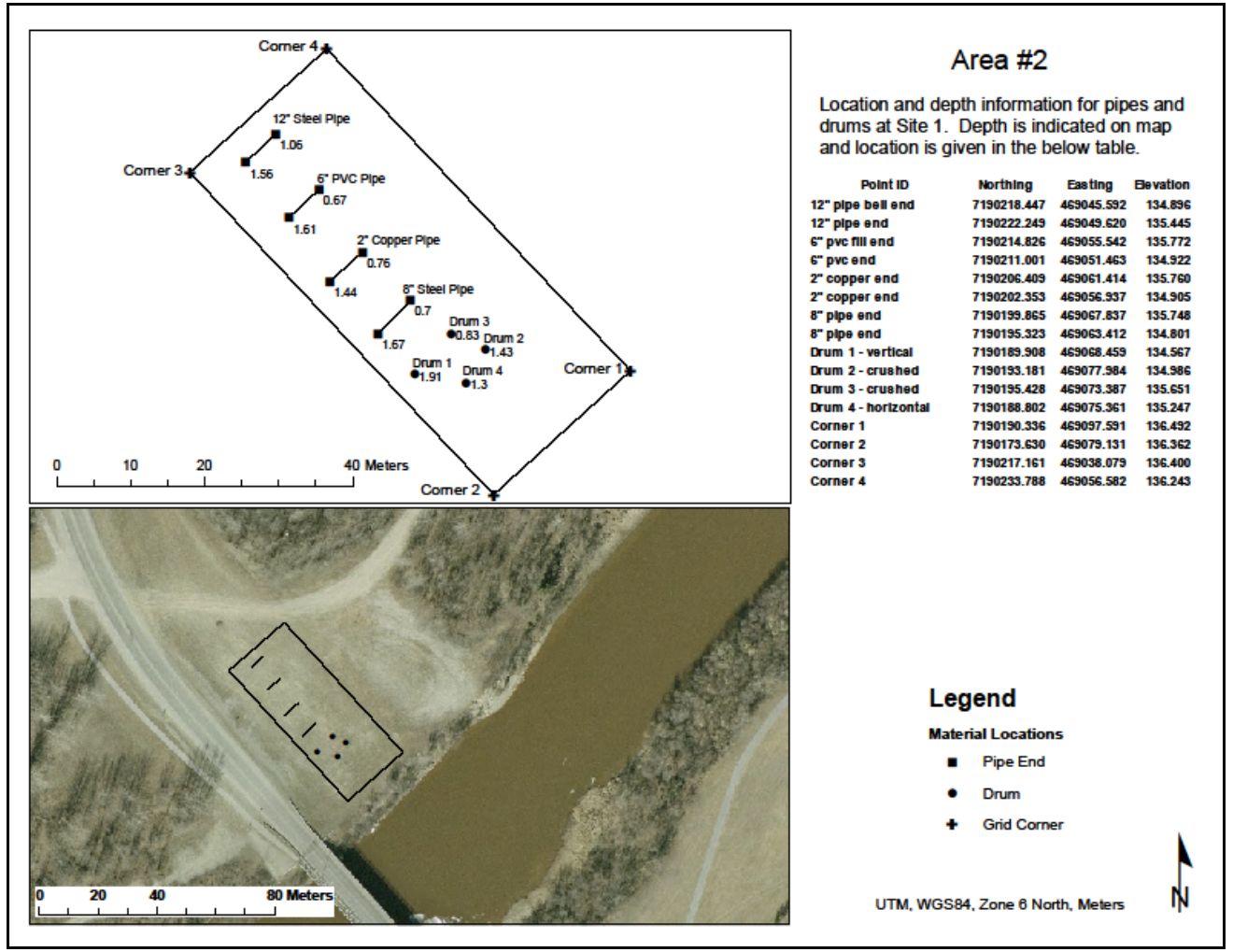

Figure B1. Area \#2 Fort Wainwright plan view.

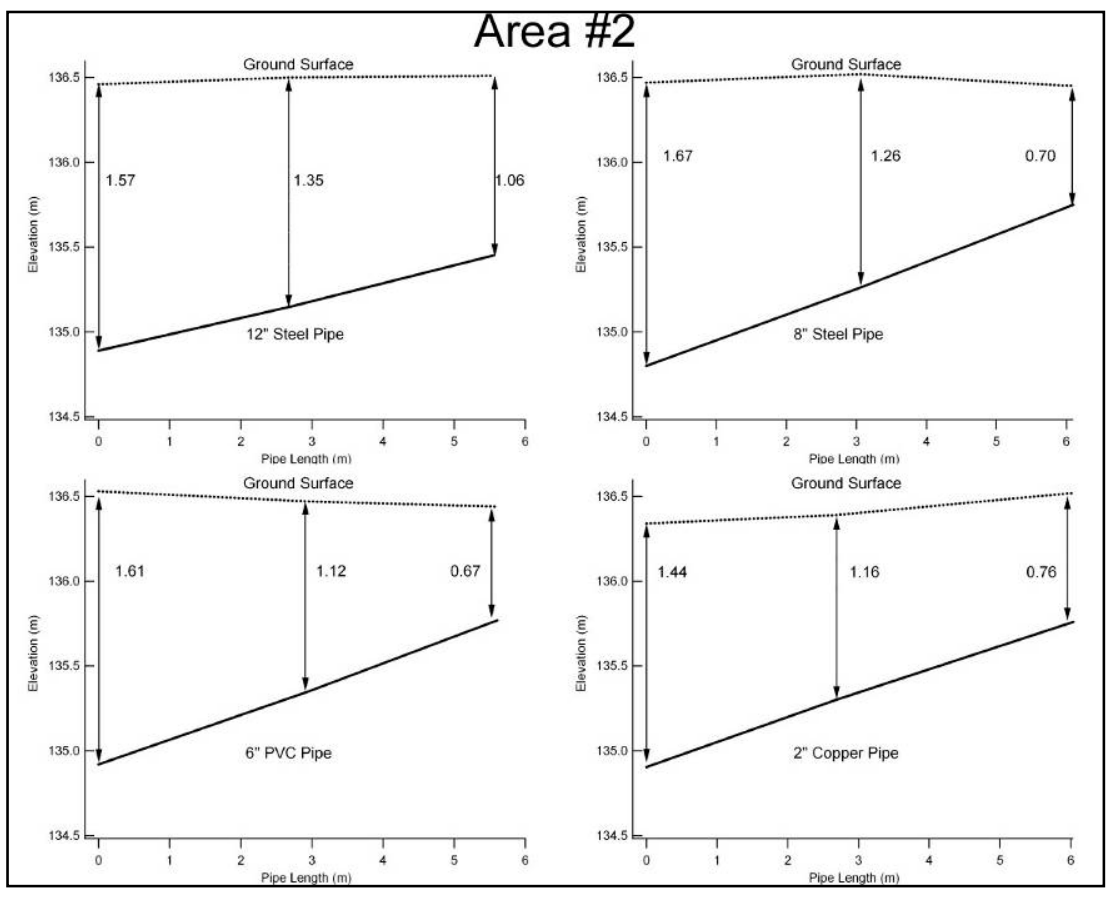

Figure B2. Area \#2 Fort Wainwright cross-section view of pipe placement. 


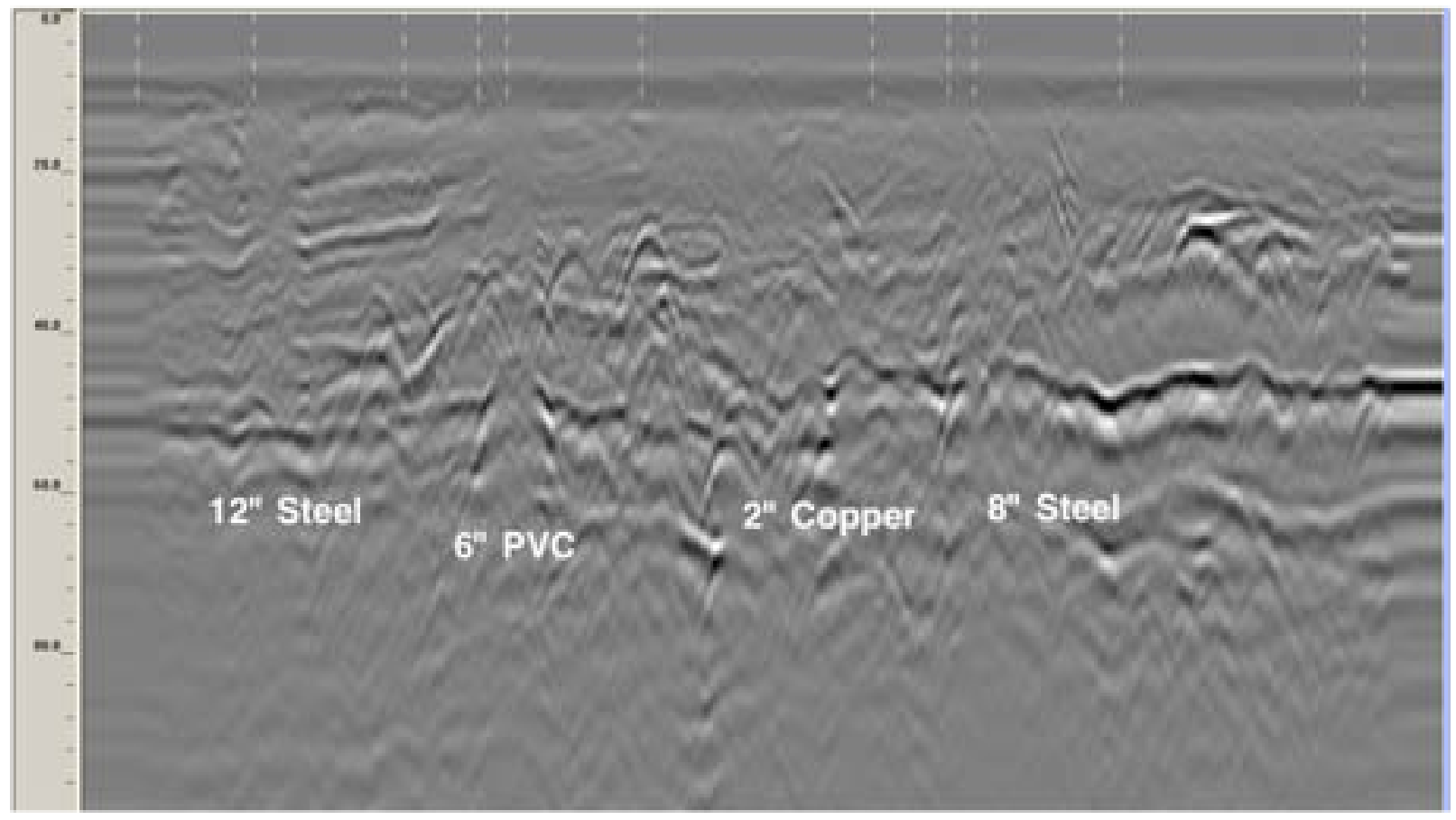

Figure B3. Area \#2 GSSI SIR-3000 GPR (200 MHz antenna) over deep end of pipes. ${ }^{1}$

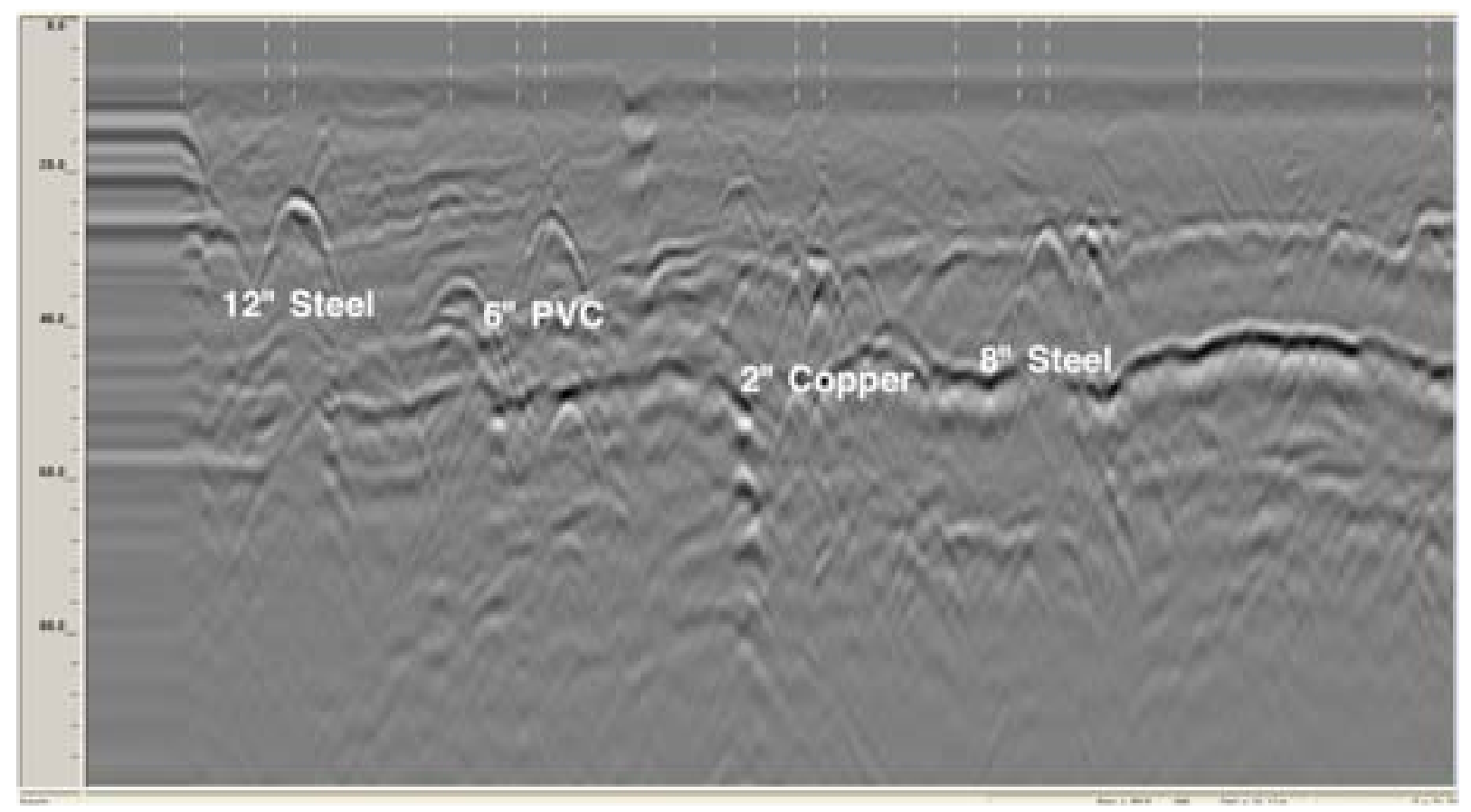

Figure B4. Area \#2 GSSI SIR-3000 GPR (200 MHz antenna) data over shallow end of pipes.

${ }_{1}^{1}$ Note: For all GSSI radargrams, fiducial marks (dotted white vertical lines) indicate 5-m spacing; depth scale is nanoseconds. Also note: For all plan view intensity maps, the color scale remains constant for the changing relative signal values. 


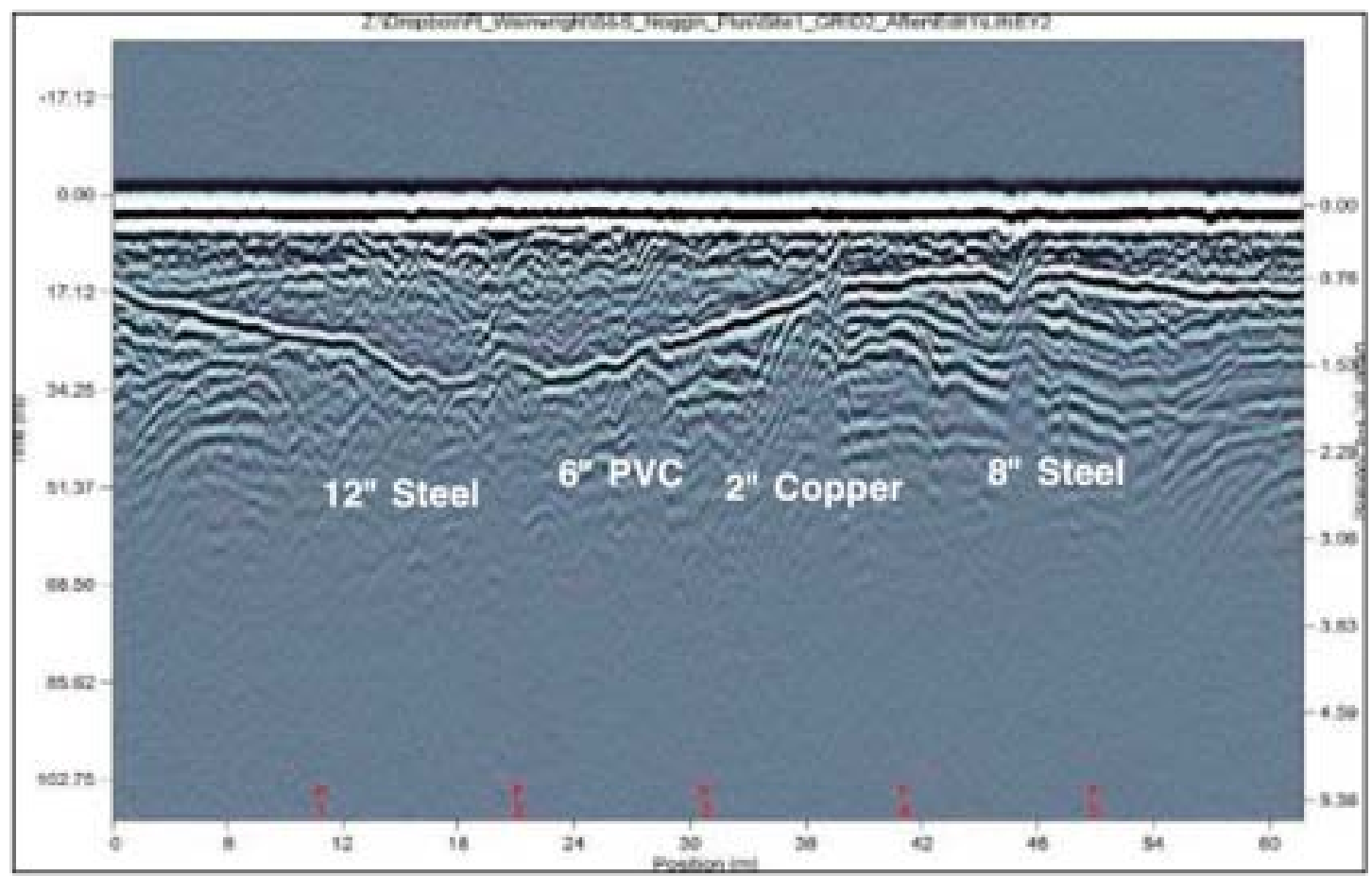

Figure B5. Area \#2 S\&S Noggin Plus (250 MHz antenna) data over deep end of pipes.

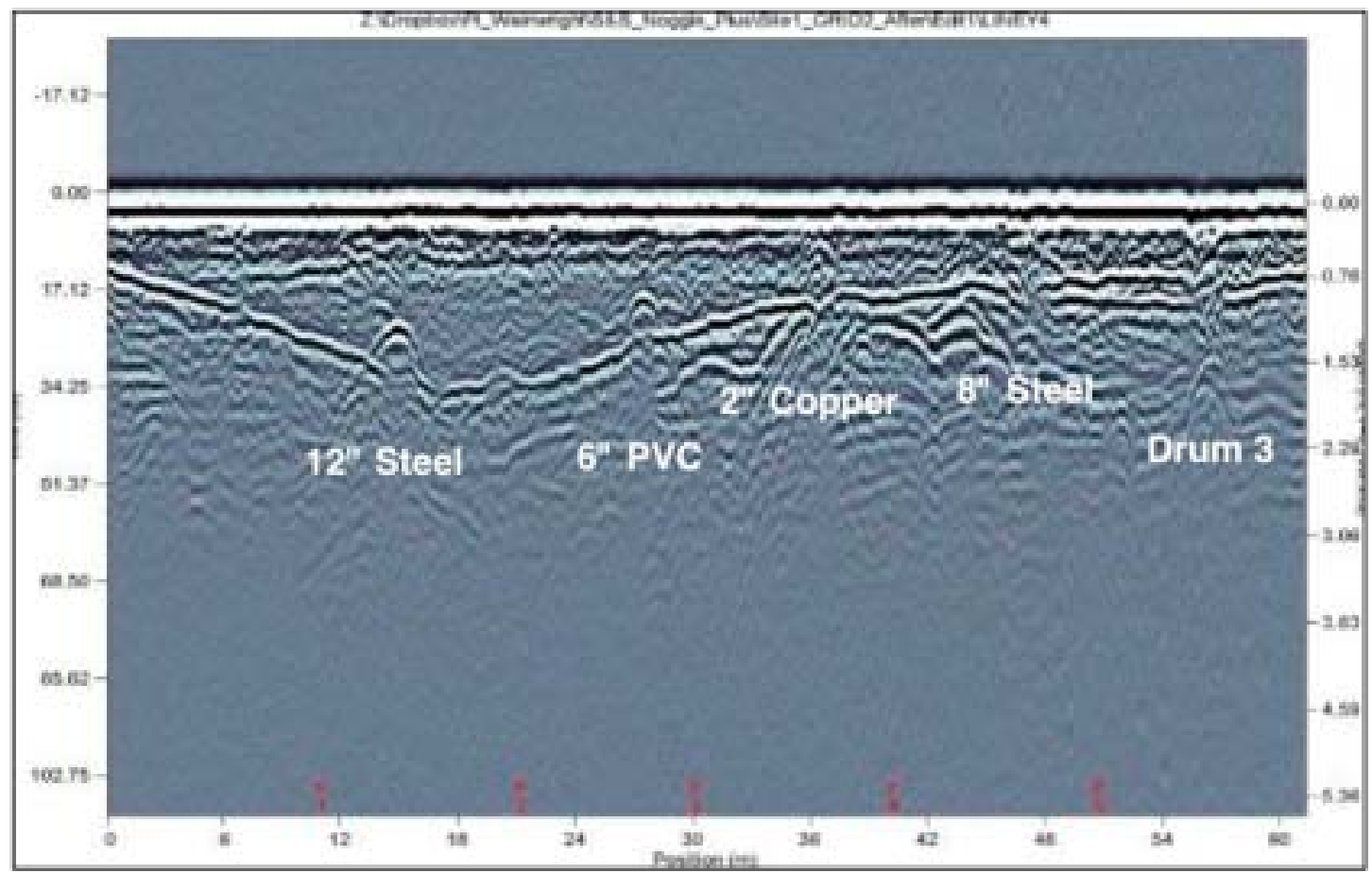

Figure B6. Area \#2 S\&S Noggin Plus (250 MHz antenna) data over shallow end of pipes. 


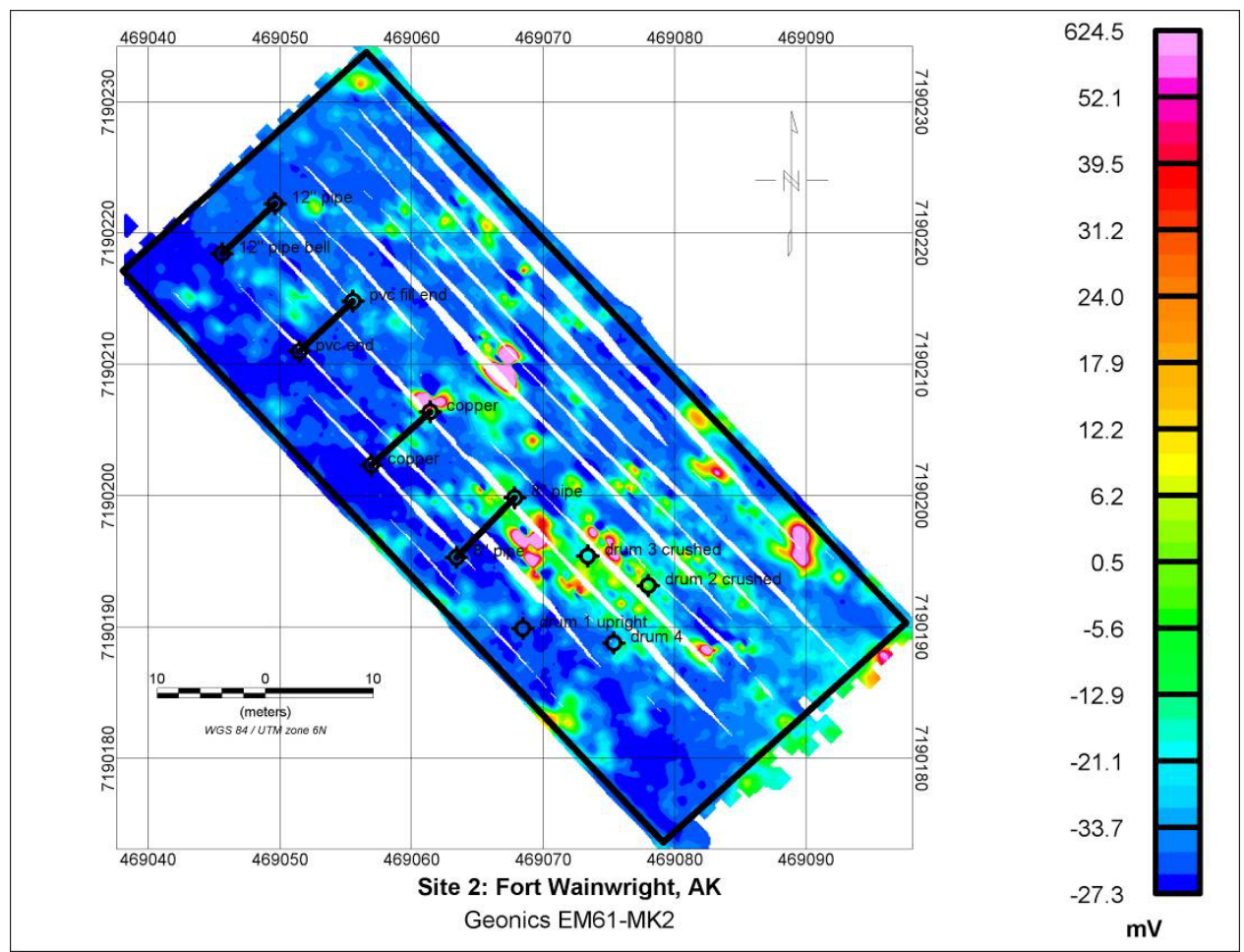

Figure B7. Area \#2 Geonics EM61-MK2 channel 1 data before installation.

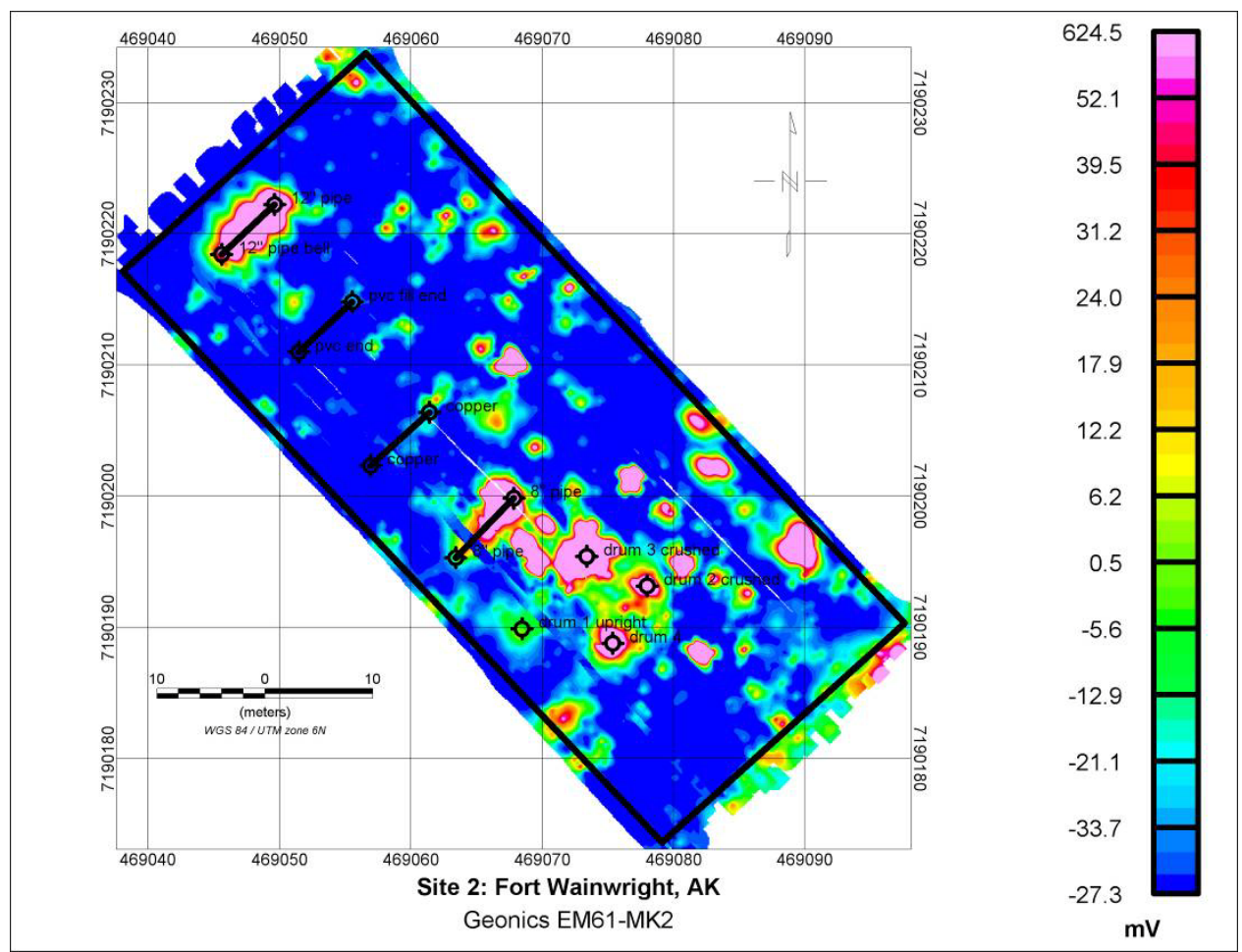

Figure B8. Area \#2 Geonics EM61-MK2 channel 1 data after installation. 


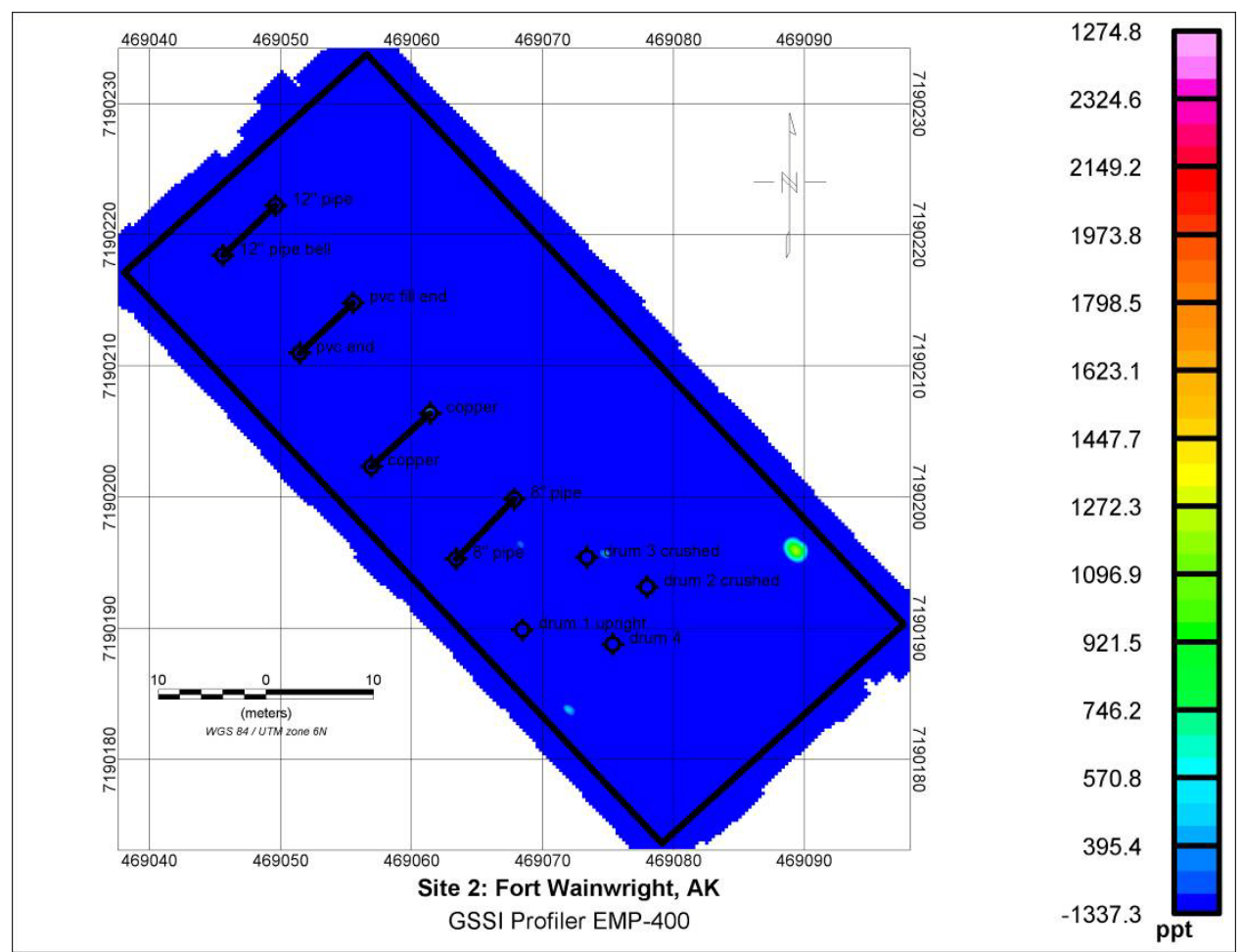

Figure B9. Area \#2 GSSI Profiler EMP-400 $(15000 \mathrm{~Hz})$ inphase data before installation.

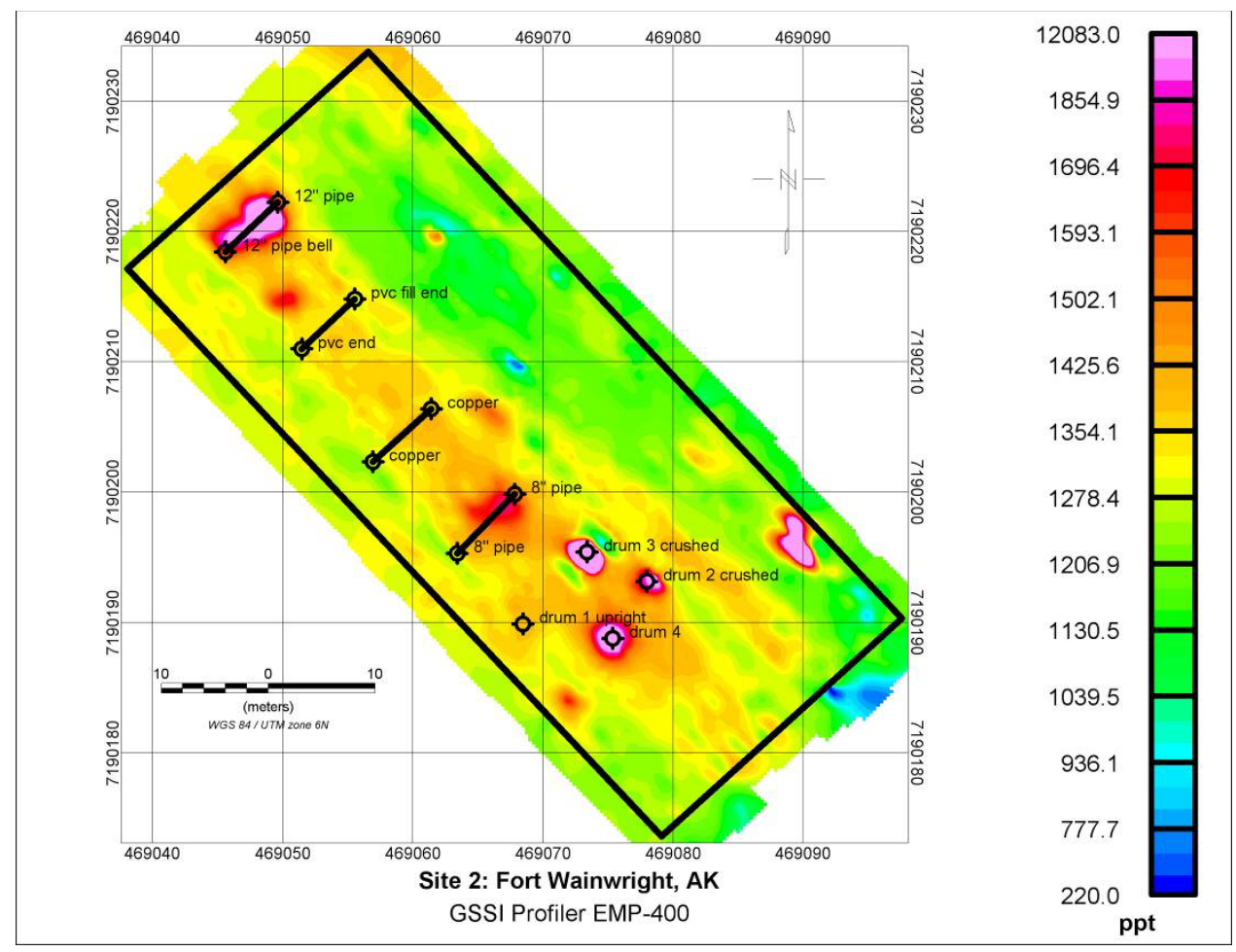

Figure B10. Area \#2 GSSI Profiler EMP-400 $(15000 \mathrm{~Hz})$ inphase data after installation. 


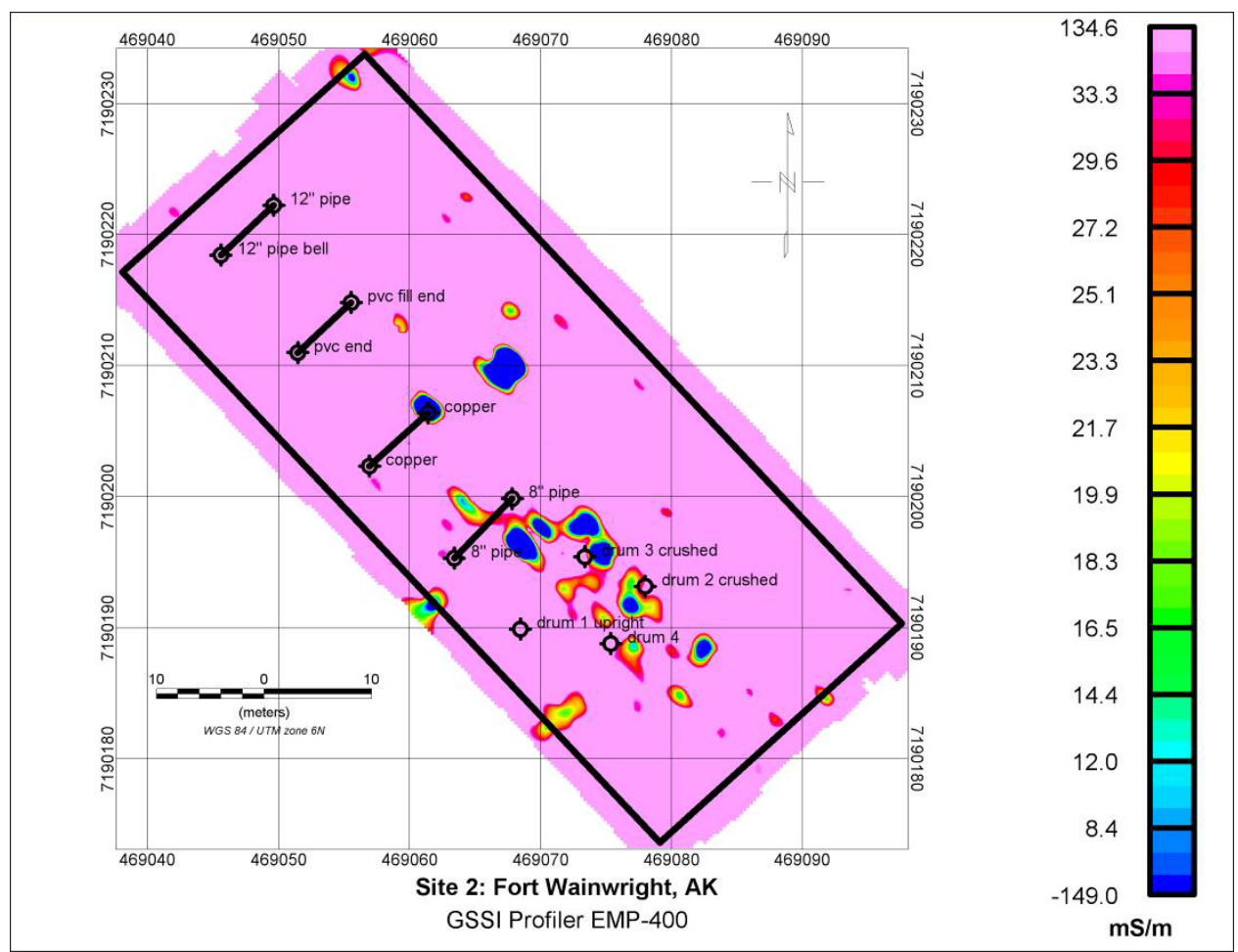

Figure B11. Area \#2 GSSI Profiler EMP-400 $(15000 \mathrm{~Hz})$ conductivity data before installation.

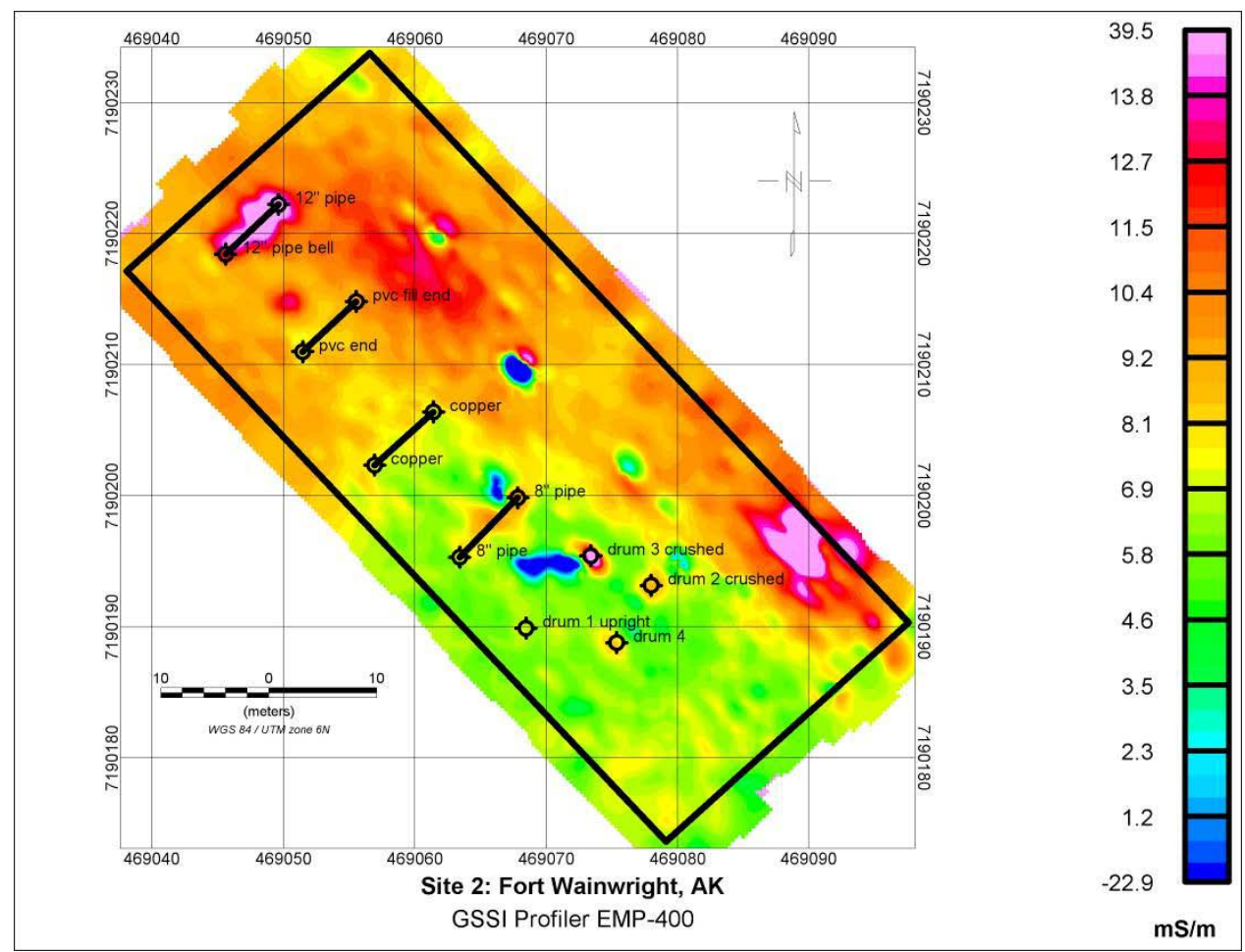

Figure B12. Area \#2 GSSI Profiler EMP-400 $(15000 \mathrm{~Hz})$ conductivity data after installation. 


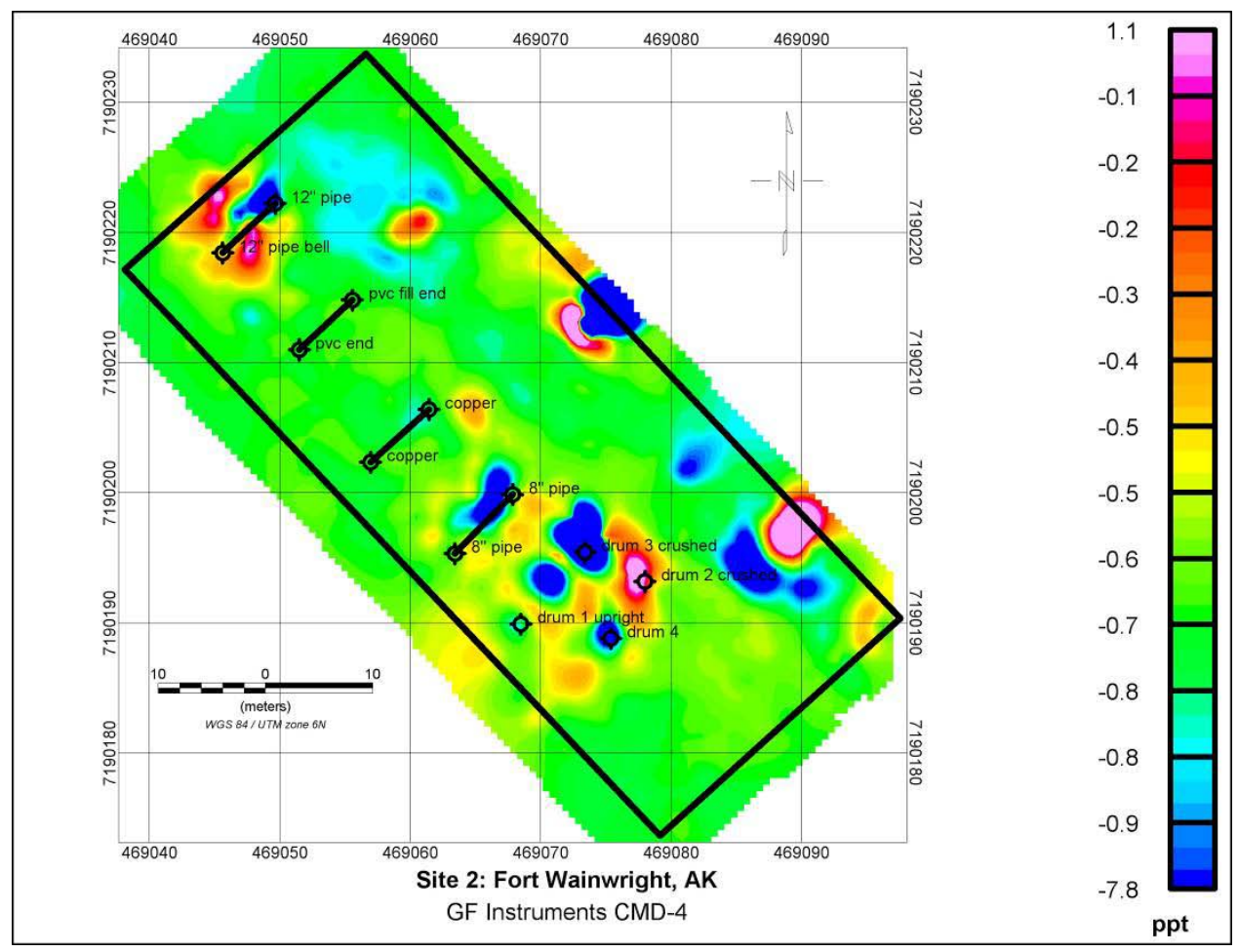

Figure B13. Area \#2 GF Instruments CMD-4 inphase data after installation.

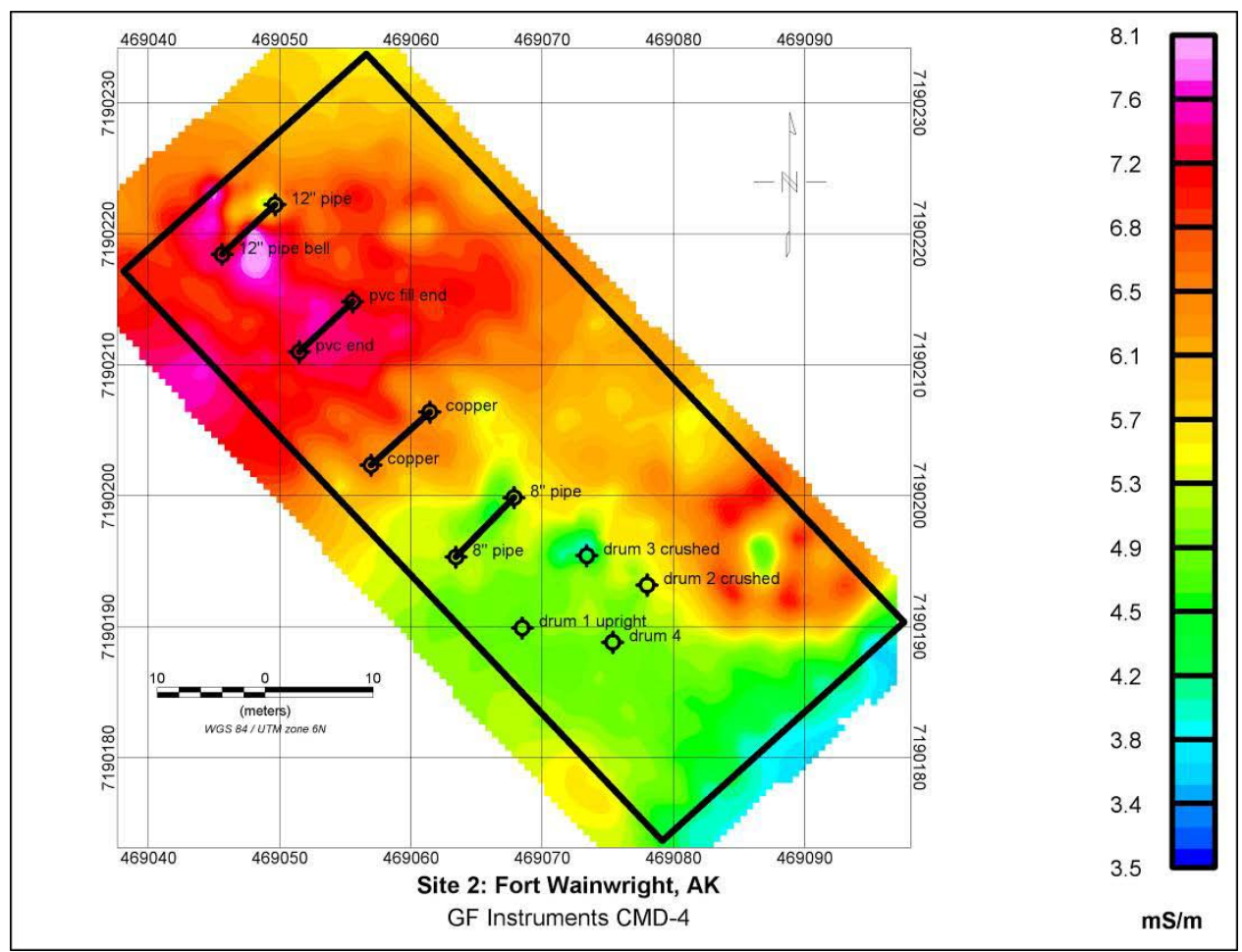

Figure B14. Area \#2 GF Instruments CMD-4 conductivity data after installation. 


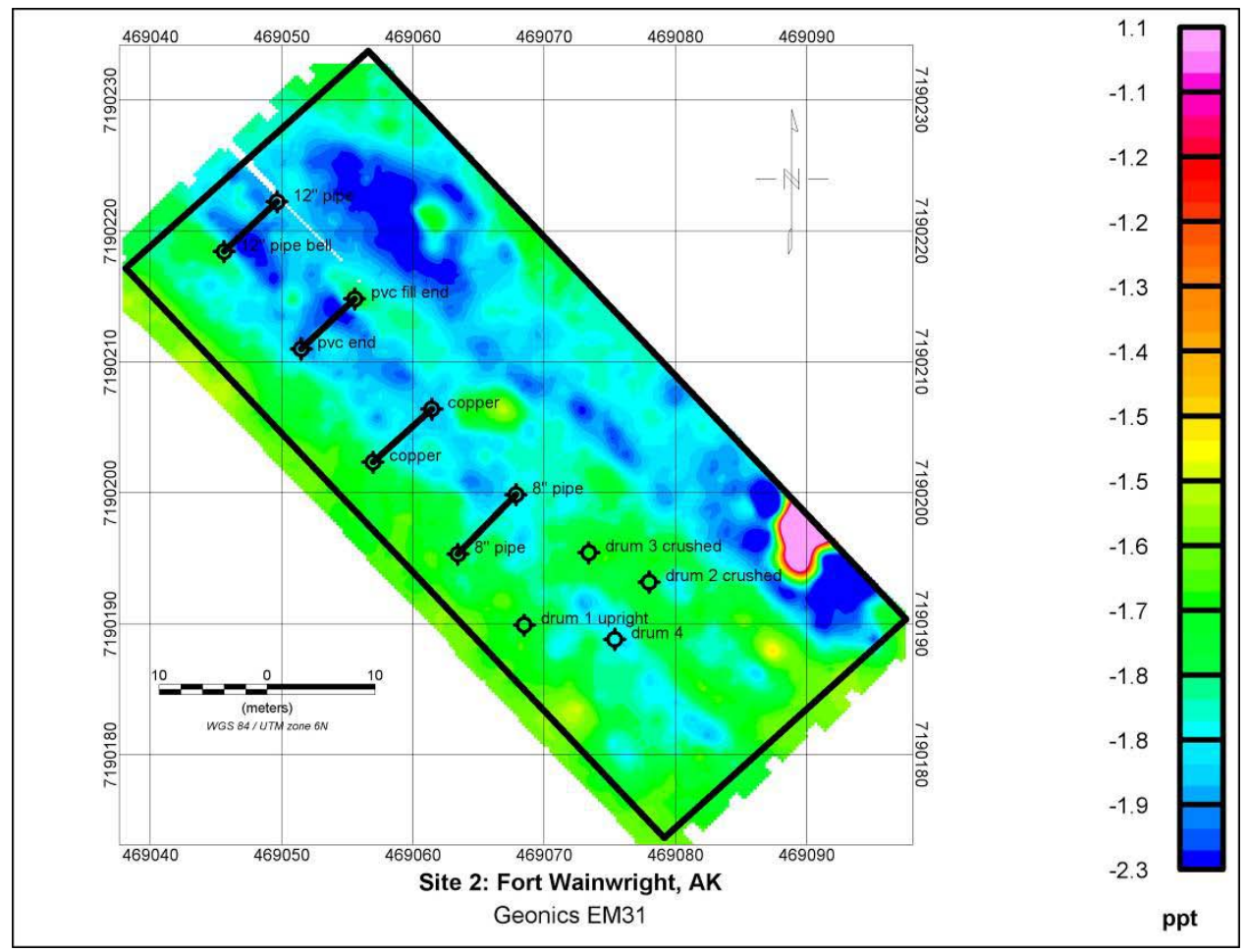

Figure B15. Area \#2 Geonics EM31 inphase data before installation.

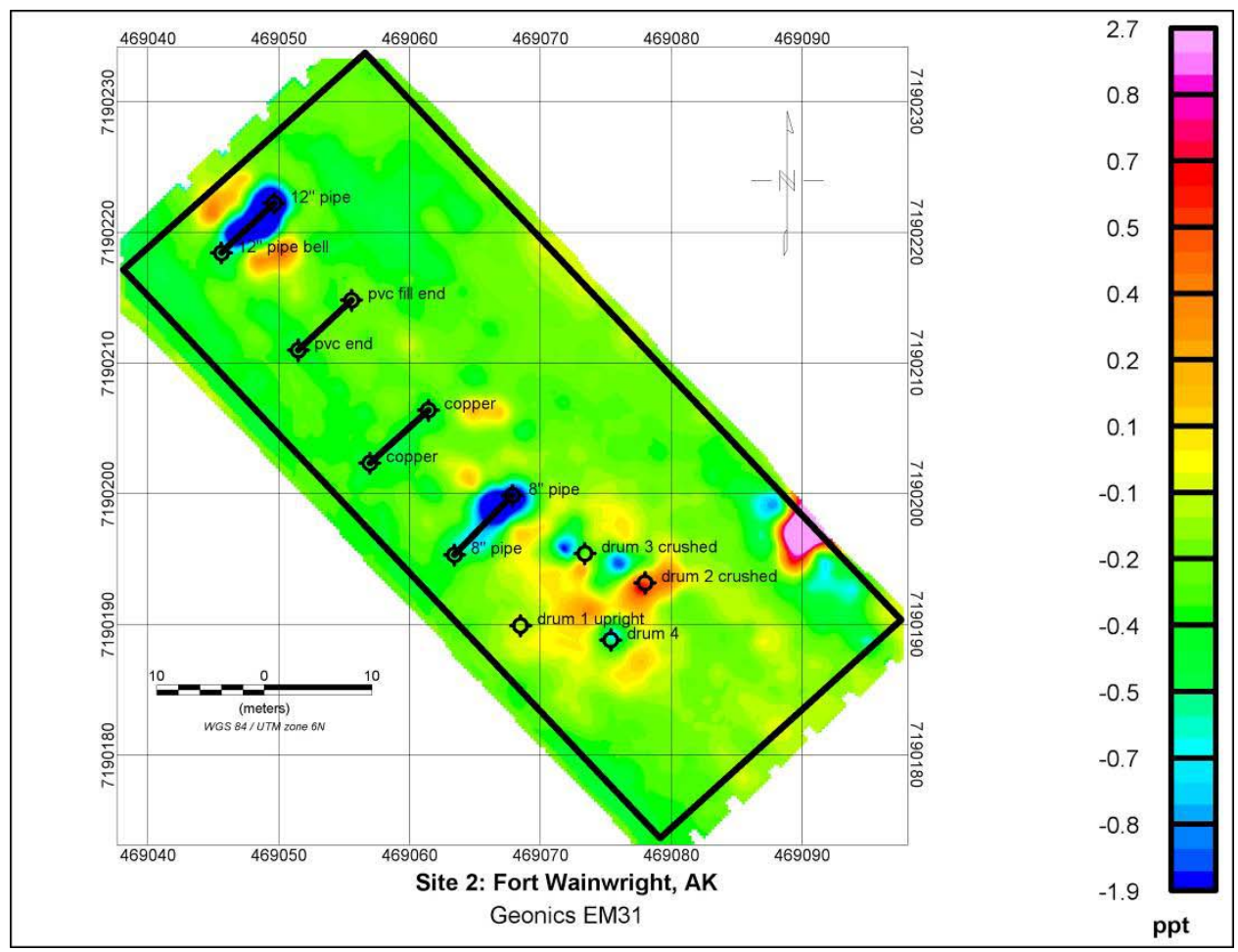

Figure B16. Area \#2 Geonics EM31 inphase data after installation. 


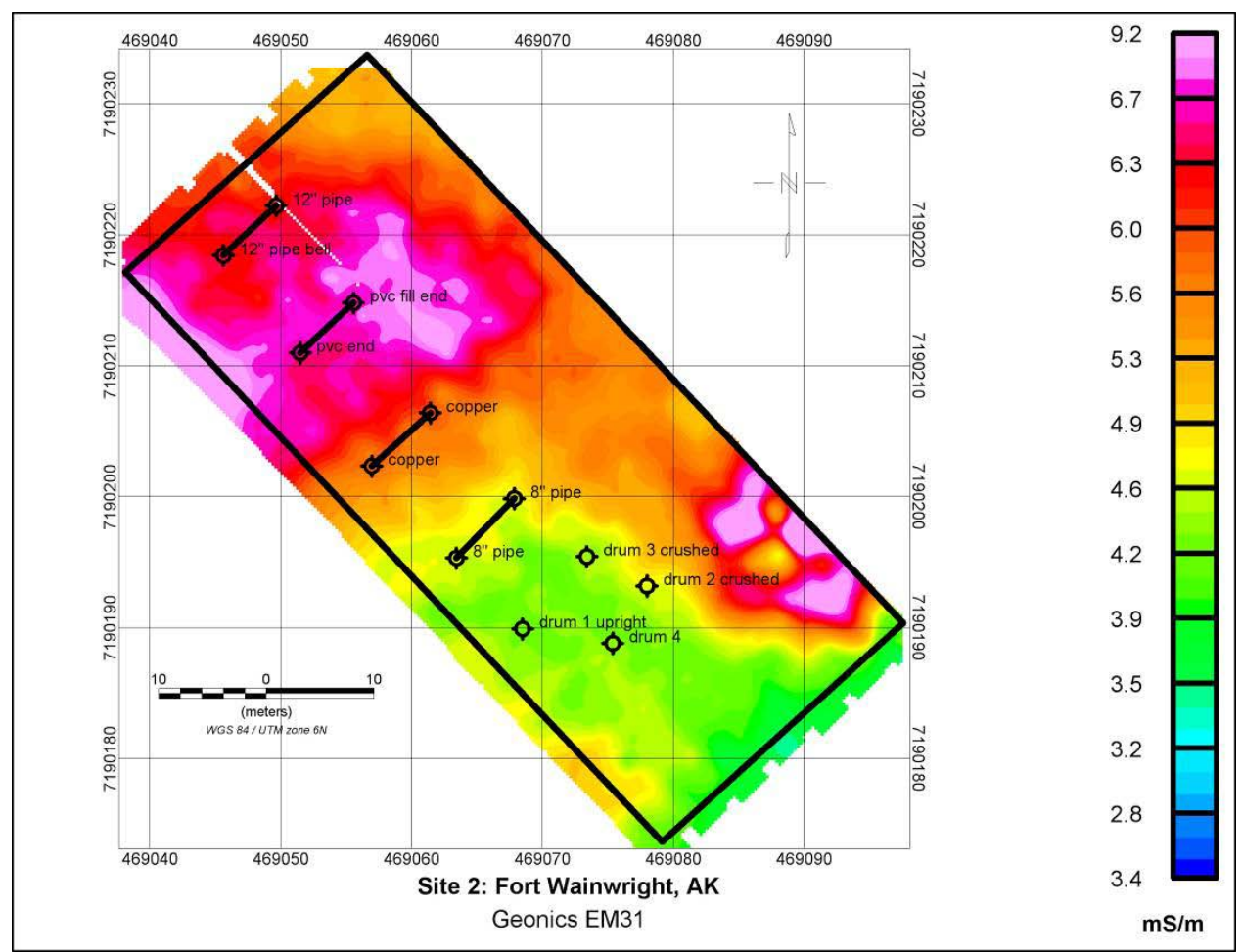

Figure B17. Area \#2 Geonics EM31 conductivity data before installation.

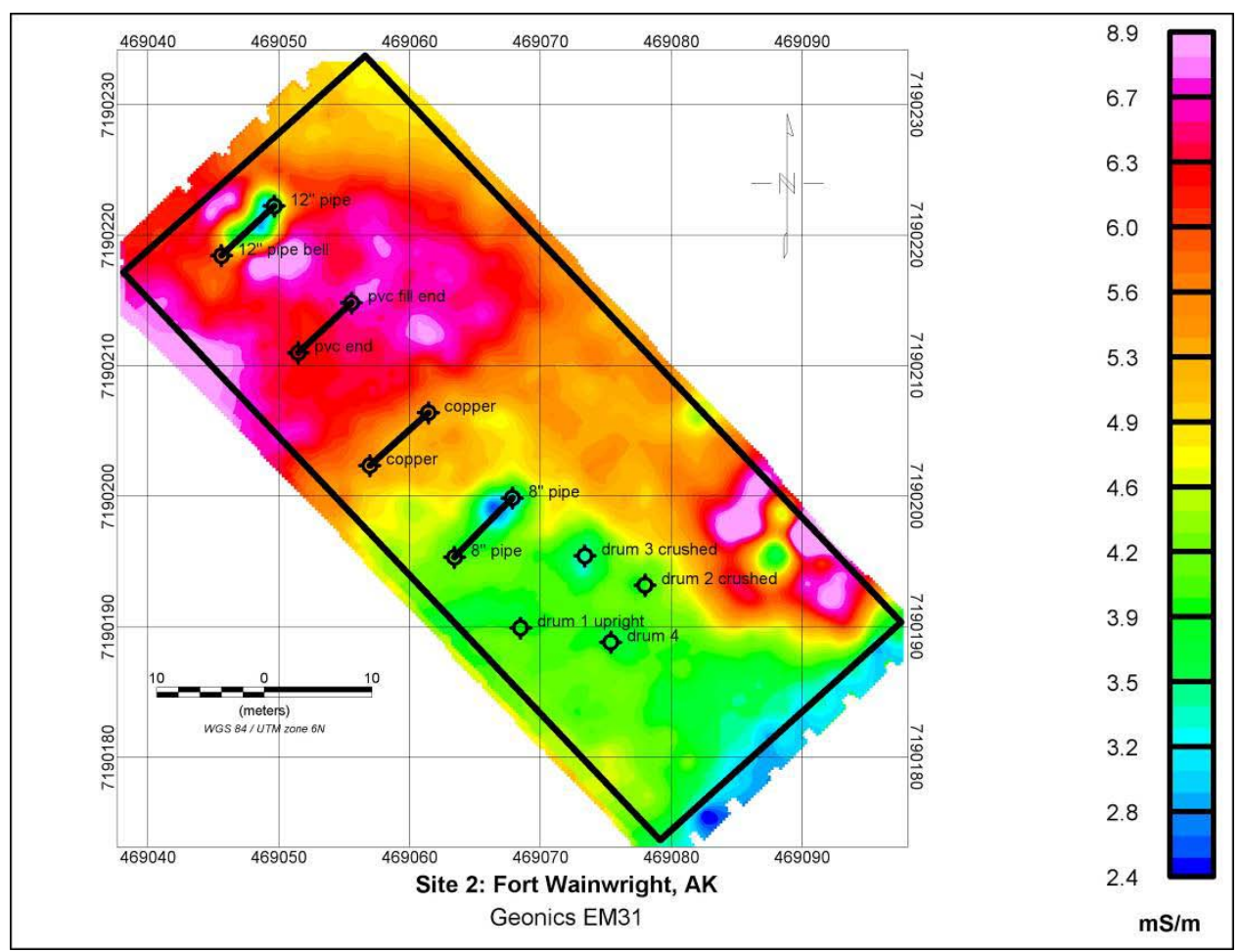

Figure B18. Area \#2 Geonics EM31 conductivity data after installation. 


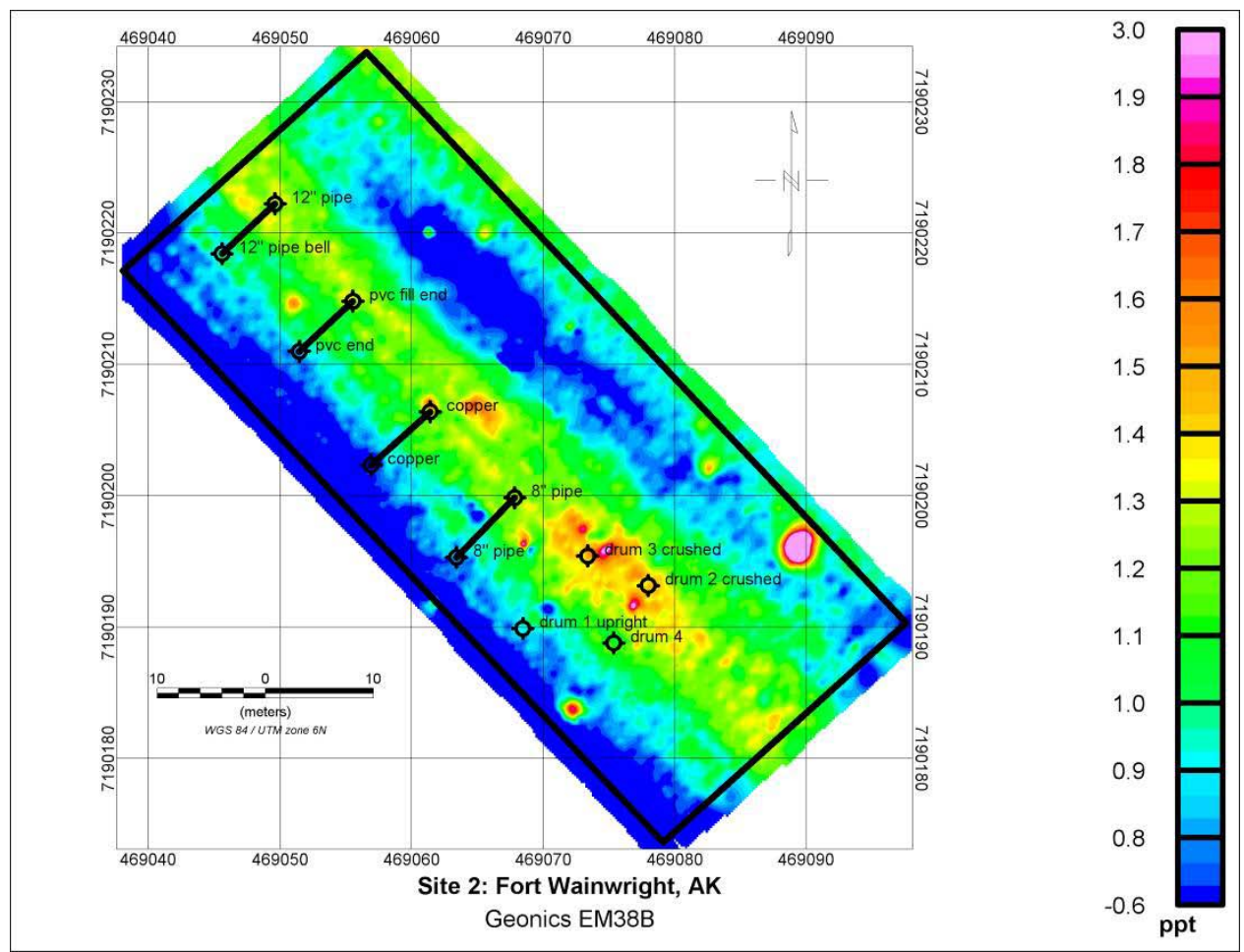

Figure B19. Area \#2 Geonics EM38B inphase data before installation.

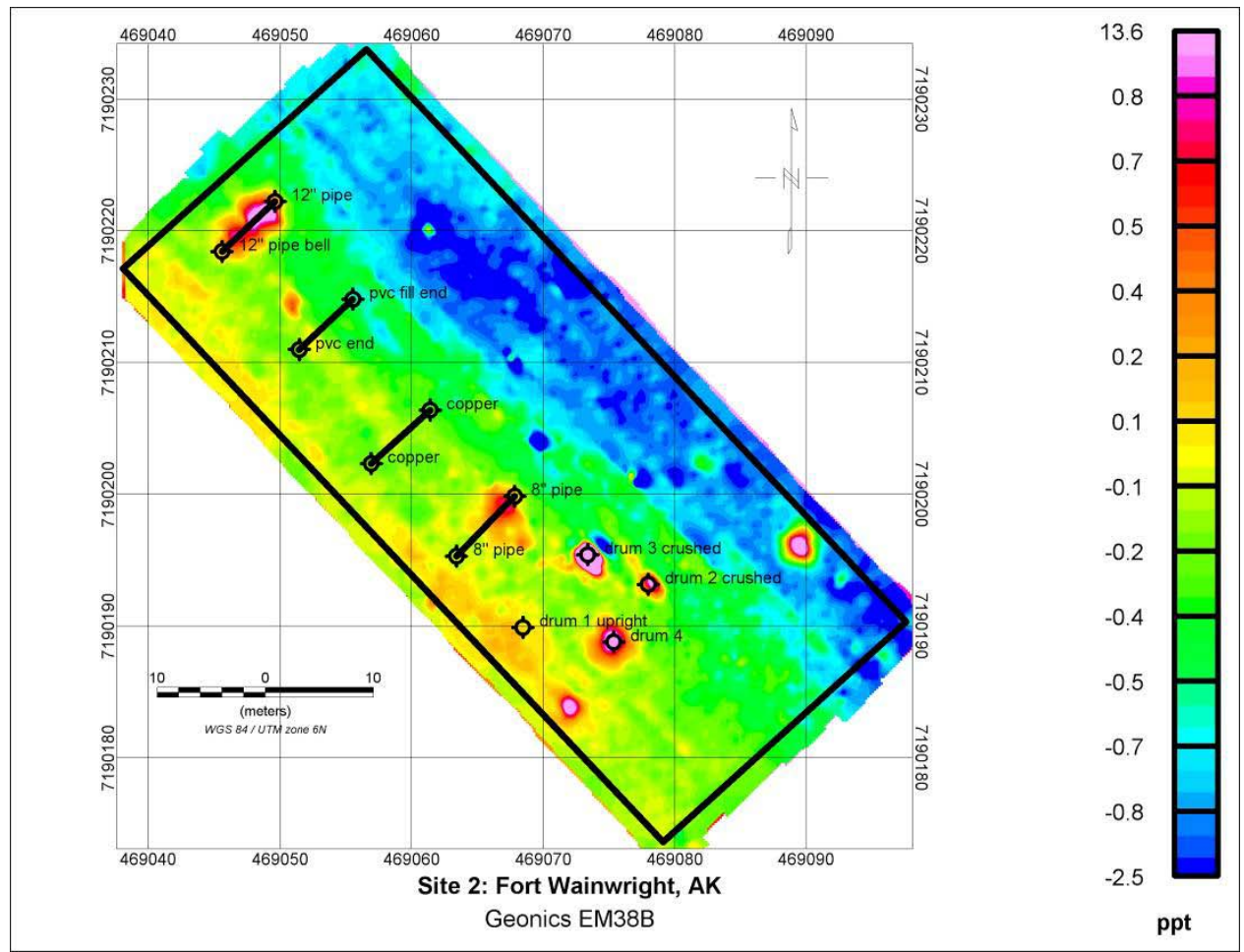

Figure B20. Area \#2 Geonics EM38B inphase data after installation. 


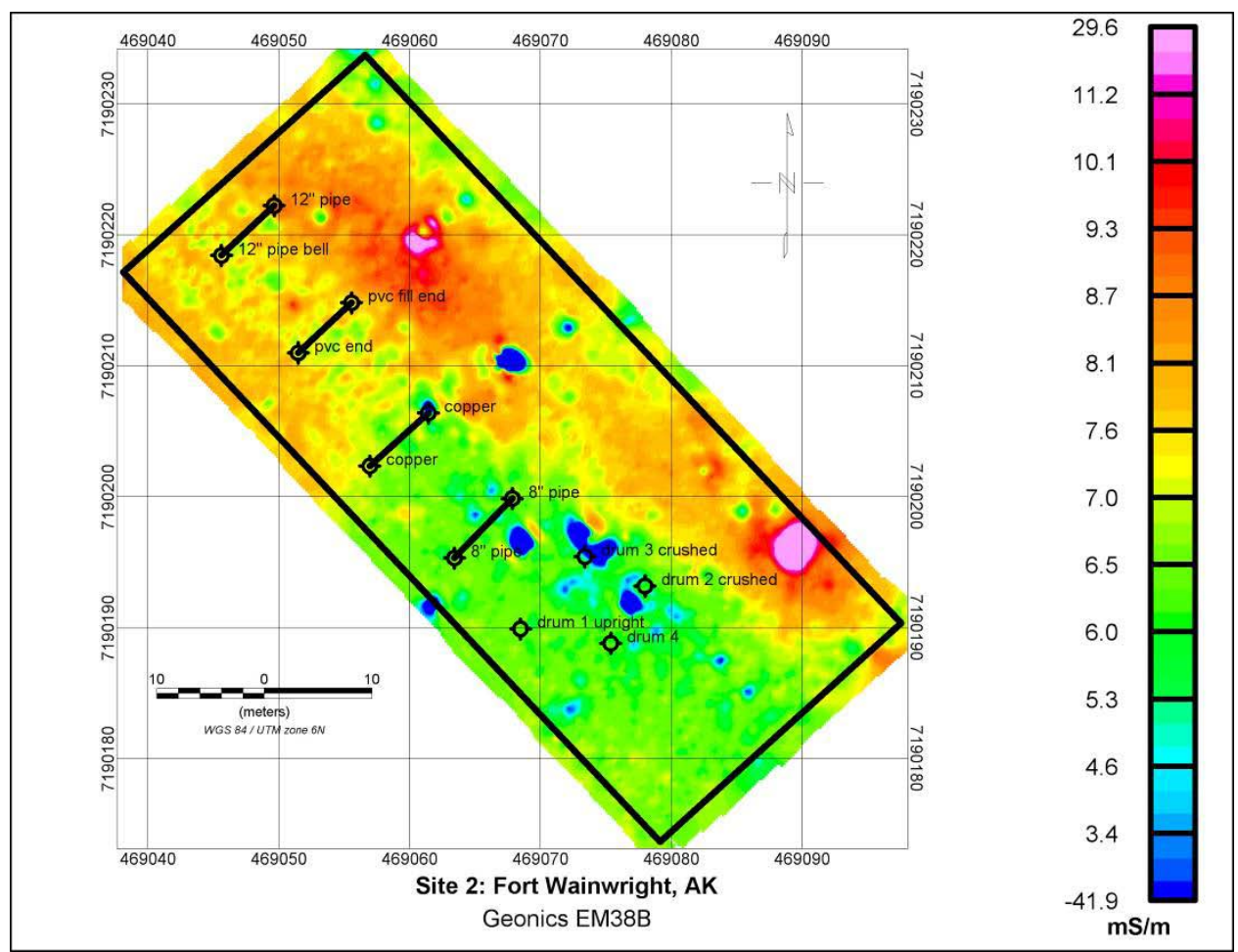

Figure B21. Area \#2 Geonics EM38B conductivity data before installation.

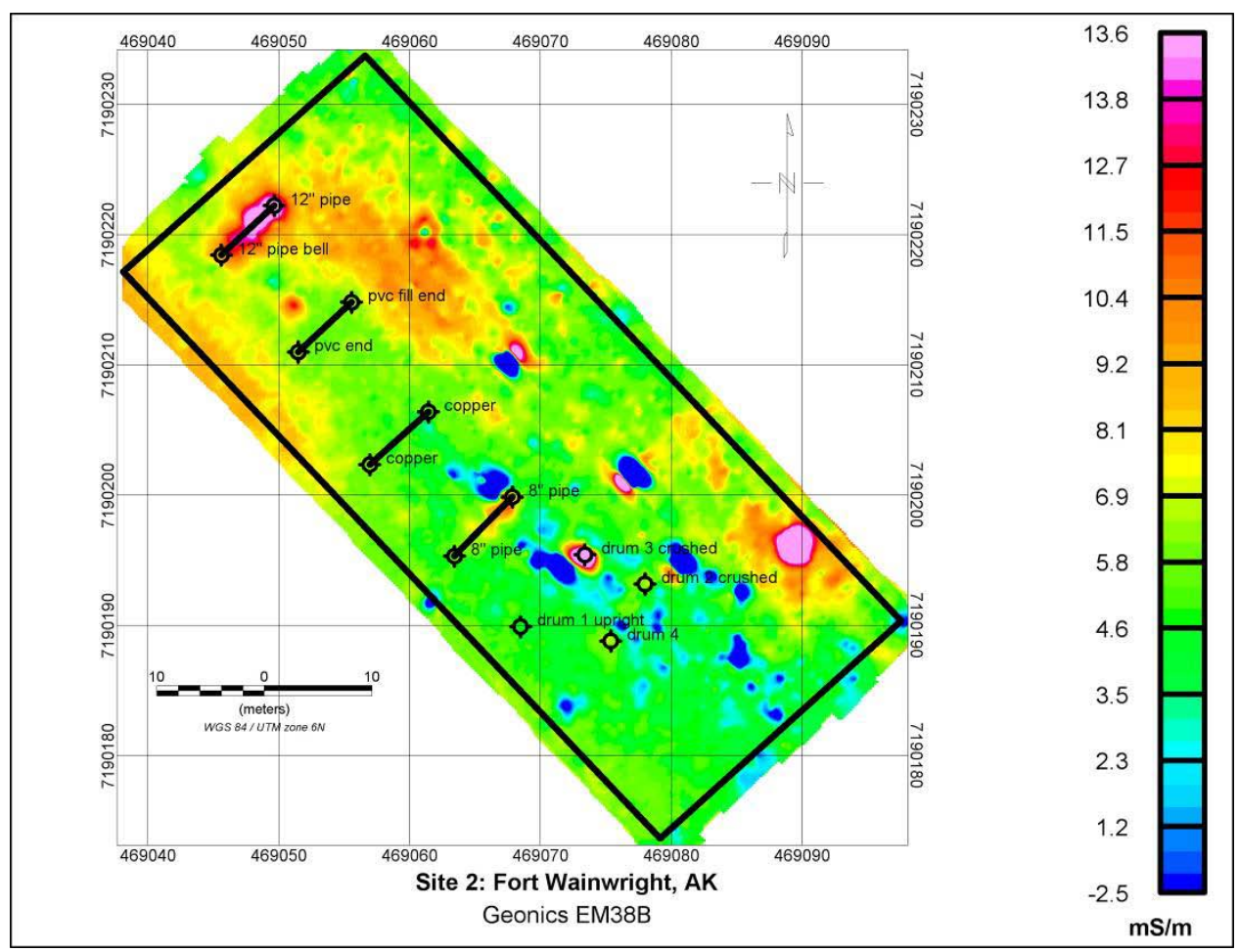

Figure B22. Area \#2 Geonics EM38B conductivity data after installation. 


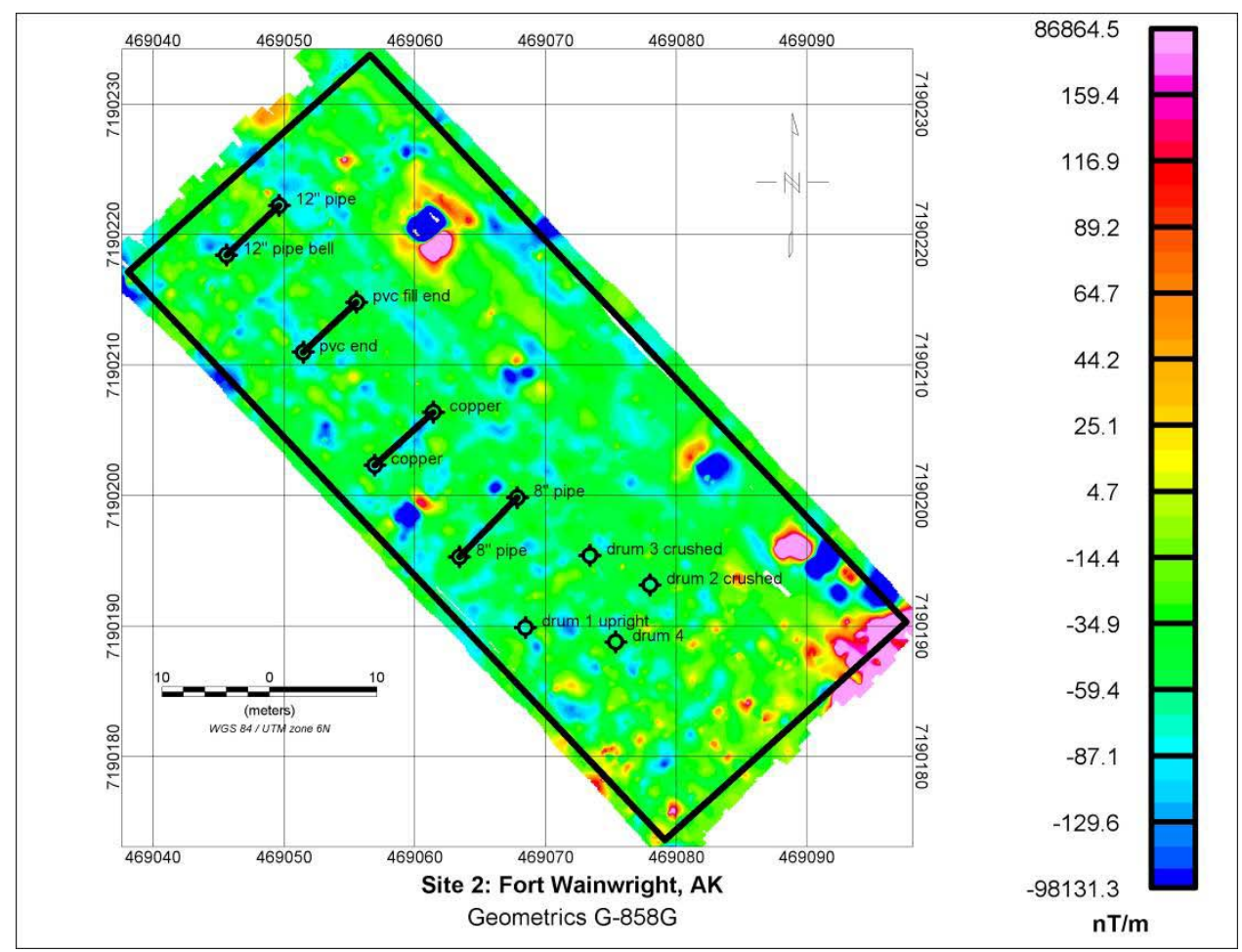

Figure B23. Area \#2 Geometrics G-858 vertical gradient data before installation.

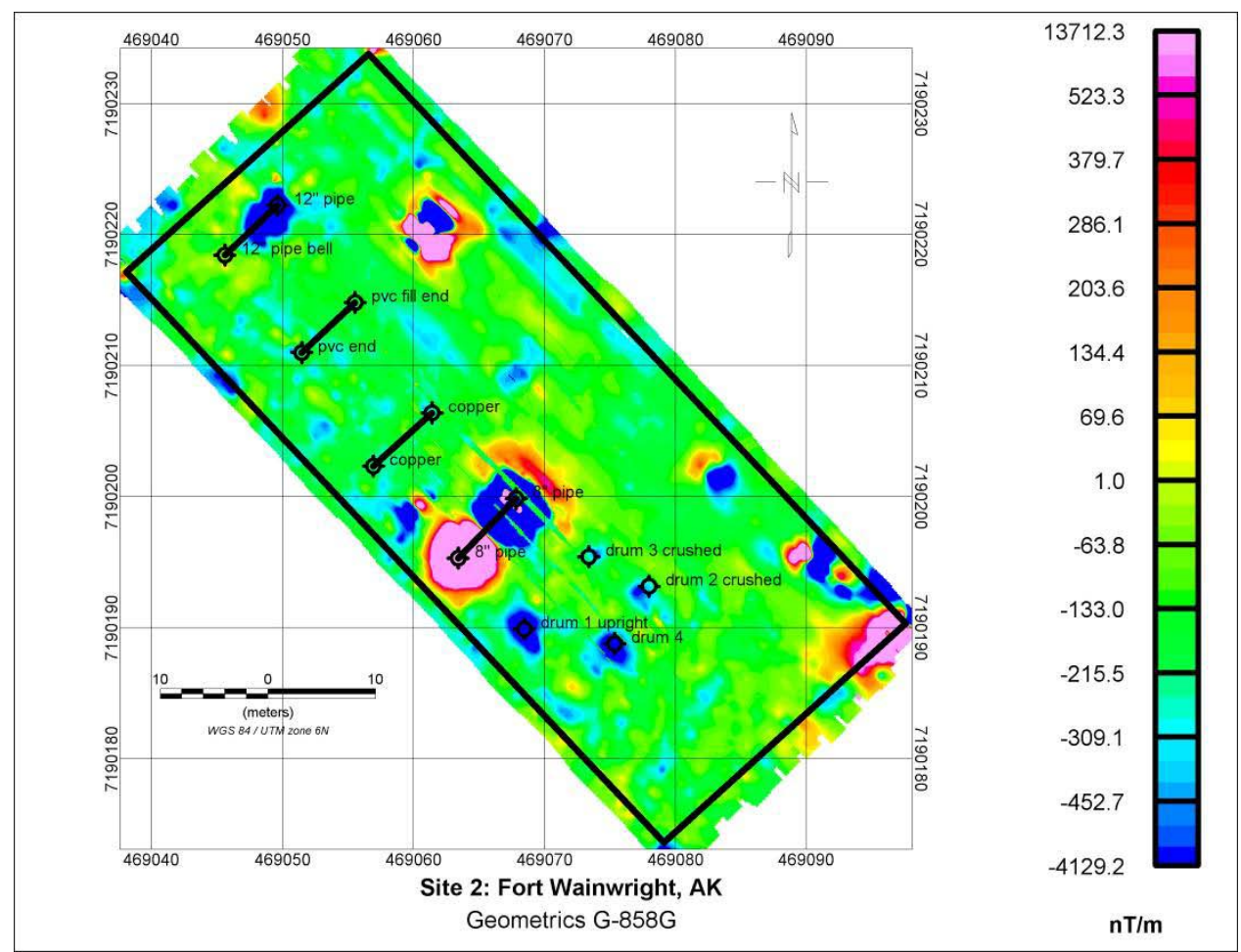

Figure B24. Area \#2 Geometrics G-858 vertical gradient data after installation. 


\section{Appendix C: Area \#3 Fort Wainwright Images}

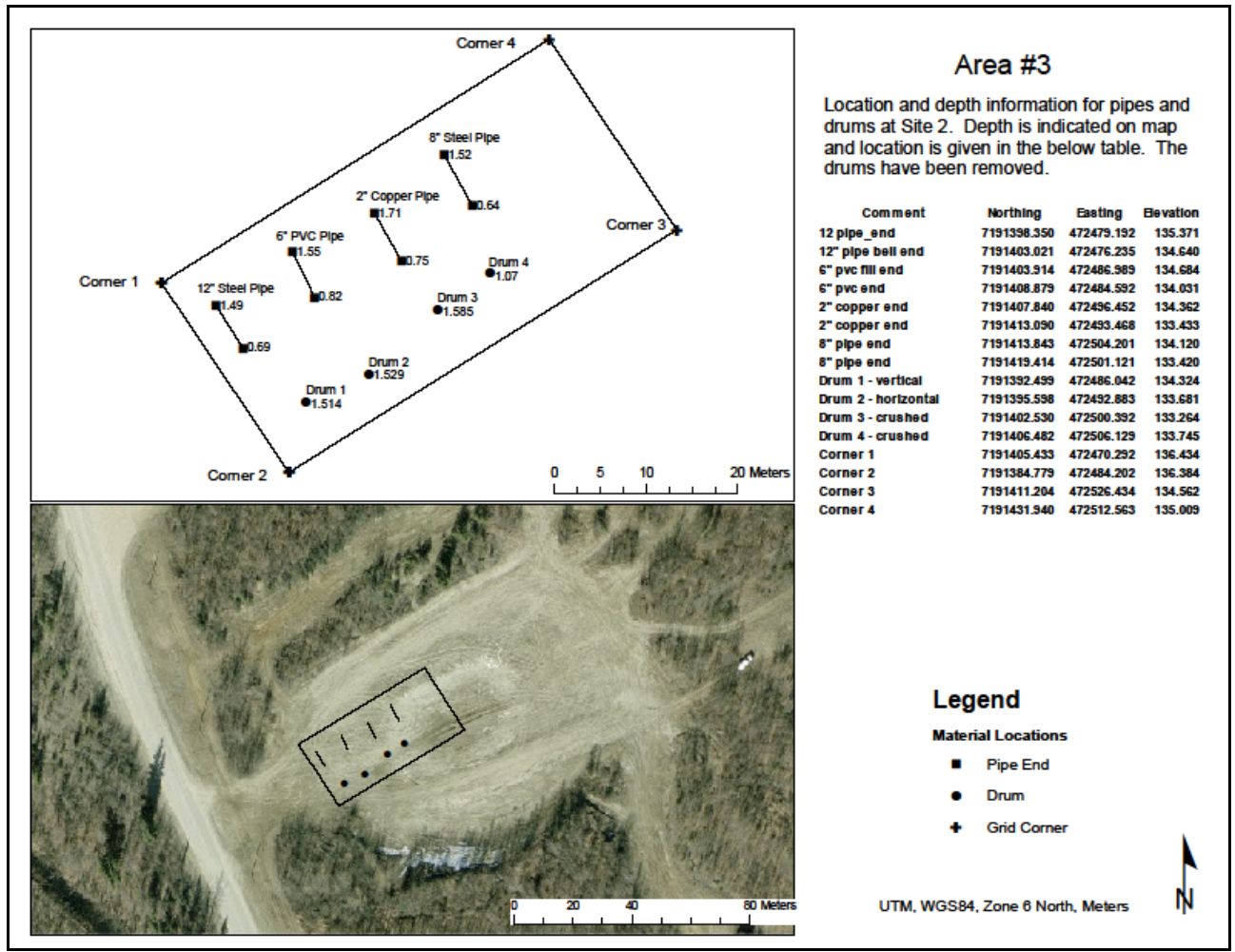

Figure C1. Area \#3 Fort Wainwright plan view.

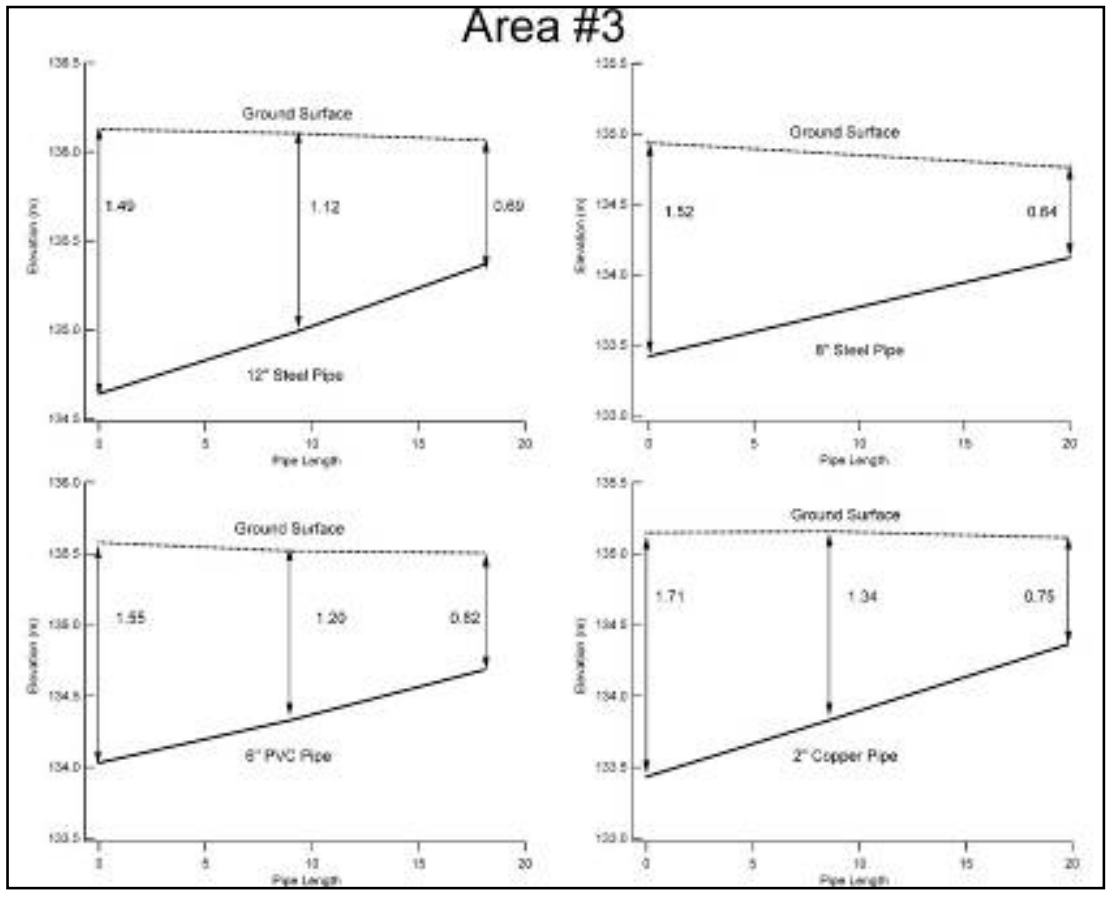

Figure C2. Area \#3 cross section view of pipe placement. 


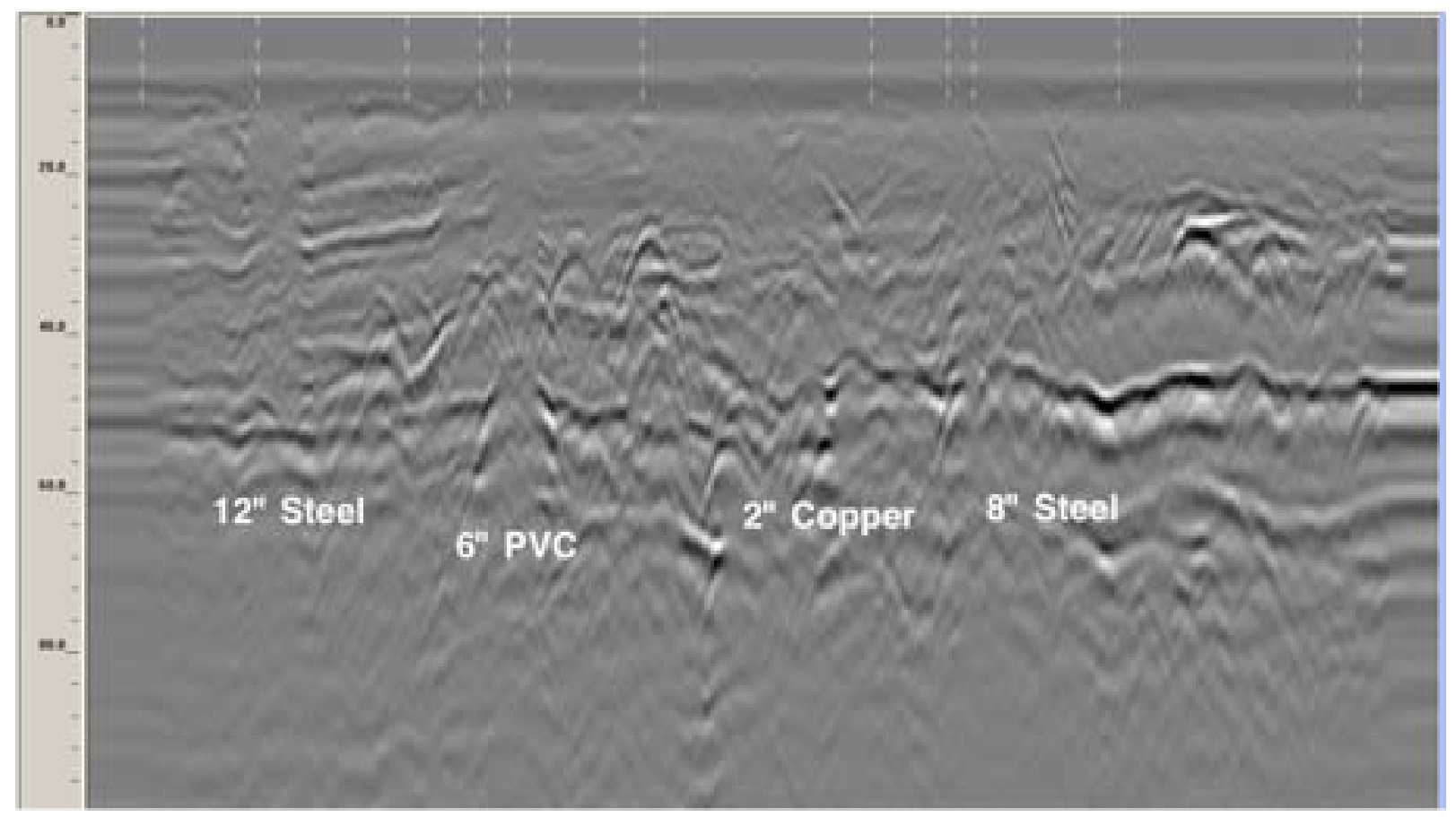

Figure C3. Area \#3 GSSI SIR-3000 GPR (200 MHz antenna) data over deep end of pipes. ${ }^{1}$

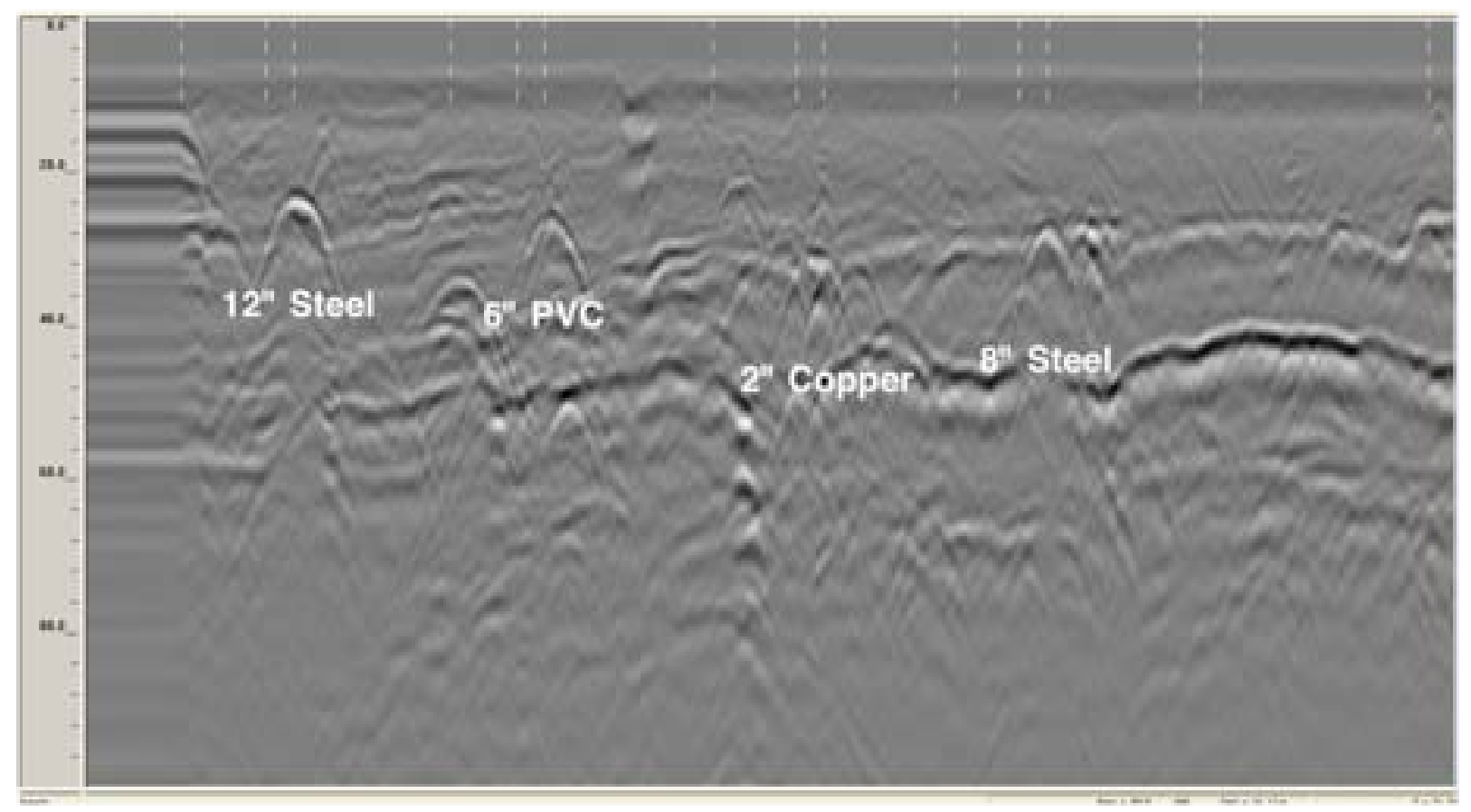

Figure C4. Area \#3 GSSI SIR-3000 GPR (200 MHz antenna) data over shallow end of pipes.

1 Note: For all GSSI radargrams, marks (dotted white vertical lines) indicate 5-m spacing; depth scale is nanoseconds. Also note: For all plan view intensity maps, the color scale remains constant for the changing relative signal values. 


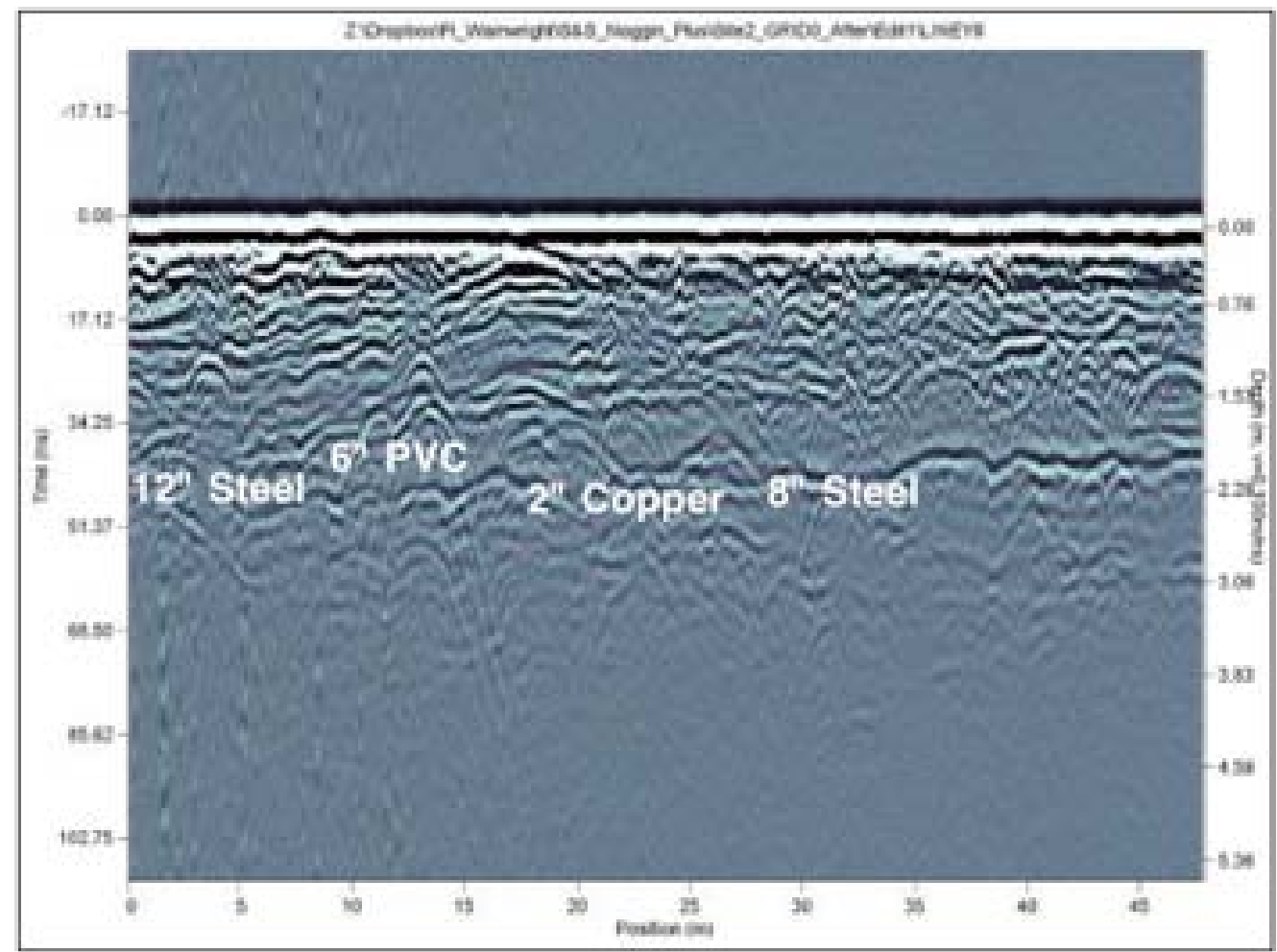

Figure C5. Area \#3 S\&S Noggin Plus GPR (250 MHz antenna) data over deep end of pipes.

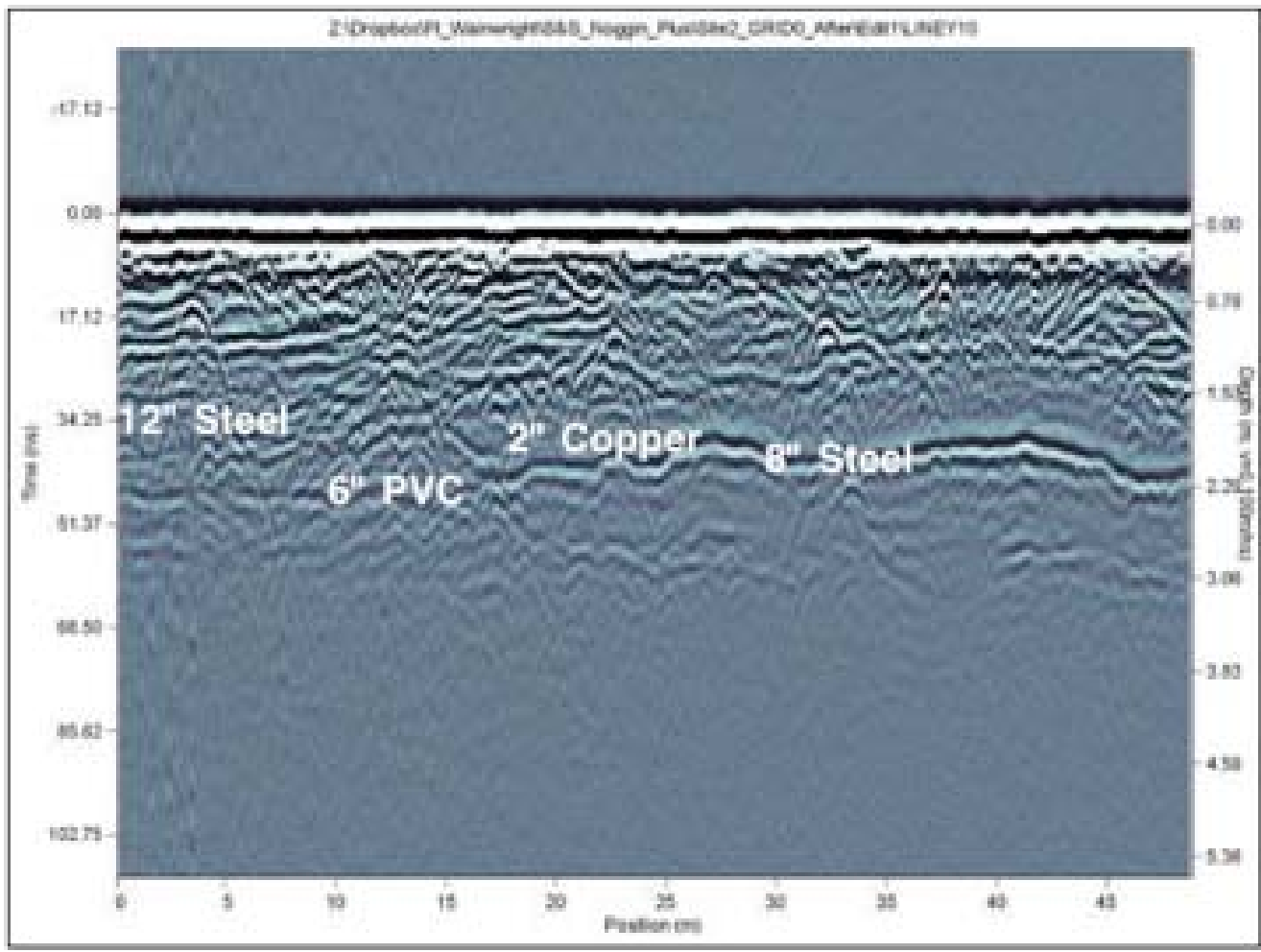

Figure C6. Area \#3 S\&S Noggin Plus GPR (250 MHz antenna) data over shallow end of pipes. 


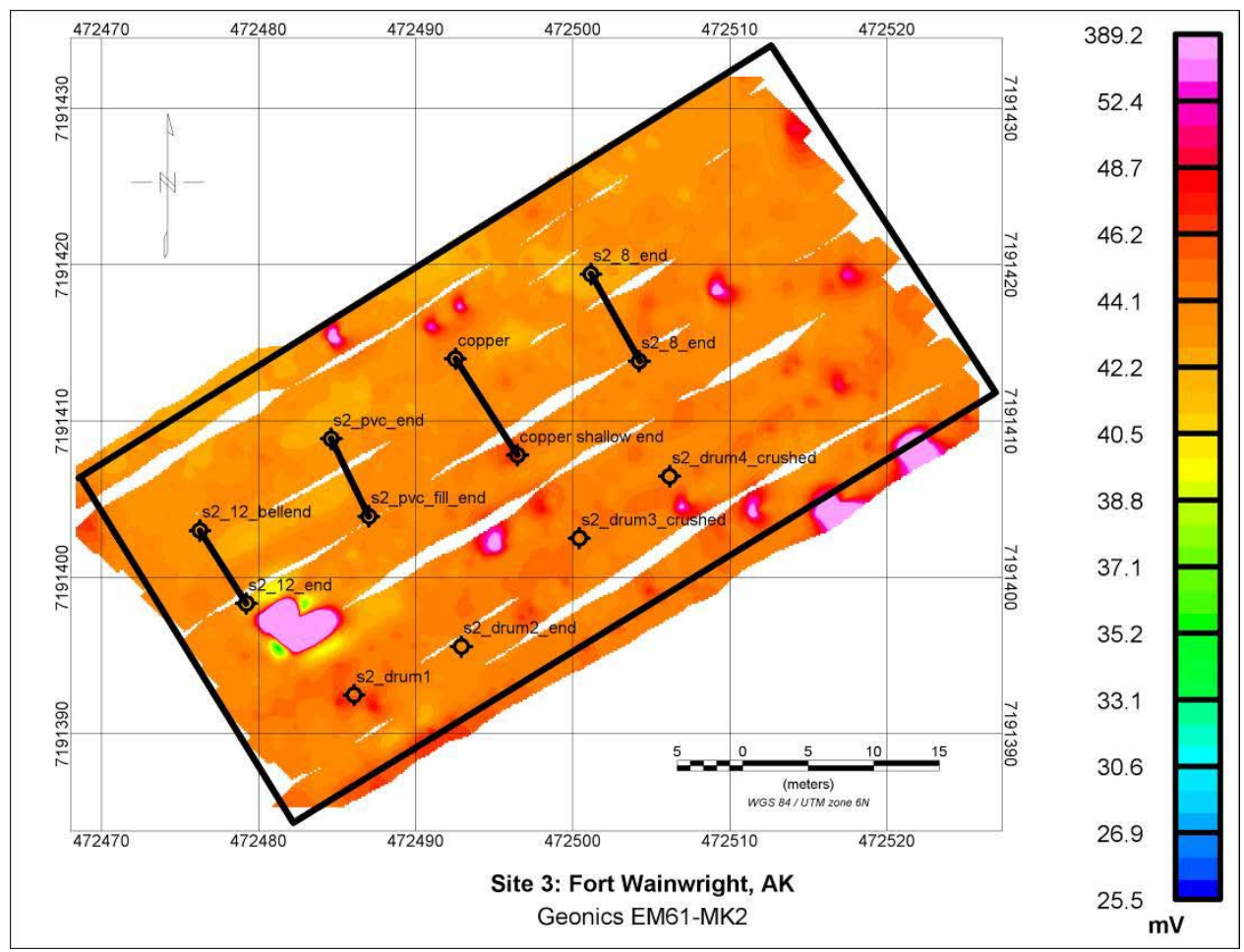

Figure C7. Area \#3 Geonics EM61-MK2 channel 1 data before installation.

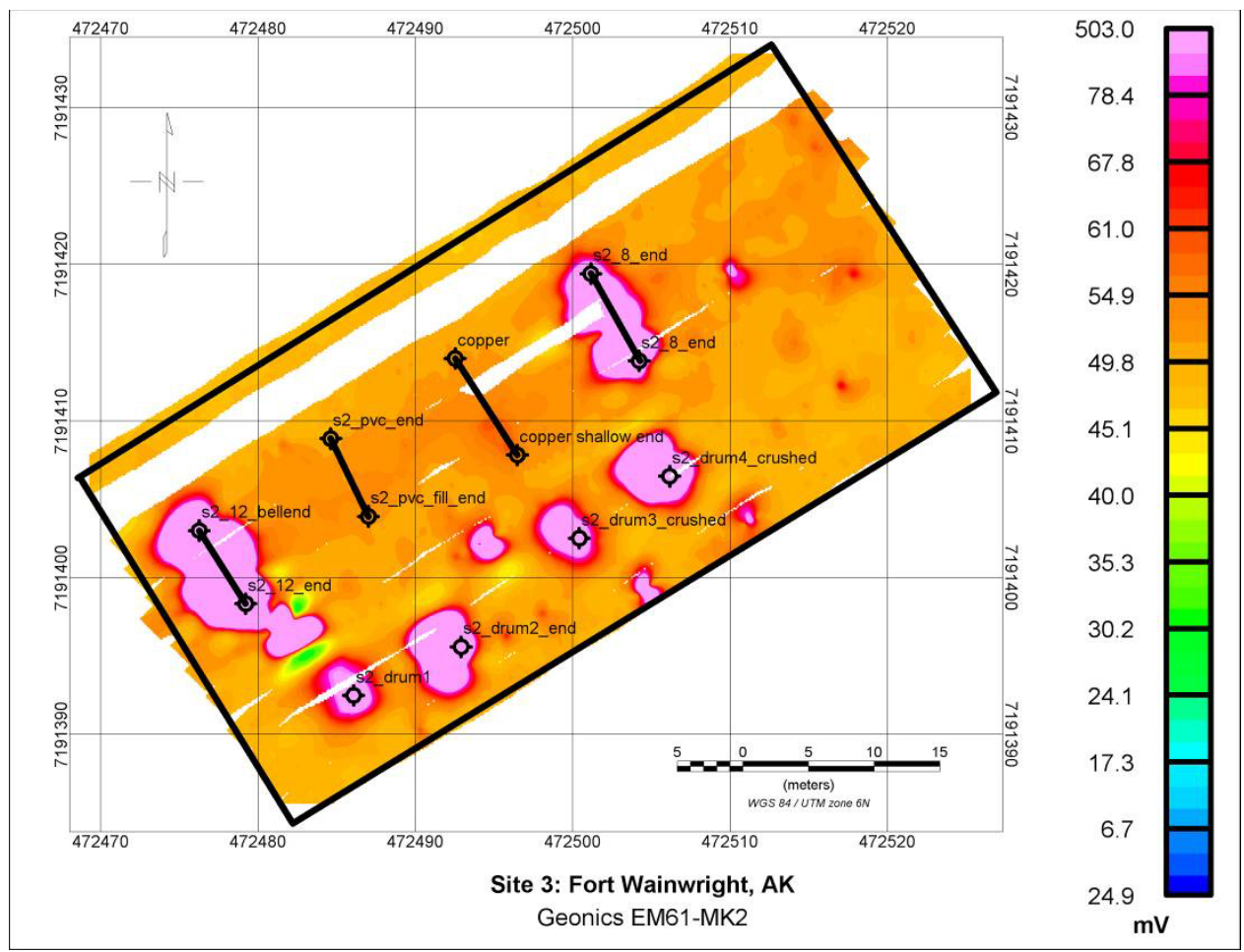

Figure C8. Area \#3 Geonics EM61-MK2 channel 1 data after installation. 


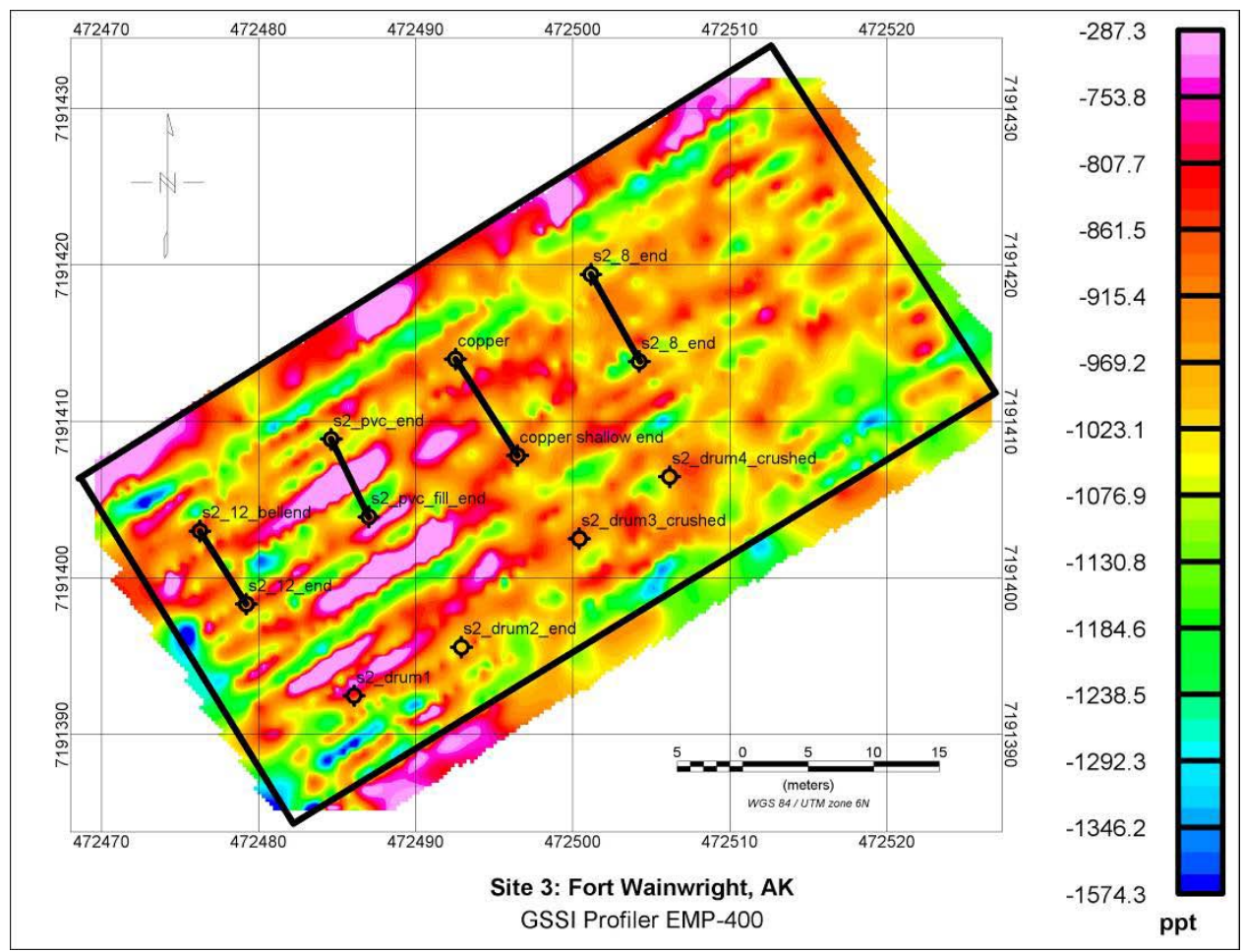

Figure C9. Area \#3 GSSI Profiler (15000 Hz) inphase data before installation.

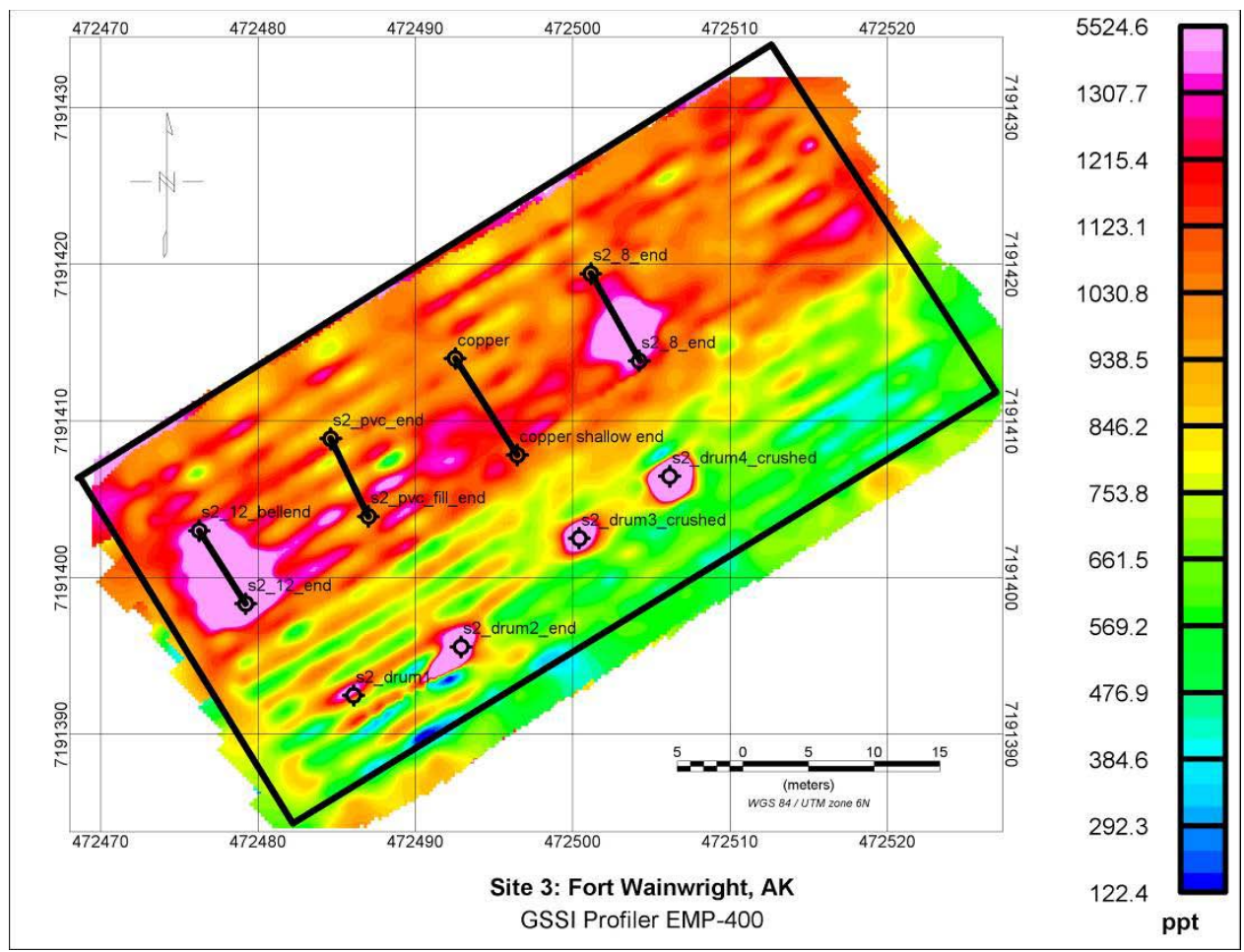

Figure C10. Area \#3 GSSI Profiler $(15000 \mathrm{~Hz})$ inphase data after installation. 


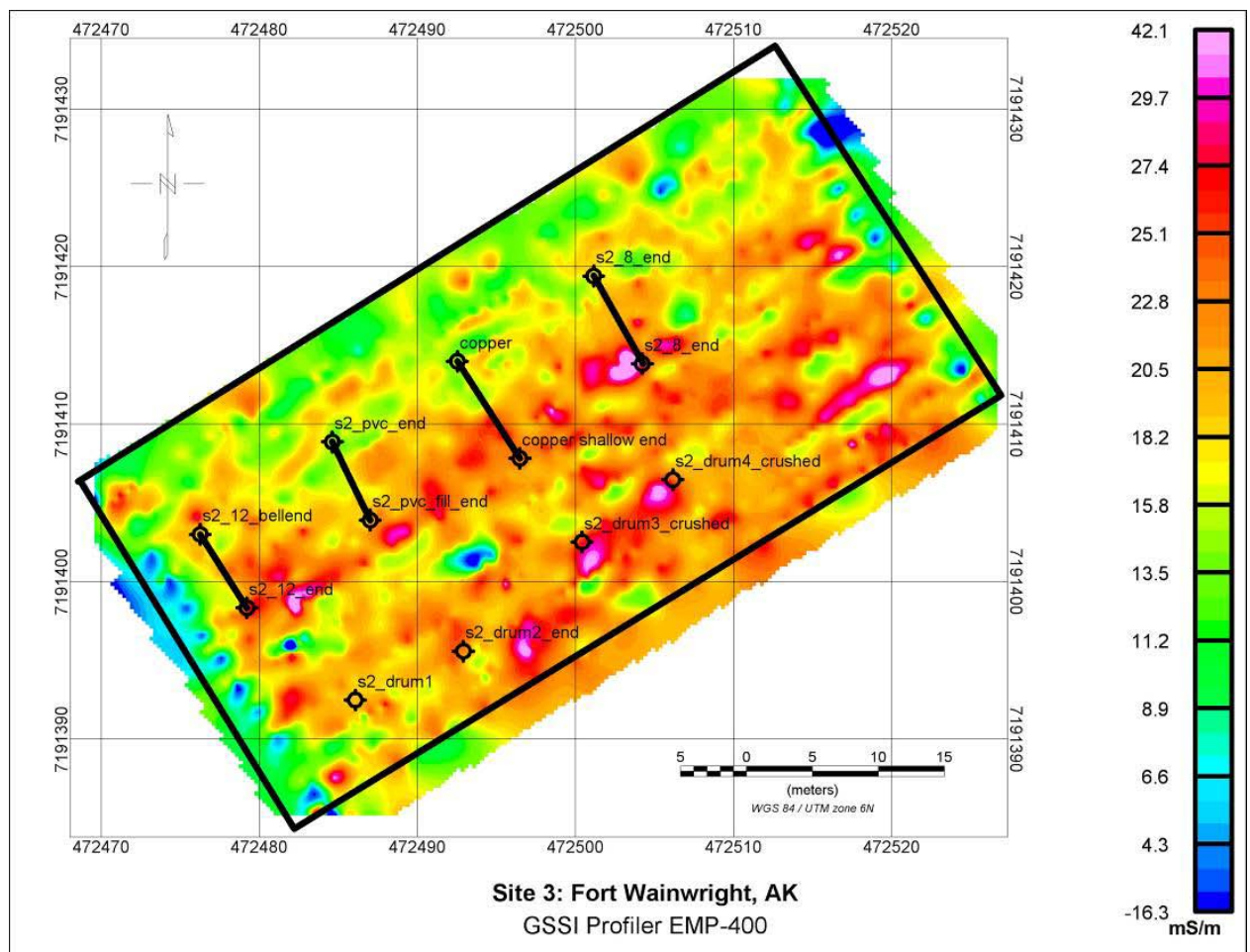

Figure C11. Area \#3 GSSI Profiler $(15000 \mathrm{~Hz})$ conductivity data before installation.

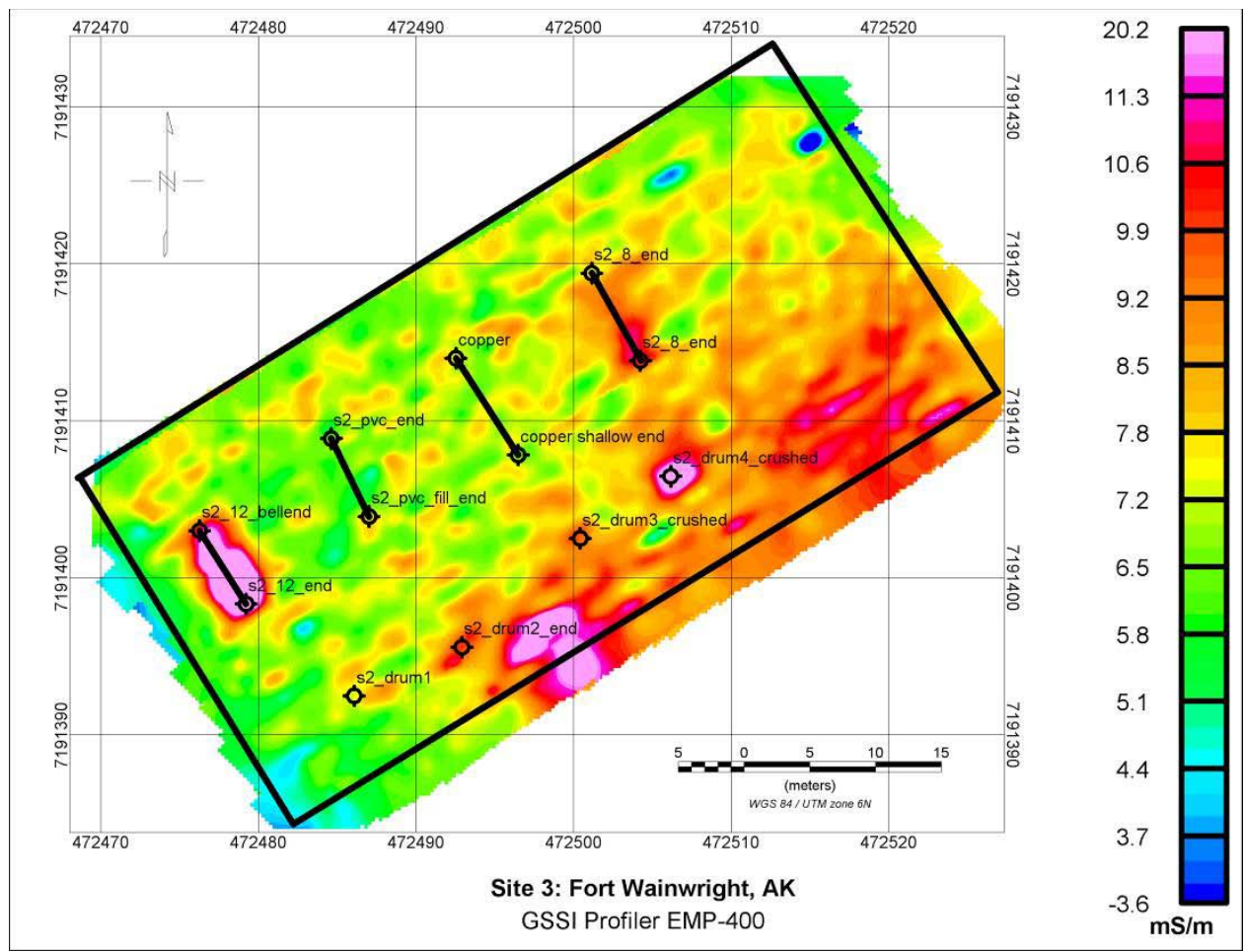

Figure C12. Area \#3 GSSI Profiler $(15000 \mathrm{~Hz})$ conductivity data after installation. 


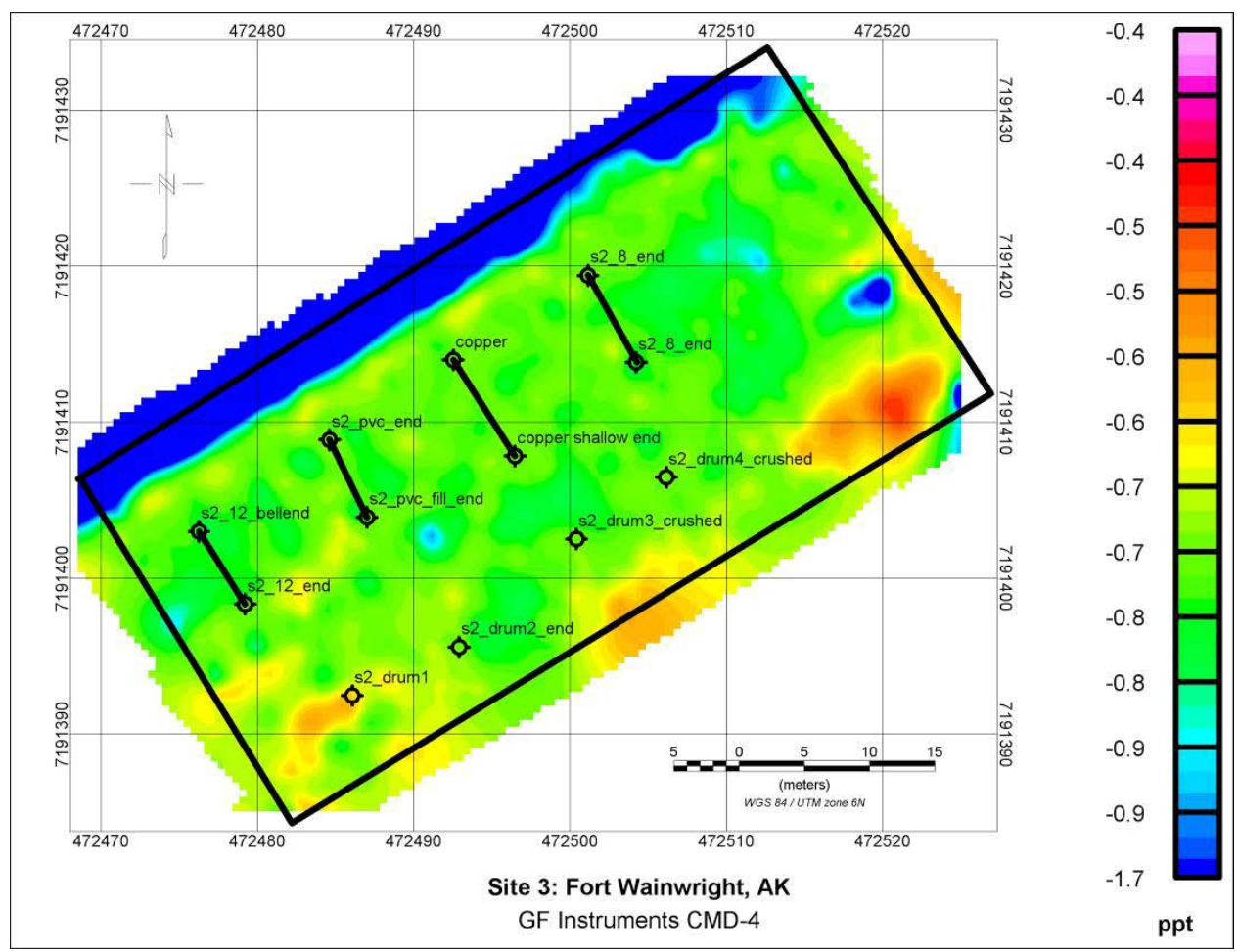

Figure C13. Area \#3 GF Instruments CMD-4 inphase data before installation.

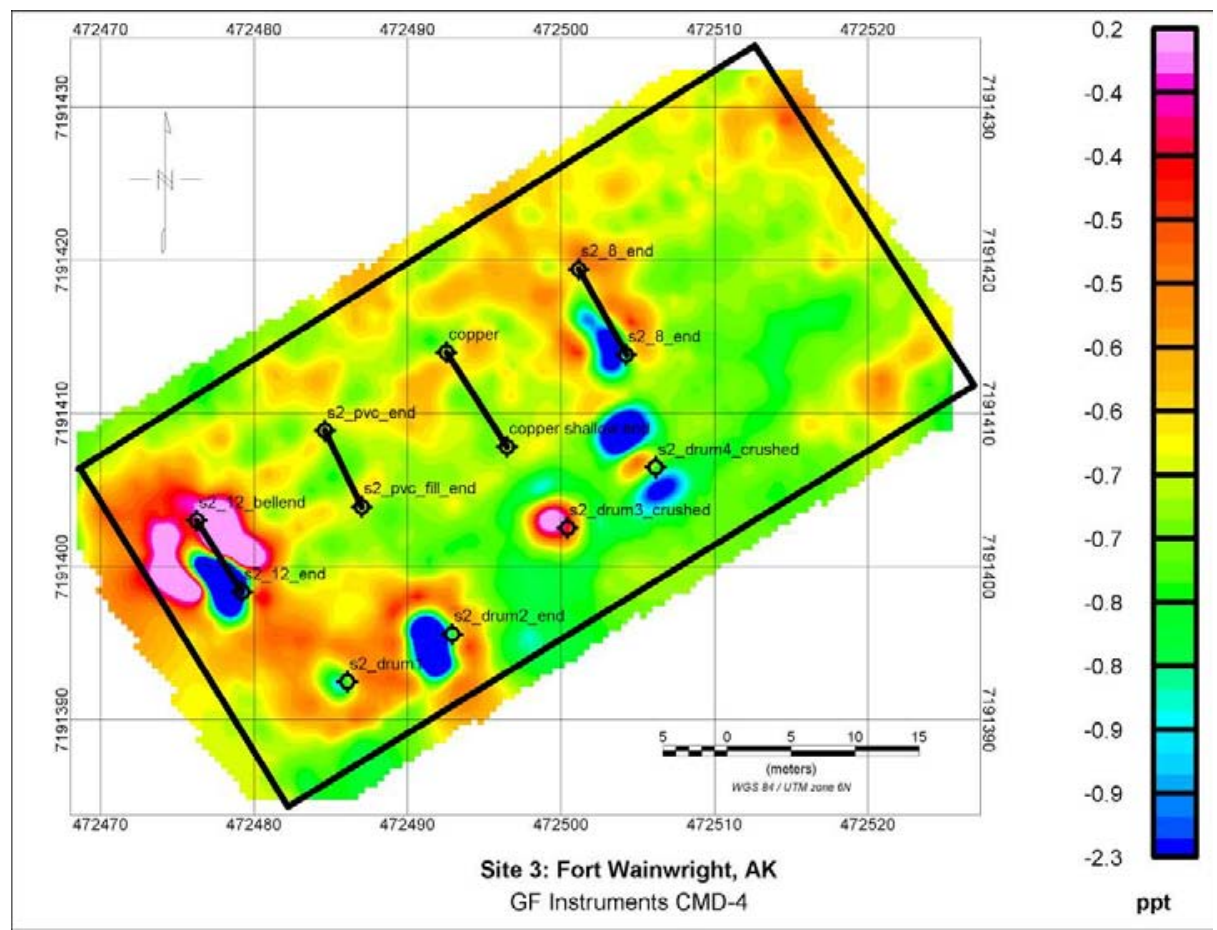

Figure C14. Area \#3 GF Instruments CMD-4 inphase data after installation. 


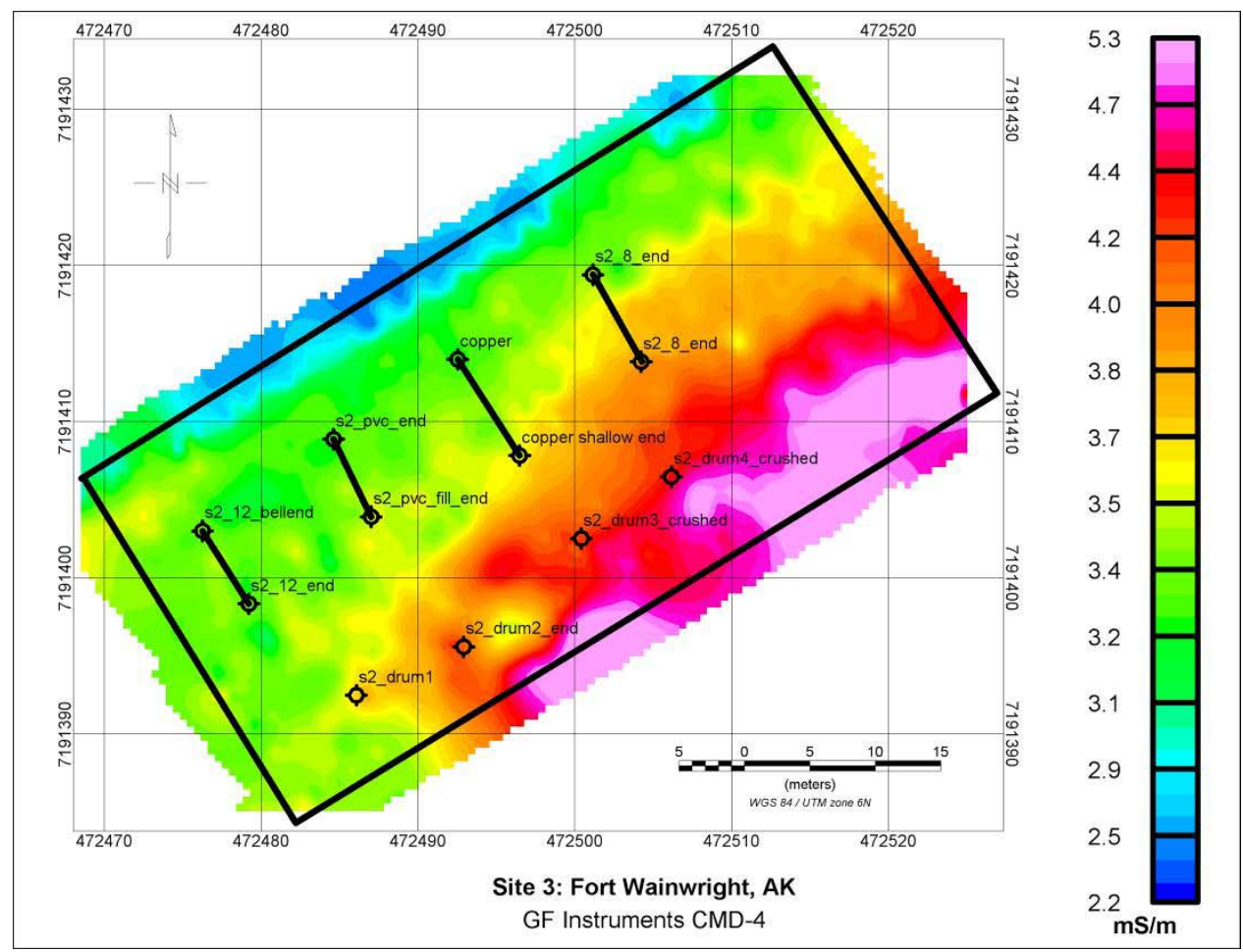

Figure C15. Area \#3 GF Instruments CMD-4 conductivity data before installation.

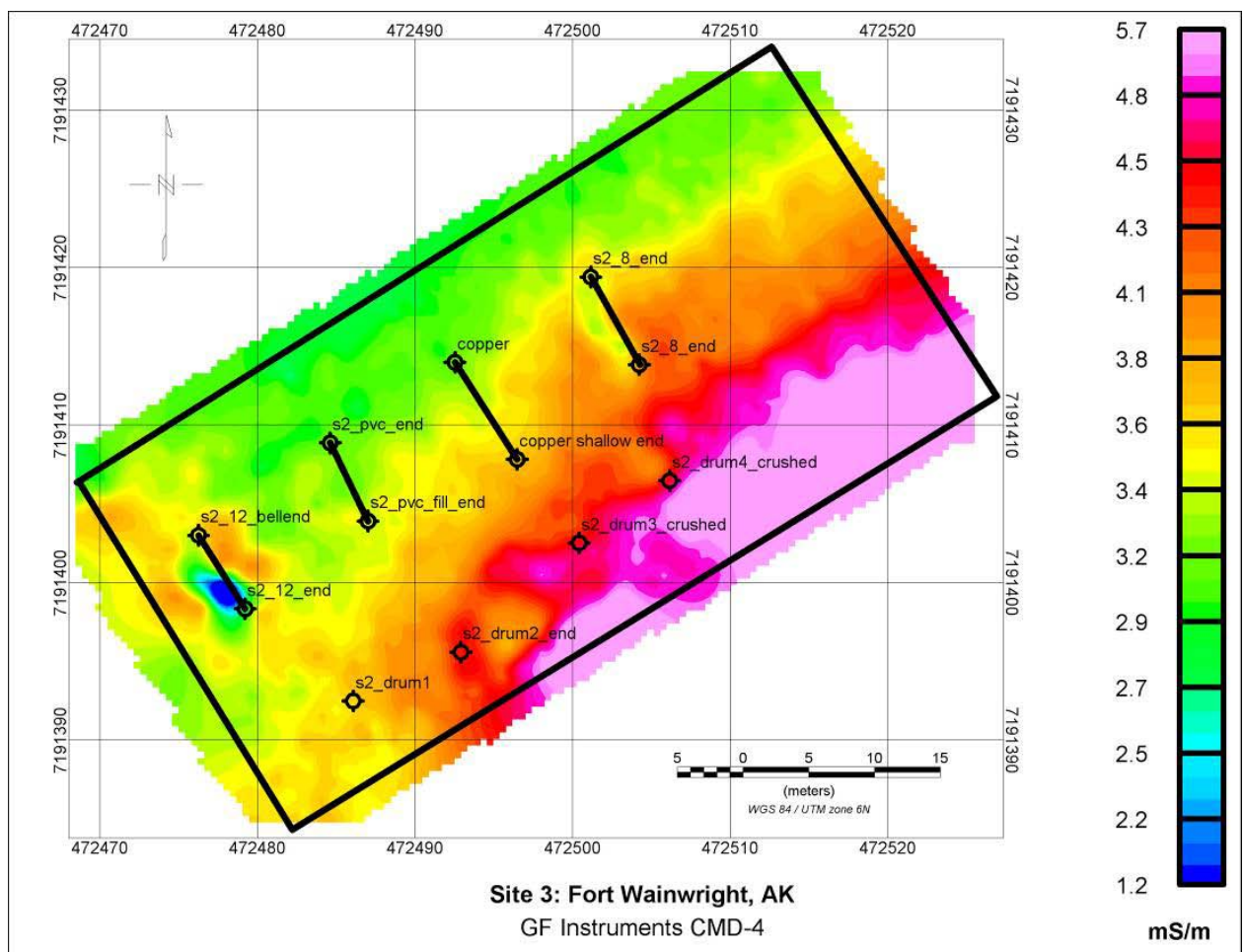

Figure C16. Area \#3 GF Instruments CMD-4 conductivity data after installation. 


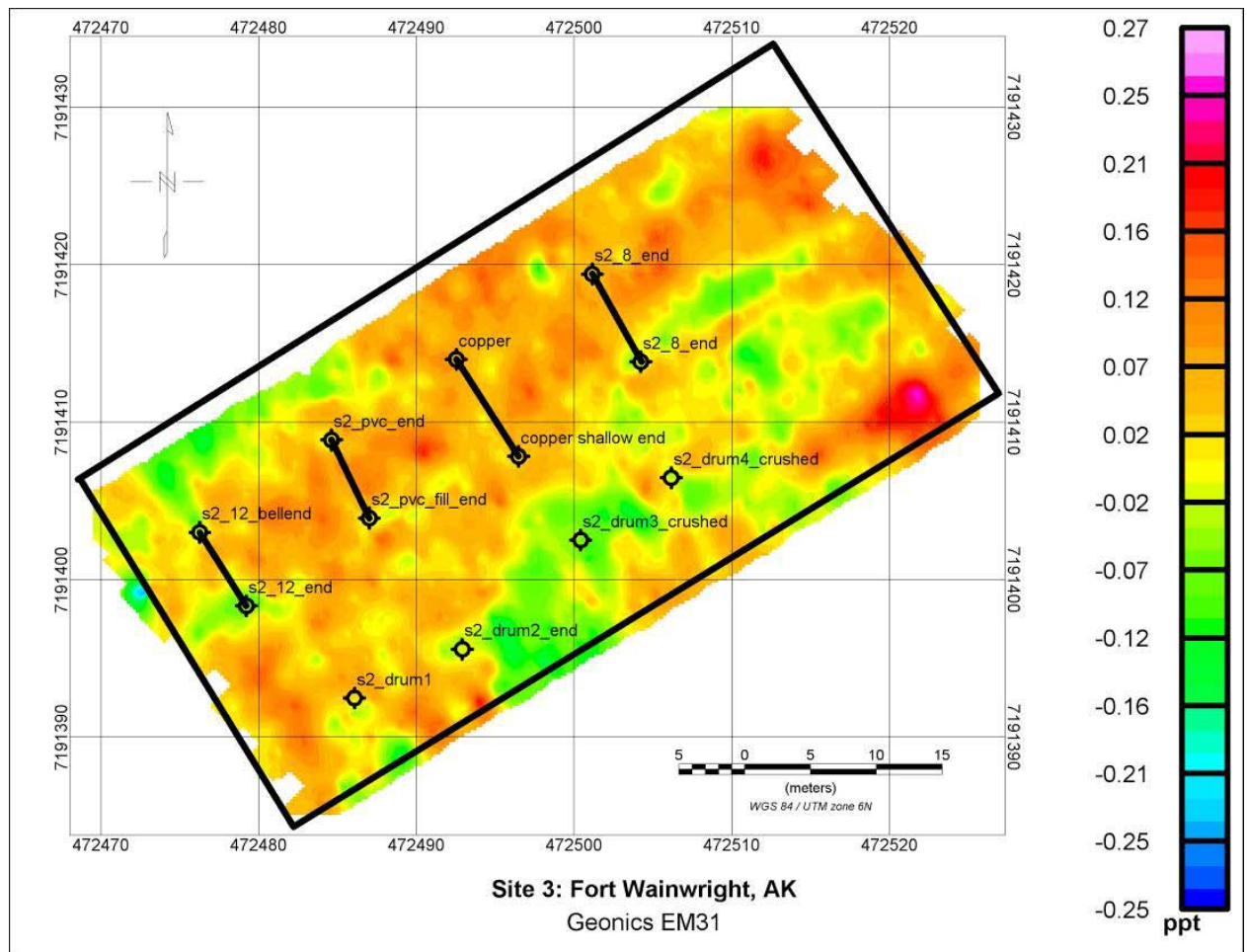

Figure C17. Area \#3 Geonics EM31 inphase data before installation.

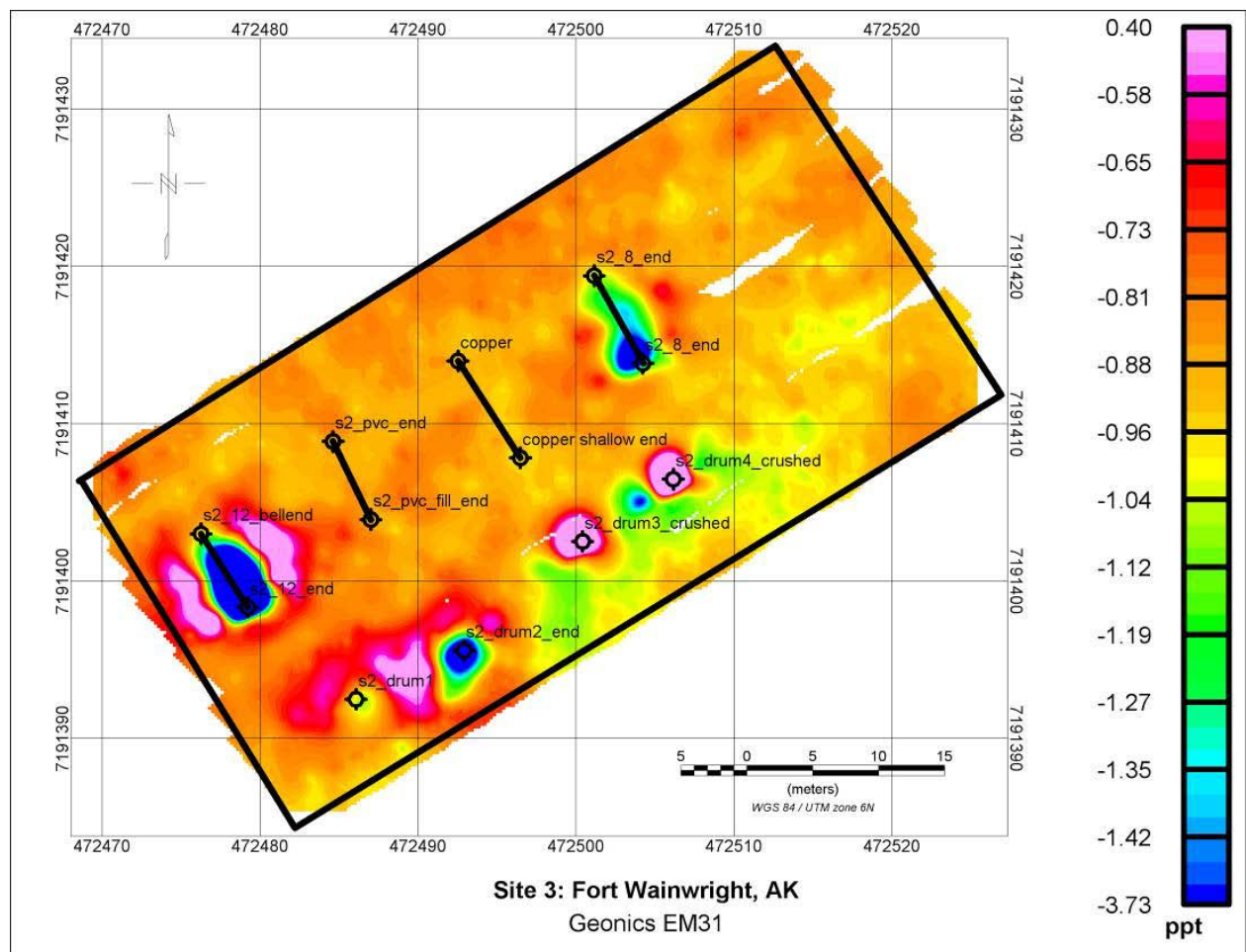

Figure C18. Area \#3 Geonics EM31 inphase data after installation. 


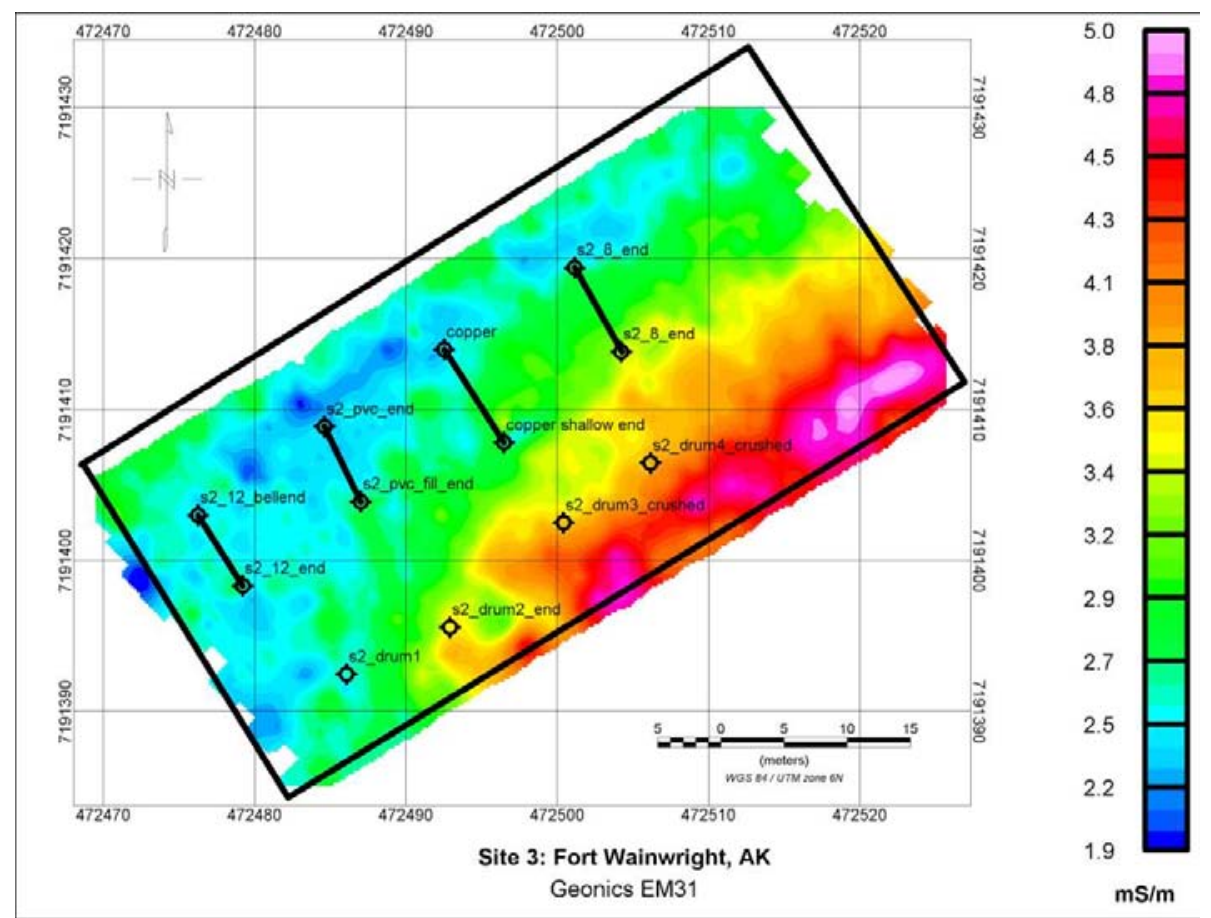

Figure C19. Area \#3 Geonics EM31 conductivity data before installation.

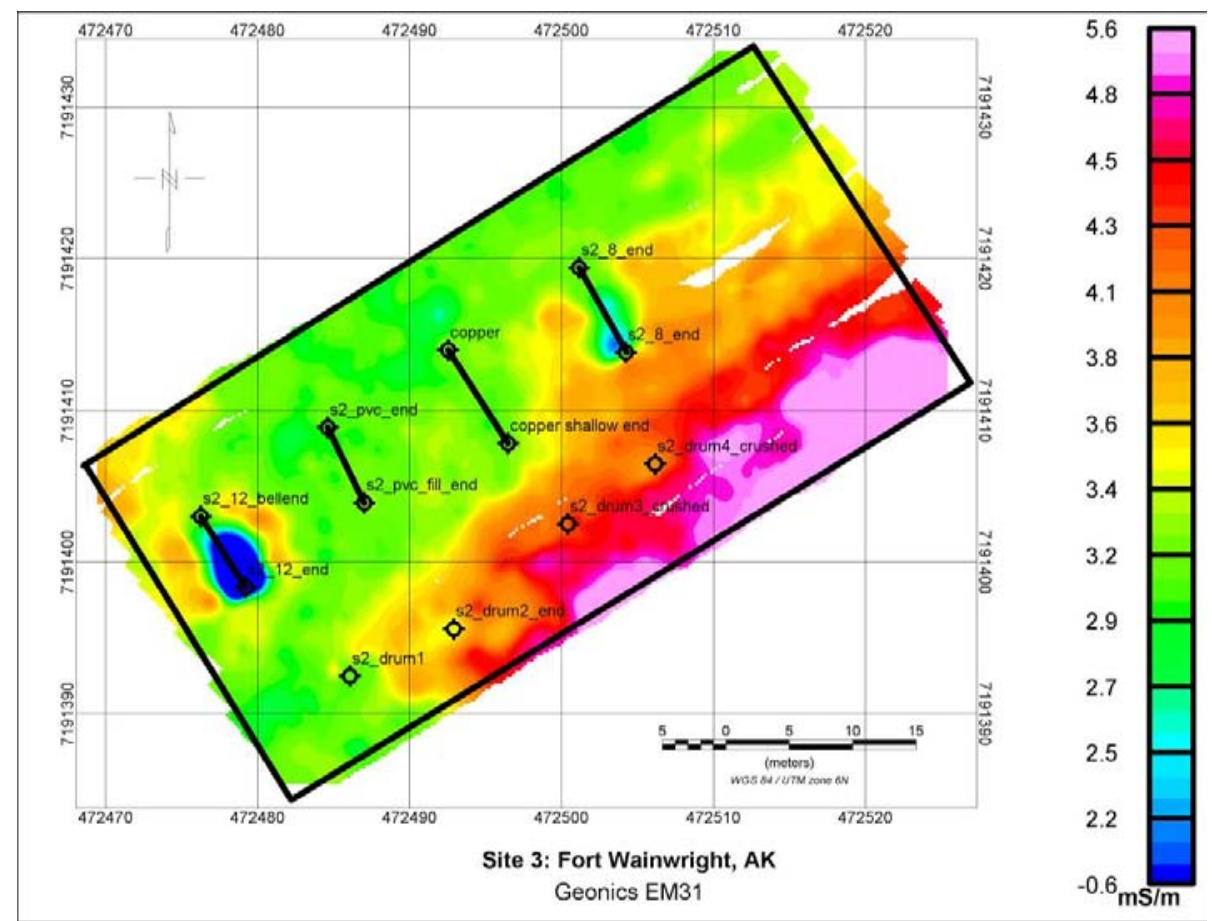

Figure C20. Area \#3 Geonics EM31 conductivity data after installation. 


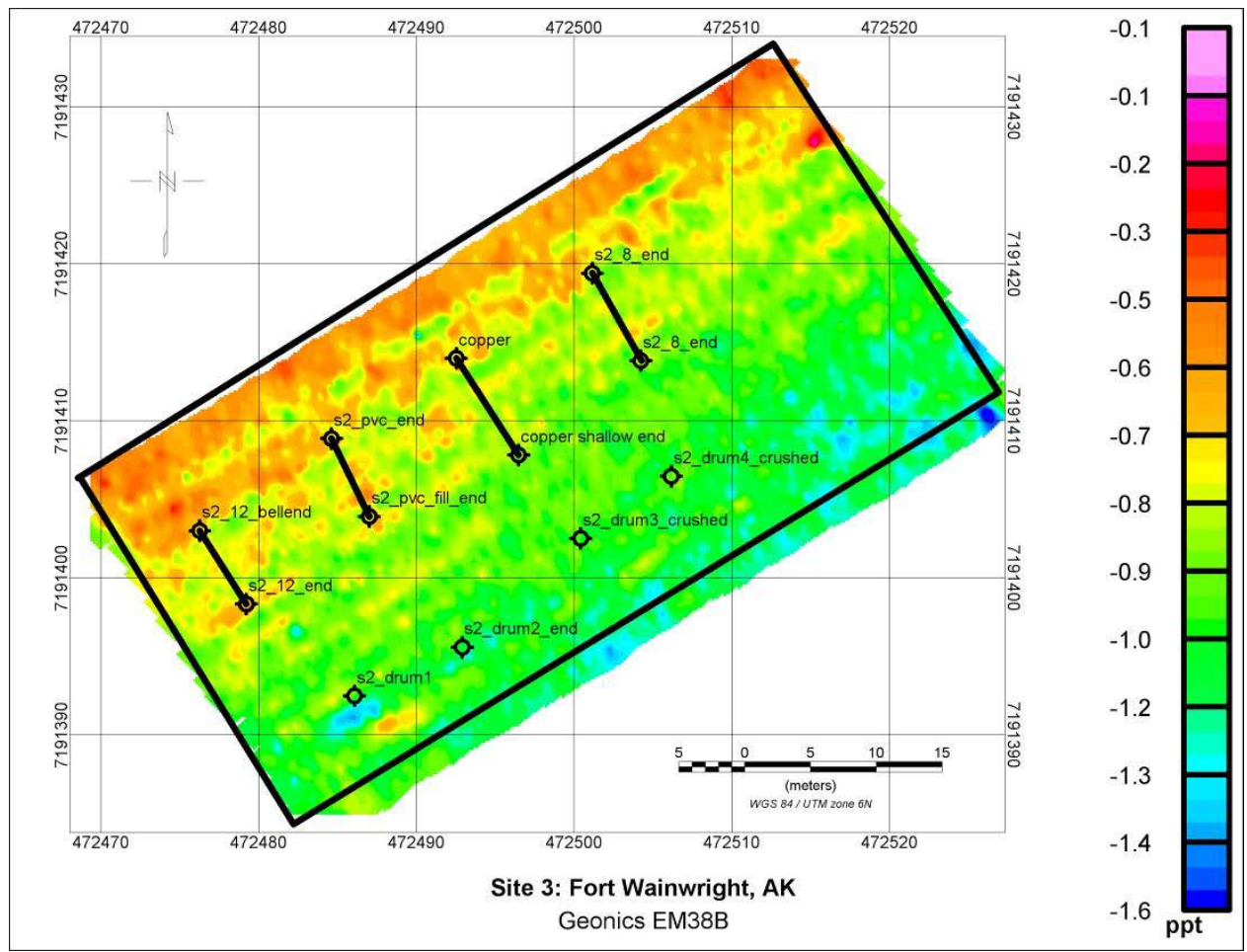

Figure C21. Area \#3 Geonics EM38B inphase data before installation.

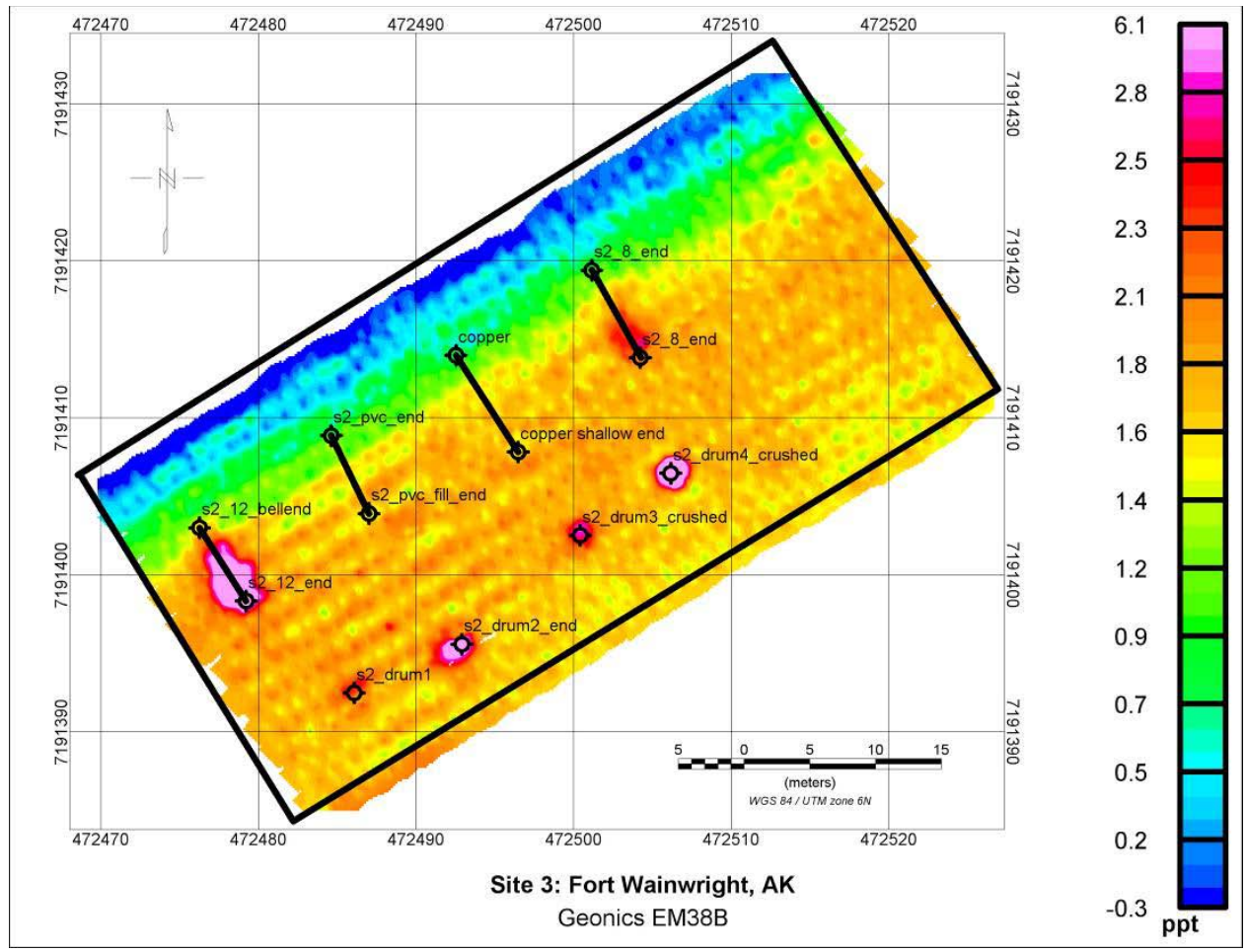

Figure C22. Area \#3 Geonics EM38B inphase data after installation. 


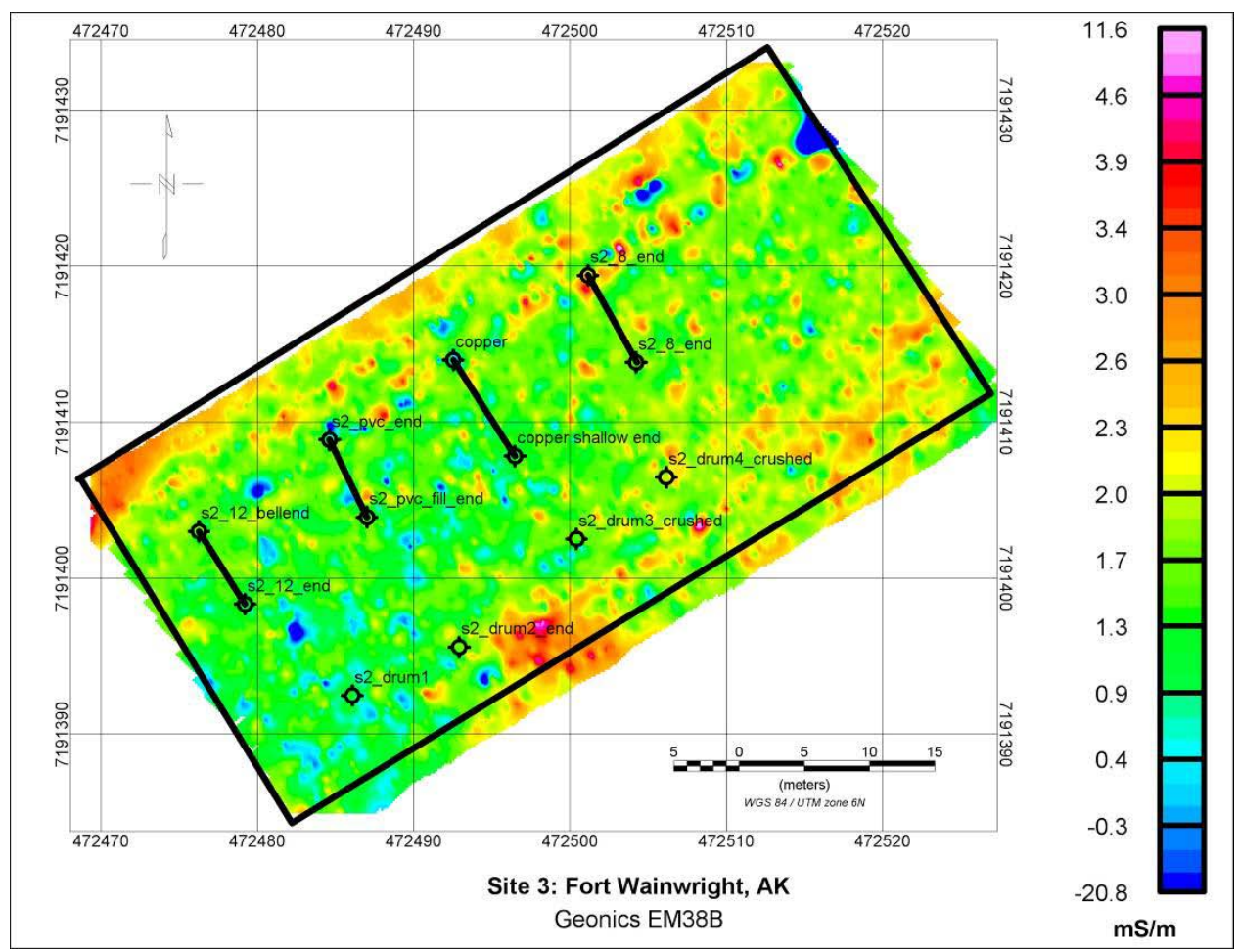

Figure C23. Area \#3 Geonics EM38B conductivity data before installation.

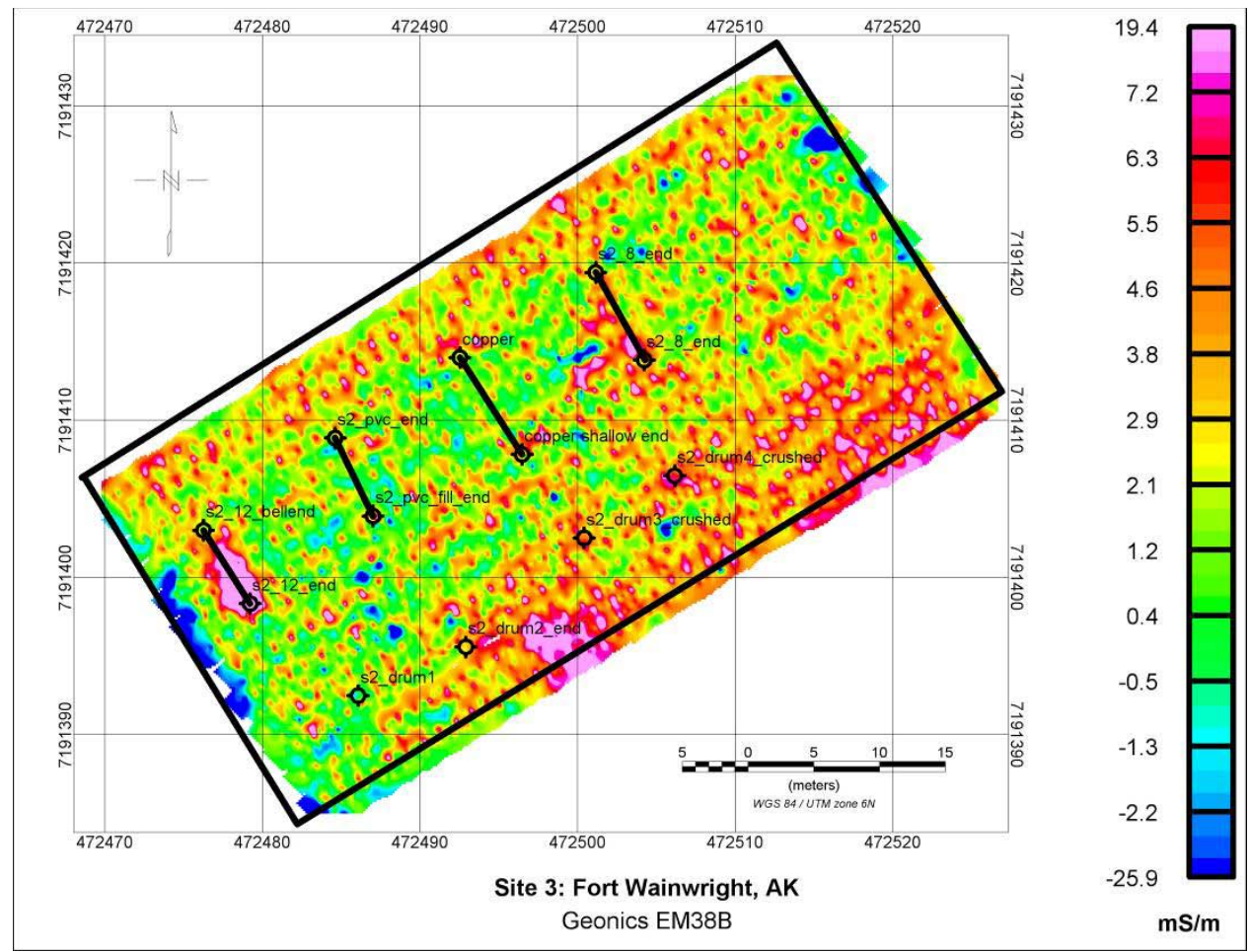

Figure C24. Area \#3 Geonics EM38B conductivity data after installation. 


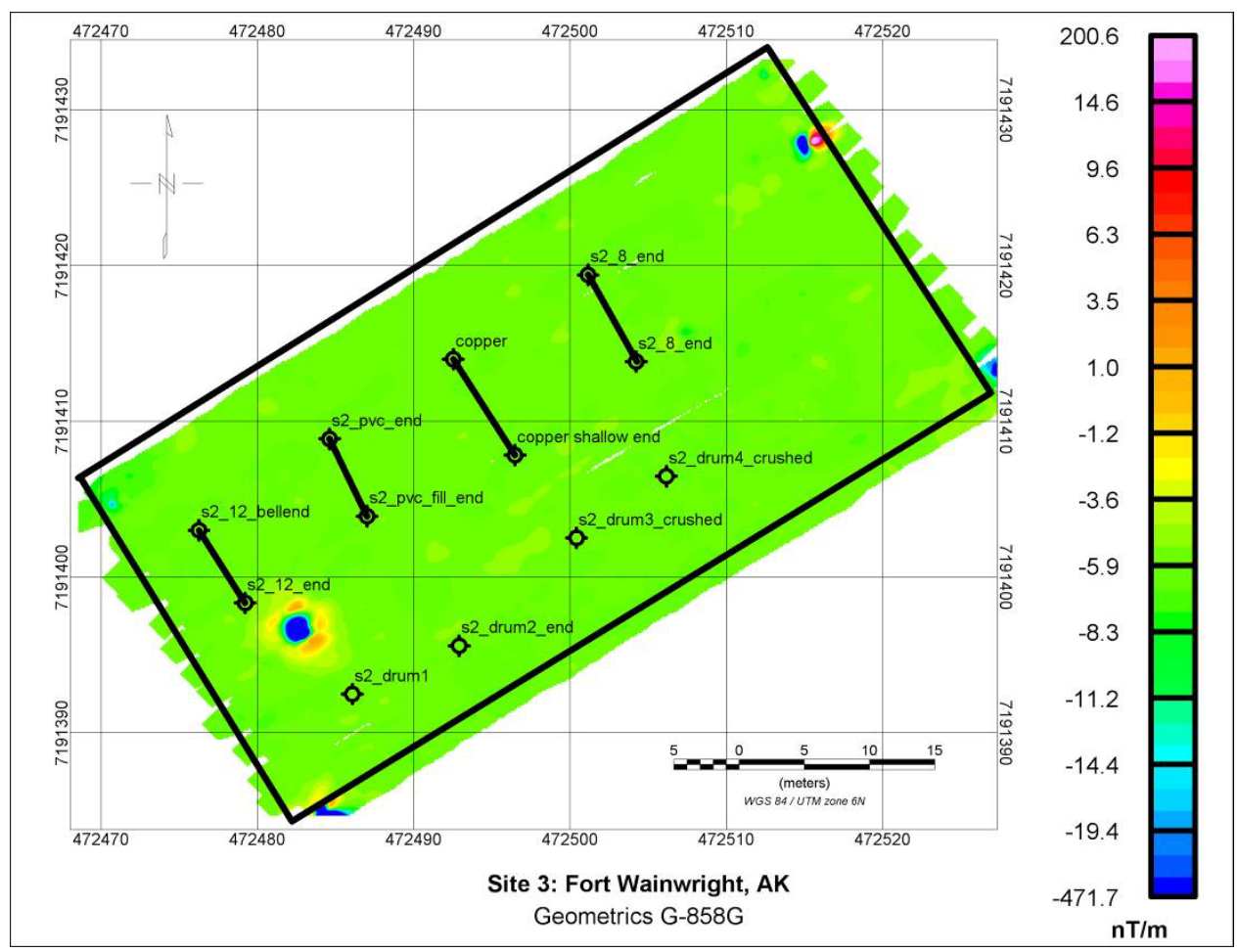

Figure C25. Area \#3 Geometrics G-858 vertical gradient data before installation.

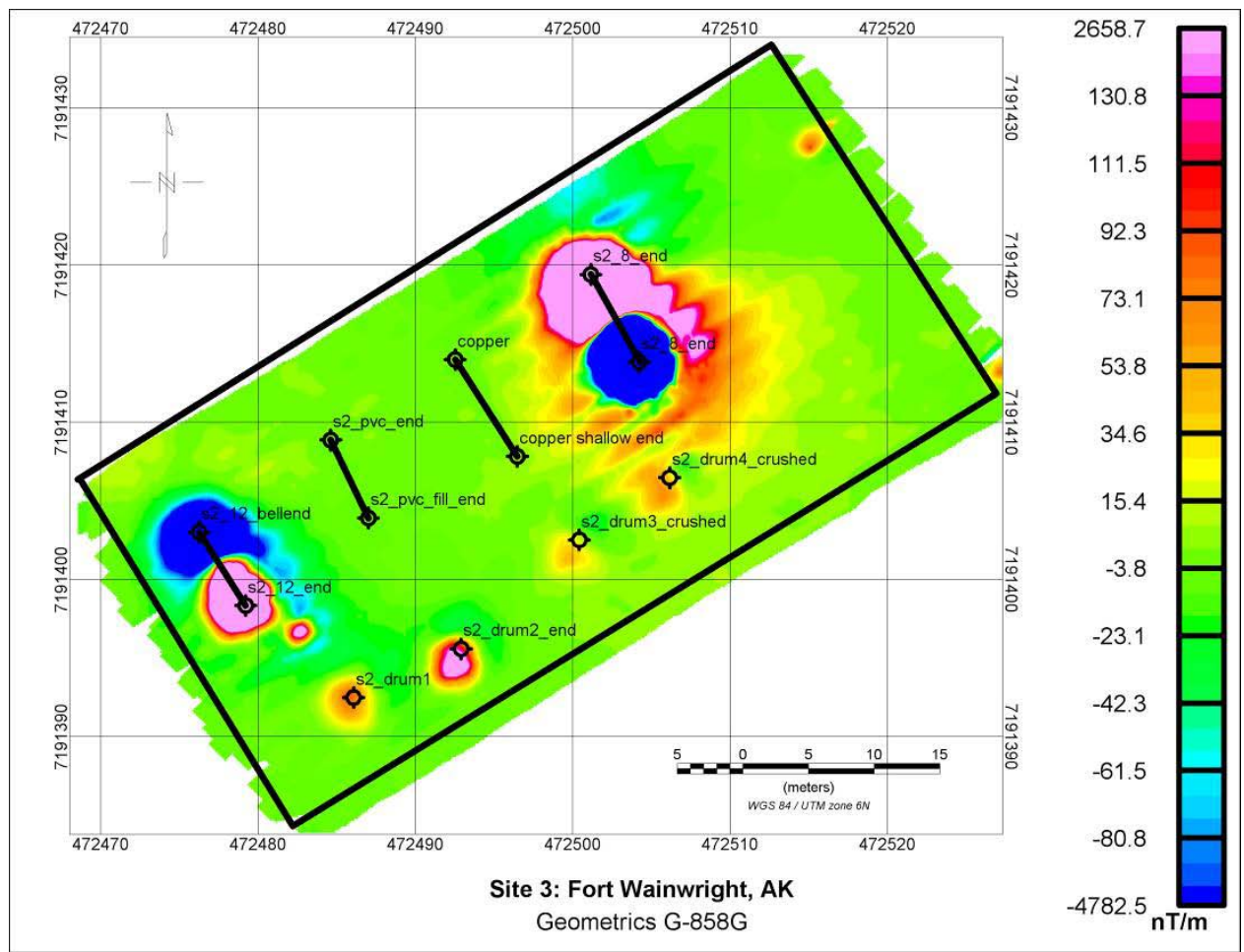

Figure C26. Area \#3 Geometrics G-858 vertical gradient data after installation. 


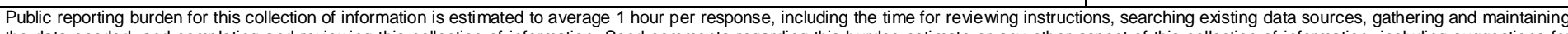

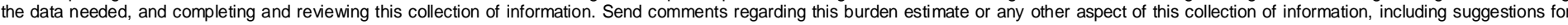

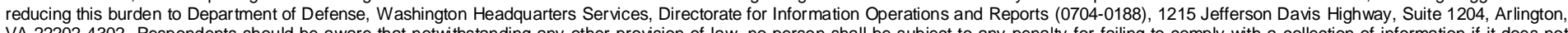

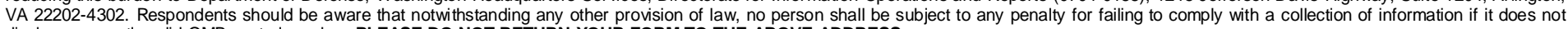
display a currently valid OMB control number. PLEASE DO NOT RETURN YOUR FORM TO THE ABOVE ADDRESS.

\begin{tabular}{l|l|l}
$\begin{array}{l}\text { 1. REPORT DATE (DD-MM-YYYY) } \\
\text { 30-09-2010 }\end{array}$ & $\begin{array}{l}\text { 2. REPORT TYPE } \\
\text { Technical Report }\end{array}$ & 3. DATES COVERED (FrOm - To)
\end{tabular}

4. TITLE AND SUBTITLE

Geophysics for Military Construction Projects

5a. CONTRACT NUMBER

5b. GRANT NUMBER

5c. PROGRAM ELEMENT NUMBER

\section{AUTHOR(S)}

Kevin L. Bjella, Beth N. Astley, and Ryan E. North

5d. PROJECT NUMBER

5e. TASK NUMBER

5f. WORK UNIT NUMBER

7. PERFORMING ORGANIZATION NAME(S) AND ADDRESS(ES)

U.S. Army Engineer Research and Development Center

Cold Regions Research

and Engineering Laboratory

Geotechnical and Structures Laboratory

3909 Halls Ferry Road

72 Lyme Road

Vicksburg, MS 39180-6199

Hanover, NH 03755-1290

9. SPONSORING / MONITORING AGENCY NAME(S) AND ADDRESS(ES)

8. PERFORMING ORGANIZATION REPORT NUMBER

ERDC TR-10-9

Headquarters

U.S. Army Corps of Engineers

Washington, DC 20314-1000

11. SPONSOR/MONITOR'S REPORT NUMBER(S)

\section{DISTRIBUTION / AVAILABILITY STATEMENT}

Approved for public release; distribution is unlimited.

13. SUPPLEMENTARY NOTES

\section{ABSTRACT}

Buried infrastructure at Military Construction (MILCON) project sites can cause large project cost overruns if not located and removed prior to the start of the project. This project demonstrated how geophysical survey tools can be utilized to locate buried materials. Utility piping and 55-gallon drums were buried in three soil types at various depths and standard off-the-shelf geophysical equipment was used to image the materials and quantify the benefits and pitfalls of each method. The techniques and examples from this demonstration can be used as a guide by personnel involved with MILCON project scoping when historic buried utilities or debris of unknown are present or suspected.

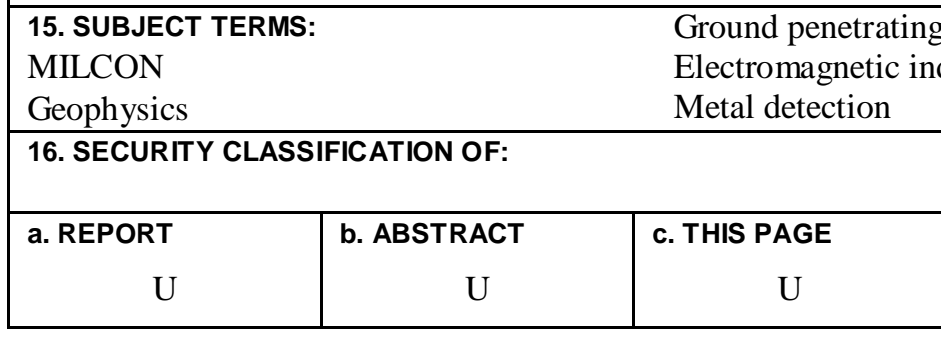

Electrical conductivity profiling

Capacitively-coupled resistivity
Geophysics

16. SECURITY CLASSIFICATION OF:

a. REPORT

$\mathrm{U}$

$\mathrm{U}$
17. LIMITATION OF ABSTRACT

U

\section{NUMBER 19 19. NAME OF RESPONSIBLE}

OF PAGES

80

\section{PERSON}

19b. TELEPHONE NUMBER (include area code) 